


\section{Impact Assessment of EC 2030 Green Deal Targets for Sustainable Crop Production}

Johan Bremmer, ${ }^{1}$ Ana Gonzalez-Martinez, ${ }^{1}$ Roel Jongeneel, ${ }^{1}$ Hilfred Huiting, ${ }^{2}$ Rob Stokkers, ${ }^{1}$ Marc Ruijs ${ }^{1}$

1 Wageningen Economic Research

2 Wageningen Plant Research

Wageningen Economic Research

Wageningen, December 2021

REPORT

2021-150

ISBN 978-94-6447-041-3 
Johan Bremmer, Ana Gonzalez-Martinez, Roel Jongeneel, Hilfred Huiting, Rob Stokkers, Marc Ruijs, 2021. Impact Assessment of EC 2030 Green Deal Targets for Sustainable Crop Production.

Wageningen, Wageningen Economic Research, Report 2021-150. 70 pp.; 11 fig.; 33 tab.; 15 ref.

In dit rapport presenteren we een effectbeoordeling van zes doelstellingen van de Farm to Fork- en biodiversiteitsstrategieën met betrekking tot vermindering van het gebruik en risico van pesticiden, vermindering van nutriëntenverliezen, vergroting van het areaal in de EU waarop biologische productie plaatsvindt en verhoging van de hoeveelheid land dat bestaat uit landschapselementen met grote diversiteit. Er zijn vier scenario's ontwikkeld waarvan de effecten zijn beoordeeld: (1) vermindering van gebruik en risico van bestrijdingsmiddelen, (2) vermindering van gebruik en verlies van nutriënten (3) vergroting van het biologische areaal en (4) een combinatie van de scenario's 1 en 2 uitgebreid met de doelstelling om meer land met landschapselementen met grote diversiteit te hebben. De effectbeoordeling is uitgevoerd op bedrijfsniveau en heeft betrekking op tien gewassen en zeven caselanden in de hele EU. Met de resultaten van de casestudies is onderzocht wat de gevolgen zijn van deze doelstellingen voor het productievolume van de gewassen in de EU, de prijzen, de internationale handel en indirect landgebruik.

In this report we present an Impact Assessment on six objectives of the Farm to Fork and Biodiversity strategies with respect to reduction of pesticide use and risk, reduction of nutrient losses, increase of the area in the EU under organic production and increase of the amount of agricultural land under high-diversity landscape features. Four scenarios have been developed for which the impacts have been assessed: (1) reduction of use and risk of pesticides, (2) reduction of use and losses of nutrients, (3) increase of area under organic production and (4) a combination of the Scenarios 1 and 2 extended with the added objective to have more land with high-diversity landscape features. The impact assessment has been executed at farm level, covering ten crops and seven case countries across the EU. The results of the case studies have been used to explore the consequences of these objectives for the production volume of the crops in the EU, market prices, the international trade and indirect land use.

Key words: impact assessment, sustainability, crop protection, nutrient management, organic farming, weed control, farm level analysis, macro-economic analysis

This report can be downloaded for free at https://doi.org/10.18174/558517 or at www.wur.eu/economic-research (under Wageningen Economic Research publications).

(C) 2021 Wageningen Economic Research

P.O. Box 29703, 2502 LS The Hague, The Netherlands, T +31 (0)70 3358330 , E communications.ssg@wur.nl, http://www.wur.eu/economic-research. Wageningen Economic Research is part of Wageningen University \& Research.

\section{(cc) BY-NC}

This work is licensed under a Creative Commons Attribution-Non Commercial 4.0 International License.

(c) Wageningen Economic Research, part of Stichting Wageningen Research, 2021

The user may reproduce, distribute and share this work and make derivative works from it. Material by third parties which is used in the work and which are subject to intellectual property rights may not be used without prior permission from the relevant third party. The user must attribute the work by stating the name indicated by the author or licensor but may not do this in such a way as to create the impression that the author/licensor endorses the use of the work or the work of the user. The user may not use the work for commercial purposes.

Wageningen Economic Research accepts no liability for any damage resulting from the use of the results of this study or the application of the advice contained in it.

Wageningen Economic Research is ISO 9001:2015 certified.

Wageningen Economic Research Report 2021-150 | Project code 2282300482

Cover photo: Shutterstock 


\section{Contents}

$\begin{array}{ll}\text { Preface } & 5\end{array}$

$\begin{array}{ll}\text { Summary } & 6\end{array}$

S.1 Introduction $\quad 6$

S.2 Main results $\quad 6$

$\begin{array}{lll}\text { S.3 Other findings } & 7\end{array}$

S.4 Recommendations $\quad 8$

S.5 Research methods $\quad 8$

1

Introduction

10

2

Research methods

12

2.1 Impact Assessment (IA) Framework 12

2.2 Six objectives translated into four scenarios $\quad 13$

2.3 Case studies at farm level $\quad 14$

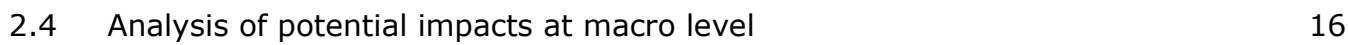

$\begin{array}{lll}3.1 & \text { Introduction } & 22\end{array}$

3.2 Typical crop farms $\quad 22$

3.2.1 Overview $\quad 22$

$\begin{array}{lll}3.2 .2 & \text { Wheat } & 23\end{array}$

3.2.3 Rapeseed 24

$\begin{array}{lll}3.2 .4 & \text { Sugar beet } & 24\end{array}$

$\begin{array}{lll}3.2 .5 & \text { Maize } & 24\end{array}$

$\begin{array}{lll}3.2 .6 & \text { Apples } & 24\end{array}$

3.2.7 Tomatoes 24

$\begin{array}{lll}3.2 .8 & \text { Grapes } & 25\end{array}$

3.2.9 Olives 25

3.2.10 Citrus 25

3.2.11 Hops $\quad 25$

3.3 Scenario 1 - Reduction pesticide use and risk $\quad 25$

$\begin{array}{lll}3.3 .1 & \text { Overview } & 25\end{array}$

3.3.2 Wheat 26

3.3.3 Rapeseed 28

3.3.4 Sugar beet $\quad 29$

3.3.5 Maize 29

3.3.6 Apples 30

$\begin{array}{lll}3.3 .7 & \text { Tomatoes } & 30\end{array}$

3.3.8 Grapes 30

3.3.9 Olives 31

3.3.10 Citrus 31

3.3.11 Hops 31

3.4 Scenario 2 - Reduction nutrient losses and fertiliser use 32

$\begin{array}{lll}3.4 .1 & \text { Overview } & 32\end{array}$

3.4.2 Wheat 33

3.4.3 Rapeseed 34

$\begin{array}{lll}3.4 .4 & \text { Sugar beet } & 34\end{array}$

$\begin{array}{lll}3.4 .5 & \text { Maize } & 34\end{array}$

$\begin{array}{lll}3.4 .6 & \text { Apples } & 35\end{array}$ 
3.4.7 Tomatoes $\quad 35$

3.4.8 Grapes 35

$\begin{array}{lll}3.4 .9 & \text { Olives } & 36\end{array}$

3.4.10 Citrus 36

3.4.11 Hops 36

3.5 Scenario 3 - Expansion of organic area 36

3.6 Scenario 4 - Combined reduction of pesticide and risk, nutrient losses and fertiliser use and $10 \%$ set aside $\quad 38$

3.7 The Moroccan case - fresh tomatoes $\quad 39$

$\begin{array}{lll}3.8 & \text { Conclusions } & 39\end{array}$

4.1 Introduction

4.2 Scenario 1 - Reduction of pesticide use and risk 41

4.2.1 Production and prices $\quad 41$

4.2.2 Trade impacts $\quad 42$

4.2.3 Indirect land use change $\quad 43$

4.2.4 Production value 44

4.3 Scenario 2 - Reduction of nutrient losses and fertiliser use $\quad 45$

4.3.1 Production and prices $\quad 45$

4.3.2 Trade impacts 47

$\begin{array}{lll}\text { 4.3.3 Indirect land use change } & 47\end{array}$

$\begin{array}{lll}\text { 4.3.4 Production value } & 48\end{array}$

4.4 Scenario 3 - Expansion of organic area $\quad 49$

4.4.1 Production and prices $\quad 49$

4.4.2 Trade impacts 50

4.4.3 Indirect land use change $\quad 51$

4.4.4 Production value $\quad 52$

4.5 Scenario 4 - Combined reduction of pesticide use and risk, nutrient losses and fertiliser use and $10 \%$ set aside $\quad 52$

4.5.1 Production and prices $\quad 52$

4.5.2 Trade impacts 54

4.5.3 Indirect land use change $\quad 54$

4.5.4 Production value $\quad 55$

5 Discussion, conclusions and recommendations $\quad 56$

$\begin{array}{lll}5.1 & \text { Discussion } & 56\end{array}$

$\begin{array}{lll}5.2 & \text { Conclusions } & 59\end{array}$

$\begin{array}{lll}5.3 & \text { Recommendations } & 60\end{array}$

$\begin{array}{ll}\text { References and websites } & 62\end{array}$

$\begin{array}{lll}\text { Appendix } 1 & \text { Questionnaire } & 63\end{array}$

$\begin{array}{lll}\text { Appendix } 2 & \begin{array}{l}\text { Overview of institutes and experts involved in case } \\ \text { studies }\end{array}\end{array}$

$\begin{array}{lll}\text { Appendix } 3 & \text { Sensitivity Analysis } & 68\end{array}$ 


\section{Preface}

Sustainable crop production is increasingly the focus of European policy. The Farm to Fork and Biodiversity strategies are at the heart of the European Green Deal Roadmap aiming to make food systems fair, healthy and environmentally-friendly. Both strategies contain clear new targets to be met by 2030 which should contribute to a sustainable food system. These targets create challenges for all relevant public and private stakeholders.

Croplife Europe and Croplife International have requested us to execute an ex-ante impact assessment, in which we explore the consequences at farm and macro level of achieving these new targets. This impact assessment has been executed by a team from Wageningen Research with support from experts in research institutes located in the case study countries. The research team wants to thank all experts who have contributed to the execution of the case studies. Furthermore, we thank the colleagues from both outside and inside Wageningen UR for reviewing the results. We thank the representatives of Croplife Europe and Croplife International and other stakeholders who have guided the project and commented on the output of this study. Finally, we want to thank Michal Kicinski from Croplife Europe for the open and involved manner in which he supervised this project.

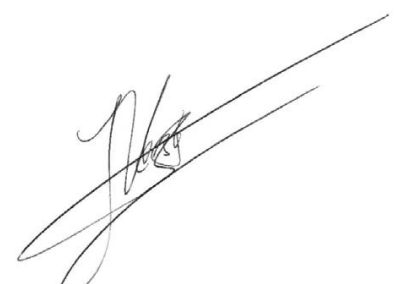

Prof.dr.ir. J.G.A.J. (Jack) van der Vorst General Director Social Sciences Group (SSG)

Wageningen University \& Research 


\section{Summary}

\section{S.1 Introduction}

As part of its Green Deal Roadmap, the EU Commission has launched the Farm to Fork (F2F) and Biodiversity (BD) strategies to cope with the environmental and climate challenges. Currently it is uncertain what the implications of the proposed targets could be for EU agriculture and the food system. Explorations into the consequences are vital for both policymakers and stakeholders to have an informed debate on the future food production in the EU.

CropLife Europe, along with CropLife International as well as several agri-food chain stakeholders commissioned this study to assess the potential impacts of six key targets of the F2F and BD strategies. The study focuses on the impacts on a selected number of annual crops (wheat, rapeseed, maize, sugar beet and tomatoes) and perennial crops (apples, olives, grapes, citrus and hops), taking into account the present knowledge of farmers and available technologies.

In the study four scenarios have been developed in which the following objectives of the Green Deal are combined:

- Scenario 1: $50 \%$ reduction in the overall use and risks of pesticides and a $50 \%$ reduction in the use of more hazardous pesticides

- Scenario 2: $50 \%$ reduction in nutrient losses and a $20 \%$ reduction in the use of fertilisers

- Scenario 3: at least $25 \%$ of the agricultural land under organic production

- Scenario 4: objectives of scenarios 1 and 2 combined with the objective to place at least $10 \%$ of the agricultural land under high-diversity landscape features. In this scenario the effect of the increase of organic production to $25 \%$ of the agricultural area is not included.

\section{S.2 Main results}

According to the assessment at macro level, the realisation of the objectives of the F2F and BD strategies will result in a decrease of the produced volumes per crop in the entire EU on average ranging from 10 to $20 \%$ (Scenario 4). The production volume can decline up to $30 \%$ for some crops such as apples, but there are also crops of which the production hardly suffers as a result of the F2F strategy such as sugar beets. The produced volume of perennial crops will decline more than that of annual crops. Prices of products such as wine, olives and hops will increase. By consequence, international trade will change significantly: EU exports were found to decline and EU imports will increase (the volume of the import of products can double).

The realisation of the objective to increase the area under organic production to $25 \%$ will under the assumptions made in this study with respect to technological developments result in a production decline of less than $10 \%$ and go together with a price increase of just under $13 \%$. Increasing the area under organic production could contribute to the reduction of the overall use and risk of pesticides and the reduction of nutrient losses, assumed that the use and risk of pesticides in organic production measured by the Harmonised Risk Indicator I would be lower than in conventional production. For annual crops this is indeed the case, but the findings suggest that for some perennial crops the opposite is true. In such cases, there would be no reason to shift to organic production from a sustainability point of view. 


\begin{tabular}{|c|c|c|c|c|}
\hline Scenario & Production \& prices & Trade & $\begin{array}{l}\text { Indirect Land Use } \\
\text { Change }\end{array}$ & $\begin{array}{l}\text { Negative impact on } \\
\text { the value of } \\
\text { production }\end{array}$ \\
\hline $\begin{array}{l}3 \text { - Expansion of } \\
\text { organic area }\end{array}$ & $\begin{array}{l}\text { Production declines are } \\
\text { below } 10 \% \text { in most } \\
\text { cases } \\
\text { Price increases less } \\
\text { than } 13 \%\end{array}$ & $\begin{array}{l}\text { Increases in net } \\
\text { imports (maize, } \\
\text { rapeseed and citrus) } \\
\text { Increases in net } \\
\text { exports (hops) }\end{array}$ & $\begin{array}{l}\text { ILUC } 1: 0.5 \text { million ha } \\
\text { ILUC2: } 1.6 \text { million ha }\end{array}$ & Almost EUR 3.4 billion \\
\hline
\end{tabular}

Source: Authors.

\section{S.3 Other findings}

- The realisation of the objectives to reduce the risk and use of pesticides by $50 \%$ and to reduce nutrient losses $(50 \%)$ have significant impacts on yield levels. Estimated yield losses per case study vary:

- From 0 to $30 \%$ in Scenario 1 (reduction of pesticide use and risk)

- From 2 to $25 \%$ in Scenario 2 (reduction of fertiliser use)

- From 7 to $50 \%$ in Scenario 4 (objectives of Scenario 1 and 2, and $10 \%$ of the agricultural land under high-diversity landscape features)

- The estimated yield level of organic production is $7 \%$ to $54 \%$ lower than conventional production presented in the reference scenario.

- Impacts of F2F objectives for permanent crops such as grapes, apples, olives, citrus fruits are found to be higher than for annual crops such as oilseed, rapeseed, wheat, maize and sugar beets. This is due to the fact that for permanent crops there are less options available to reduce the negative impacts of the implementing the reduction targets than is the case for annual crops.

\footnotetext{
1 ILUC1: the changes in land use that occur outside the EU due to the substitution of local (EU) production with imported (non-EU) production which is eventually consumed within the EU. ILUC2: the changes in land use that occur outside the EU to produce additional commodities that compensate the 'loss' of EU production that is not exported to the EU.
} 
- While yield impacts (at market level) for arable crops are comparable to those of JRC study, our study shows that yield loss impacts for perennial crops tend to be higher than those of the JRC study.

- The decline in yields negatively affects production and generates a decrease of supply in the EU home market, which induces increases in commodity prices.

- The impacts on EU trade are significant and in percentage terms larger than the shocks to production. The general pattern is that EU imports (e.g. maize, rapeseed) substantially increase, whereas EU exports (e.g. wheat, olives, wine) decrease.

- The estimated indirect land use change effect of the assessed crops is 2.5 (related to additional import) and 4.4 (related to reduced EU export) million ha (conditional on unchanged EU crop demands for food and feed).

- The income of farmers is likely to suffer since revenues tend to decline, probably at a faster pace than expected cost declines.

\section{S.4 Recommendations}

On the basis of the results the following recommendations are presented:

1. To help reduce/overcome the negative impacts of reduction of pesticides and nutrients, especially for permanent crops, there is an increased need for innovations in crop protection techniques, such as biocontrol, breeding, precision agriculture, biostimulants and other techniques that contribute to the resilience of crop production against pests, weeds and diseases. Removing legislative barriers to new breeding techniques, in order to shorten the breeding process significantly could help. This will contribute to making crop production more sustainable in the mid-term for annual crops and in the long term for permanent crops, while reducing the negative impacts on yield and quality of products.

2. Consider the pros and cons of the use of the Harmonised Risk Indicator to measure the reduction of pesticide use and risk, since this measure is susceptible for decisions to change the category of an active substance.

3. In addition to market challenges, the objectives to reduce pesticide use and nutrient emissions could be perceived as a disincentive to shift to organic production. This was found to be the case for permanent crops, which made use of copper-based active substances. Moreover, expanding organic production may face market constraints (e.g. insufficient demand growth) that could erode the current price premium for organic products and therewith their attractiveness/profitability: a price premium is needed to cover additional costs per unit of product. These aspects need further research.

4. The European Union, the MSs and private stakeholders should take into account the following potential trade-offs and combine efforts to develop mitigation strategies:
a. F2F/BD create a competitive disadvantage relative to EU imports (raises a level playing field issue, causing an increase in trade dependency),
b. indirect land-use effects (close to 7 million ha),
c. a likely farm income loss and
d. a reduced EU contribution to 'zero-hunger' SDG.

\section{S.5 Research methods}

The study consisted of two phases: In the first phase of the study, we have investigated the potential consequences of each of the scenarios at farm level. For this 7 case countries and 10 case crops have been selected, which we have combined into 25 case studies, consisting of crop-country combinations. Each case study has been executed by local experts filling in a detailed questionnaire capturing the responses of farmers to cope with the proposed reduction targets. This implies that in the scenarios the spraying schemes and fertiliser use have been adjusted in such a way that the farmer complies 
with the objectives reducing the negative impacts as much as possible, making use of available technologies and knowledge. The impacts at farm level for each of the four scenarios have been assessed for a 'typical' farm (which can differ from an average farm) in the region and have been measured relative to a baseline situation. The main parameters assessed are the level of yield and quality loss of the products. The experts have been provided by the authors with the necessary background information about the policy scenarios and reported their results with accompanying information to better understand the optimised farmer responses to the policy shocks.

In the second phase of the study, the results of the case studies have been used to explore the consequences at macro level, by extrapolating the results from the case studies to all EU MSs. Subsequently the AGMEMOD model, a partial equilibrium model comprising key agricultural sectors, with a representation of EU policy and MS level detail and some targeted equilibrium displacement (EDM) models, have been applied to calculate the market impacts (e.g. new balance in produced volume for each of the case crops, the corresponding adjusted price level, and the net effects on trade). The adjusted price level is a response to changes in the volume of production as well as changes in the quality level of the considered crop products. The changes lead to an overall reduction of the price and the availability of the product. Furthermore we have calculated the indirect land use change, namely the additional area that will be required elsewhere in the world to compensate for the reduced production volume in the EU.

A unique feature of this study is the data collection at farm level, which allowed the researchers to assess the farmer responses at a very detailed and practical level. The assessment also addressed the potential quality impact of the EU policy objectives on crops, with consequences for their potential use and the prices farmers receive. So far, such impacts pertaining to the quality of the crops have not been addressed in any other study.

The study also faces limitations, namely that it focuses on crop production, leaving out of scope the potential impacts of the EU F2F and BD strategies on the animal production sector as well as consumer behaviour (changing diets, reduction of food waste). As a consequence our results may overestimate the trade and indirect land use impacts. Moreover, as the focus of the modelling tools used was on the EU, the world market responsiveness to the EU policy interferences may have been underestimated. 


\section{Introduction}

\section{Policy context}

The European Green Deal was launched by the European Commission in December 2019, its main goal being to make Europe the first climate-neutral continent by 2050. It maps a new, sustainable and inclusive growth strategy to boost the economy, improve people's health and quality of life, care for nature, and leave no one behind. At the heart of the Green Deal is the Farm to Fork strategy (F2F), which was launched by the European Commission in May 2020 in order to achieve a fair, healthy and environmentally-friendly food system by 2030 . According to the F2F strategy, there is a need to reduce dependency on pesticides and antimicrobials, reduce excess fertilisation, increase organic area under farming, improve animal welfare and reverse biodiversity loss. The Commission will ensure that the strategy is implemented in close coherence with the other elements of the Green Deal, amongst others the Biodiversity strategy (BD) for 2030, launched simultaneously with the F2F strategy. Many targets in the BD strategy overlap with the F2F strategy.

As outlined in the F2F strategy, the Commission will table a legislative proposal for a framework for a sustainable food system by the end of 2023 to accelerate and facilitate this transition and ensure that all foods placed on the EU market become increasingly sustainable. This will promote policy coherence at EU and national levels, mainstream sustainability in all food-related policies and strengthen the resilience of food systems. Following a broad consultation and impact assessment, the Commission will work on common definitions and general principles and requirements for sustainable food systems and foods.

The use of chemical pesticides in agriculture may contribute to soil, water and air pollution, biodiversity loss and can harm non-target plants, insects, birds, mammals and amphibians. The Commission has already established two Harmonised Risk Indicators (HRI) to quantify the progress in reducing the use and risks linked to pesticides. ${ }^{2}$ The latest Commission publication, according to Harmonised Risk Indicator 1, demonstrates a $21 \%$ decrease in the use and risks from pesticides since the reference period 2011-2013 (Eurostat, 2021). The Commission will take additional action to reduce the overall use and risk of chemical pesticides ${ }^{3}$ by $50 \%$ and the use of more hazardous pesticides ${ }^{4}$ by $50 \%$ by 2030 .

The excess of nutrients (especially nitrogen and phosphorus) in the environment, stemming from excess use and the fact that not all nutrients used in agriculture are effectively absorbed by plants, is an important source of air, soil and water pollution and climate impacts. It has reduced biodiversity in rivers, lakes, wetlands and seas. The Commission will act to reduce nutrient losses by at least $50 \%$, while ensuring that there is no deterioration in soil fertility. This will reduce the use of fertilisers by at least $20 \%$ by 2030 .

The market for organic food is set to continue growing and organic farming needs to be further promoted according to the F2F strategy. This is expected to have a positive impact on biodiversity, creating jobs and attracting young farmers. The legal framework supports the shift to this type of farming already. In addition to CAP measures, such as eco-schemes, investments and advisory

\footnotetext{
2 Harmonised Risk Indicators are defined in the Directive 2009/128/EC establishing a framework for Community action to achieve the sustainable use of pesticides (the Sustainable Use Directive). These indicators are needed to measure progress in the reduction of risks from pesticide use for human health and the environment. The European Commission calculates them for the EU, and MSs should calculate the Harmonised Risk Indicators at a national level. The data to be used for the calculations shall be statistical data collected in accordance with Union legislation concerning statistics on plant protection products, i.e. Regulation (EC) No 1185/2009 on pesticide statistics, and other relevant data.

3 Chemical pesticides have a synthetic origin. However, in organic farming, pesticides from natural origin such as copper based active ingredients are applied. Since these active ingredients are subject to the same regulation, we will use the term pesticides from now on.

4 These are plant protection products containing active substances that meet the cut-off criteria as set out in points 3.6.2. to 3.6.5 and 3.8.2 of Annex II to Regulation (EC) No $1107 / 2009$ or are identified as candidates for substitution in accordance with the criteria in point 4 of that Annex.
} 
services, the Commission has put forward an Action Plan on organic farming. This plan will help MSs to stimulate both supply and demand for organic products. It will also ensure consumer trust and boost demand through promotion campaigns and green public procurement. This approach aims at helping to reach the objective of having at least $25 \%$ of the EU's agricultural land under organic farming by 2030 and a significant increase in organic aquaculture.

Farmland birds and insects, particularly pollinators, are key indicators of the health of agroecosystems and are vital for agricultural production and food security. According to Harvey et al. $(2020$, ) their alarming decline must be reversed. To provide space for wild animals, plants, pollinators and natural pest regulators, the Biodiversity strategy formulates an urgent need to bring back at least $10 \%$ of agricultural area under high-diversity landscape features. These include, inter alia, buffer strips, rotational or non-rotational fallow land, hedges, non-productive trees, terrace walls, and ponds. These landscape elements help enhance carbon sequestration, prevent soil erosion and depletion, filter air and water, and support climate adaptation. In addition, more biodiversity often helps lead to more agricultural production. According to the BD strategy, MSs will need to translate the $10 \%$ EU target to a lower geographical scale to ensure connectivity among habitats, especially through CAP instruments and CAP Strategic Plans, in line with the F2F strategy, and through the implementation of the Habitats Directive.

\section{Objective}

The aim of this study is to assess the impacts of the F2F and BD strategies on crop production in the EU. We distinguish between four different levels of effects and impacts:

- Farm level: their effects on agro production (quality and yield) and farm income (direct effects)

- National sector level: change in produced volume of plant products

- EU level: change in agro food supply, product prices, food security

- Global level: change in international trade in plant products, environmental impacts

\section{Scope}

In terms of the project scope, we have focussed on the following crops: Wheat, Rapeseed, Sugar beet, Maize, Apples, Tomatoes produced for the processing industry, Grapes for wine production, Hops, Olives for oil production and Citrus. With regard to geographical coverage, the analysis concentrates on the following countries: Finland, France, Germany, Italy, Poland, Romania and Spain. The economic research has focused on the production of quantifiable results, both based on expert indications on changes at farm level, public data and research, and impact models at farm, national sector and/or European level. In these analyses we have examined the current and future state of agri-technology and availability of farm inputs.

The following objectives of the F2F and BD strategies have been subject to the impact assessment:

- $50 \%$ reduction in the use and risk of pesticides by 2030

- $50 \%$ reduction in the use of hazardous pesticides by 2030

- $50 \%$ reduction in nutrient losses ensuring no deterioration of soil fertility

- $20 \%$ reduction in the use of fertilisers by 2030

- $10 \%$ of agricultural area to be set aside for high diversity landscape features (likely to be nonproductive areas)

- $25 \%$ of land under organic agriculture

\section{Structure of the report}

This report is structured as follows. In Chapter 2 we describe the research methods applied at both farm and macro levels. In Chapter 3 we present the analyses and results at farm level, whereas in Chapter 4 we elaborate on the analyses and results at macro level. We conclude the report in Chapter 5 providing further discussion, conclusions and policy recommendations. 


\section{Research methods}

\subsection{Impact Assessment (IA) Framework}

The effects of achieving the targets of the Farm to Fork and Biodiversity strategies have been assessed into different elements of the agro value chains. The general mechanism underlying the analysis of the impacts derived from both strategies is presented in Figure 2.1.

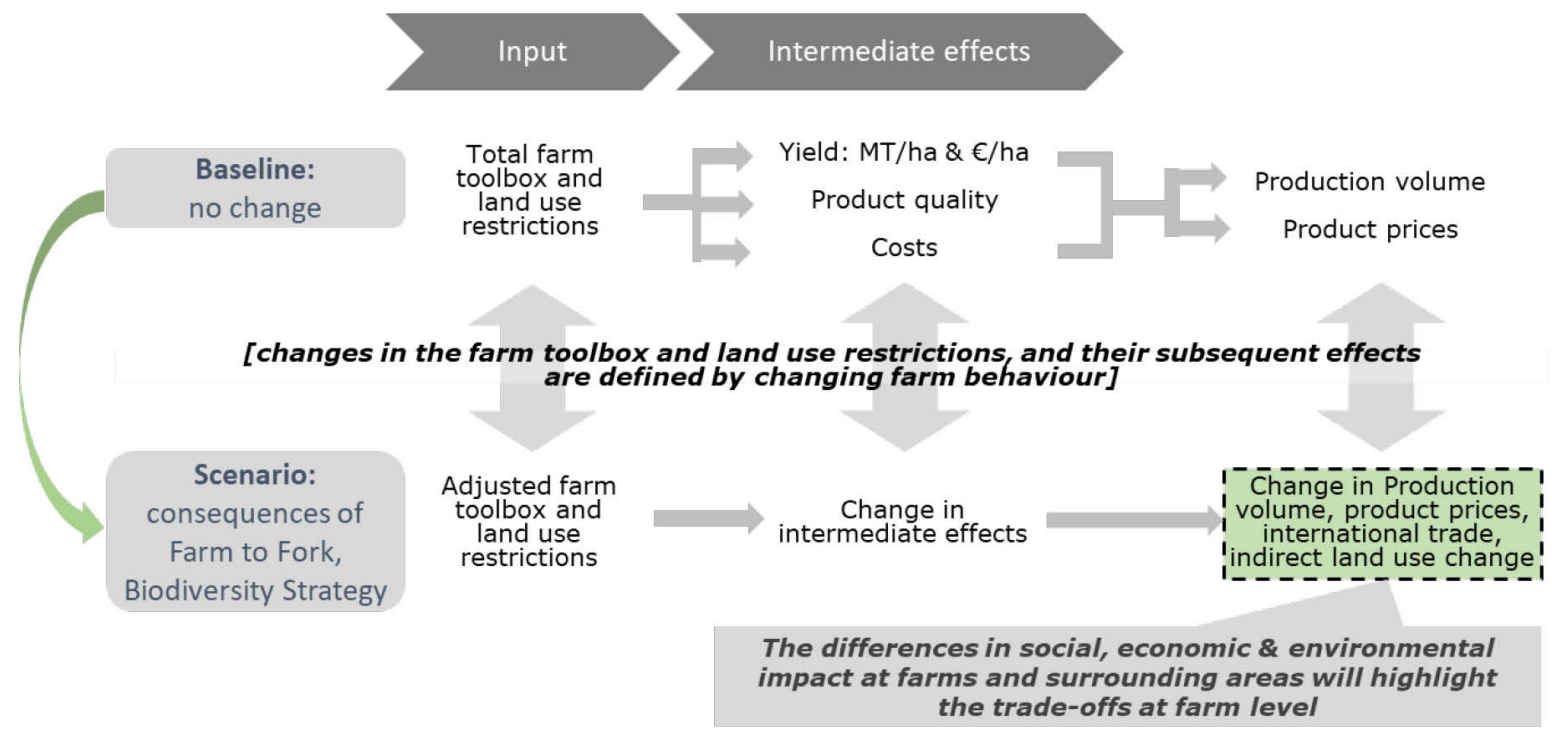

Figure 2.1 Conceptual model for analysing impacts of the Farm to Fork strategy and Biodiversity strategy

Source: Authors.

The IA framework contains two basic dimensions:

- The horizontal dimension addresses the basic steps regarding how the applied cultivation measures are linked by intermediate effects to the final social, economic and environmental impacts.

- The vertical dimension includes the alternative scenarios and corresponding adjustments in the applied cultivation measures covering the objectives derived from the F2F and BD strategies subject to the impact assessment.

A crucial element of this impact assessment is the application of the proposed objectives at farm level. This application implies that we adjust the production system (crop protection toolbox, input of nutrients and land use) according to the targets derived from the F2F and BD strategies and included in the Terms of Reference. These adjustments and consequences at farm level have also served as a basis for the estimates at national sector and EU level. The different changes, intermediate effects and impacts are summarised in Figure 2.1. The economic effects focus on the changes in yield, quality and production costs. The differences between the baseline (no change) and the scenarios (see Section 2.2 for the application of objectives from F2F and BD strategies) are the impacts and trade-offs at farm, sector, national and EU level. 


\subsection{Six objectives translated into four scenarios}

\section{Defining the scenarios}

The effects of achieving the six objectives proposed in the F2F and BD strategies have been assessed in four scenarios both at farm level and macro level:

- Scenario 1 contains the following objectives:

- $50 \%$ reduction of the overall use and risk of pesticides

- $50 \%$ reduction of the use of more hazardous pesticides

- Scenario 2 combines the following objectives:

- At least $50 \%$ reduction of nutrient losses which requires

- At least $20 \%$ reduction of the use of fertilisers

- Scenario 3 focuses on organic production derived from the objective to have at least $25 \%$ of the area under organic production in the EU by 2030. In the application of this scenario at farm level, organic production is not subject to the objectives as applied in Scenarios 1, 2 and 4. By consequence, the results show the performance of the organic farm compared to the conventional farm as defined in the reference scenario.

- Scenario 4 combines the objectives of Scenarios 1 and 2 and the additional objective derived from the F2F and Biodiversity strategies to have at least $10 \%$ of the agricultural area under high-diversity landscape features. For farmers this means that at least $10 \%$ of their land cannot be used for production and has to be set aside.

\section{Measuring progress - selected indicators}

In terms of monitoring, the following indicators have been selected by the European Union to assess the progress in the realisation of the selected objectives (European Commission, 2020):

1. $50 \%$ reduction of use and risk of pesticides: Harmonised Risk Indicator I (Eurostat, 2021). Harmonised Risk Indicators are defined in the Directive 2009/128/EC establishing a framework for Community action to achieve the sustainable use of pesticides (the Sustainable Use Directive). These indicators are needed to measure progress in the reduction of the use and risk of pesticide for human health and the environment. The European Commission calculates these statistics for the EU, while MSs are expected to calculate the Harmonised Risk Indicators at national level. The data to be used for the calculations shall be statistical data collected in accordance with Union legislation concerning statistics on plant protection products, i.e. Regulation (EC) No 1185/2009 on pesticide statistics, and other relevant data. The Harmonised Risk Indicator I divides pesticides into the following four categories:

a. Group 1

Low risk active substances which are approved or deemed to be approved under Article 22 of

Regulation (EC) No 1107/2009, and which are listed in part D of the Annex to Regulation (EU)

No 540/2011. Pesticides in this category have a weighting factor of 1 .

b. Group 2

Active substances which are approved or deemed to be approved under Regulation (EC)

No $1107 / 2009$, and not falling in other categories and which are listed in part $A$ and $B$ of the

Annex to Regulation (EU) No 540/2011. Pesticides in this category have a weighting factor of 8.

c. Group 3

Active substances which are approved or deemed to be approved under Article 24 of

Regulation (EC) No 1107/2009, which are candidates for substitution and which are listed in part E of the Annex to Regulation (EU) No 540/2011. Pesticides in this category have a weighting factor of 16 .

d. Group 4

Active substances which are not approved under Regulation (EC) No 1107/2009, and therefore are not listed in the Annex to Regulation (EU) No 540/2011. Pesticides in this category have a weighting factor of 64 .

The value of the Harmonised Risk Indicator can be calculated by summing up the volume in $\mathrm{kg}$ of the active substances of the pesticides placed on the market.

2. $50 \%$ reduction of the use of more hazardous pesticides: the volume summed up of all applied pesticides with active substances in group 3 (candidates for substitution).

3. $50 \%$ reduction of nutrient losses while ensuring no deterioration in soil fertility: gross nitrogen balance in $\mathrm{kg}$ per ha utilised on the agricultural area. 
4. $20 \%$ reduction in the use of fertilisers: reduction in use of nitrogen and phosphate in $\mathrm{kg}$ per ha.

5. At least $25 \%$ of the EU's agricultural land under organic farming: share of utilised agricultural area under organic farming.

6. At least $10 \%$ of agricultural area under high diversity landscape features: These include, inter alia, buffer strips, rotational or non-rotational fallow land, hedges, non-productive trees, terrace walls, and ponds.

\subsection{Case studies at farm level}

\section{Selection of case crops and countries}

This impact assessment started with the selection of case crops and countries. The case crops aim to represent a diversity of EU agricultural production (annual and perennial; economic importance and geographical spread). Furthermore, seven MSs have been selected for the case studies, ensuring a good geographical spread. Afterwards, combinations of the crops and countries were made in such a way that each crop has at least two cases, and each country at least two crops. In cooperation with Croplife Europe this exercise resulted in the combinations listed in Table 2.1. Because of the high diversity in growing conditions, mainly caused by differences in the amount of precipitation, for grapes two cases have been elaborated in Italy and Spain.

Table 2.1 Overview of crop-country combinations for which case studies have been executed

\begin{tabular}{|c|c|c|c|c|c|c|c|}
\hline Products & Finland & Poland & Germany & France & Spain & Italy & Romania \\
\hline Wheat & $x$ & & $x$ & $x$ & & & $x$ \\
\hline Rapeseed & $x$ & $x$ & $x$ & & & & \\
\hline Maize & & & & $x$ & & & $x$ \\
\hline Apples & & $x$ & & & & $x$ & \\
\hline Wine & & & & $x$ & $x$ & $x$ & \\
\hline Olives & & & & & $x$ & $x$ & \\
\hline Citrus & & & & & $x$ & $x$ & \\
\hline Hops & & $x$ & $x$ & & & & \\
\hline
\end{tabular}

Source: Authors.

\section{Data collection in the case studies}

To collect the data, the project team applied the following methodology. We have developed a questionnaire in Excel, including the following sheets:

1. General instructions on how to fill in the questionnaire.

2. Description of the typical farms for which the impacts of each scenario are assessed; a conventional farm (Scenarios 1, 2 and 4) and an organic farm (Scenario 3).

3. Description of the four scenarios, how to apply the objectives in the scenarios and the corresponding indicators measuring the realisation of the objectives.

4. Elaboration and assessment of the reference scenario and the four scenarios covering the objectives of the F2F and BD strategies.

5. Overview of the available active substances and group.

\section{Instructions}

The Excel sheet with the instructions contained generic guidelines on how to fill in the questionnaire: which sheets need to be filled in, which cells in each sheet, the links between the scenarios, how to deal with the time horizon to 2030, as well as anticipated technological developments.

\section{Description of typical farms}

The project team made the choice to analyse the consequences of the objectives for a typical farm and not for an average farm. A typical farm represents a large production region, and a farm type that is representative for that region. This contributes, on the one hand, to a consistent farm structure 
(rotation, machinery, crop protection management, level of technification etc.). On the other hand, it creates variety in farm types between the case studies, such as difference in farm size, level of technification and, normal yield level. In this sheet, respondents were asked to describe the region, the farm size, the rotation in case of annual crops, the soil type etc. More specifically, respondents were asked about the percentage set aside, the labour input, the machinery, the soil tillage and fertilisation, an overview of the main pests, diseases and weeds, the crop protection strategy, and the social importance of the crop for the region where it is produced. Typical farms can greatly differ between regions within a country in terms of firm size, level of technification etc. This description has been made for both conventional and for organic farms, as various aspects defining the farm differ between conventional and organic farms.

\section{Description of the four scenarios}

In this sheet a short overview presents the targets per scenario, the indicators that have been applied in accordance with the indicators used by the European Commission to monitor the progress of the realisation of the targets by MSs, and the way the objectives should be applied in the assessment. With respect to the objectives in Scenario 2 (reduction of nutrient losses) the experts have been requested to assess the consequences of a reduction of the application of fertilisers by $20 \%$.

\section{Elaboration and assessment of the scenarios}

In this sheet, the reference scenario, representing the existing situation on the typical farm, had to be defined, and the impact of implementing the targets of the F2F and BD strategies for Scenarios 1, 2 and 4 . Scenario 3 is the organic equivalent of the reference scenario, describing the differences between conventional and organic cultivation. Equivalent implies that no other objectives of the F2F and Biodiversity strategies are applied for organic production. The structure of the organic farm can be different from the conventional farm. An example is the rotation scheme.

In each scenario, the following aspects have been considered:

1. The nutrients applied in $\mathrm{kg}$ per ha, making a distinction between nitrogen and phosphate, and organic and artificial origin.

2. Soil related aspects that determine the emission of nutrients.

3. The spraying scheme.

4. Measures applied to prevent emission and improve soil fertility and resilience against pests and diseases.

5. Relation between the scenarios and the product yield and quality.

6. Impact of scenario on costs and revenues.

7. Other possible effects of the scenario.

Overview of the available active substances

All active substances including the group to which they belong are presented. The relevant active substances can be selected by a drop-down menu provided in the 'Elaboration and assessment' sheet.

The questionnaire has been included in Appendix 1.

\section{Execution of the impact assessment}

The case studies have been executed by experts with specific expertise on the cultivation of the crop who work at research organisations or universities. The members of the project team have recruited them making use of their international network. In addition, the network of members of Croplife Europe have been used to contact potential experts. The experts needed to have expertise on crop protection, nutrient management, organic farming and a basic understanding of farm economics. The case studies were executed by small teams of experts in most cases.

The experts were given instructions on how to fill in the questionnaire by a team member in an online meeting. Attention was paid to the level of technology currently available and expected to be available by 2030: What will be the impact if crop protection and nutrient management schemes will be adjusted making use of available technologies such as mechanical weed control, mating disruption, and existing alternative plant varieties? The experts were requested to fill in the scenarios in such a way that the objectives of the scenario are met, while the negative economic consequences are 
reduced as much as possible. For Scenario 1 , this implied that the application scheme had to be adjusted in such a way that the volume of the active substances from group 3 (candidates for substitution) had to be reduced by at least 50\%. Furthermore, the overall use and risk of pesticides had to be reduced in such a way that the calculated value of the HRI I was reduced by at least $50 \%$. This could be implemented by reducing the volume of the applied pesticides (the use of pesticides) and/or by replacing pesticides of a high risk weighting factor by pesticides with a lower risk weighting factor. We have made the assumption that the classification of the pesticides in the groups remains unchanged towards 2030. Furthermore, alternative non-chemical techniques that are available to farmers such as mechanical weed control, mating disruption, biocontrol agents etc. could be applied. However, it should be noted that these alternative measures can differ from the replaced measures in terms of efficacy, costs and effect on the environment. Non-chemical measures such as mechanical weed control can have effects on soil life and contribute to erosion. Furthermore, it was emphasised that the assessment had to be executed considering the expected behaviour of the farmer. This means that the expert had to assess how they would expect the farmer to respond when they would be requested to apply the selected objectives at farm level, making use of the alternative options that are available for them. The assessment, therefore, reflects what is technically and behaviourally feasible for the typical farmer.

After submission of the filled in questionnaire to the responsible team member, the project team reviewed the results. Next, an additional meeting took place with the experts, in which the approach and results were discussed and the assumptions were checked. Moreover, attention was also paid to the representativeness of the results for the entire crop production in the country, paying attention to the availability of technology, farm structure, farm size and performance. Finally, some additional questions were asked regarding which technologies and innovations will be necessary to improve the feasibility of the objectives of the F2F and BD strategies. In some cases, the answers were adjusted.

\subsection{Analysis of potential impacts at macro level}

\section{Generalisation of case study results to EU Member States}

The results of the twenty-five case studies for the ten crops in the selected seven countries are used as the basis for the exploration and analysis of the impacts at macro level. This requires a procedure of aggregation of the relevant outcomes from farm to macro level. A description of the aggregation procedure for each scenario is provided below.

Scenario 1: $50 \%$ reduction of the overall use and risk of pesticides and $50 \%$ reduction of the use of more hazardous pesticides

The case studies were executed in seven selected countries. For each of the case crops, at least two and at most four cases were carried out. The results of these cases were extrapolated to all farms in the case countries and the other Member States (MSs) of the EU. Nevertheless, it is important to note that the cases cannot be perceived as representative for the entire country. Since the F2F strategy does not differentiate in meeting the objectives between MSs no differentiation guidelines have been available a priori. The most straightforward method is to link the MSs without cases to the case countries with the largest similarities. These similarities concern climate, cultivation practices, and performance among others. However, within the case countries the project team had to deal with a lot of disparities between farms growing the same products. In particular, differences regarding farm size, farm structure, performance, rotation in case of annual crops, and regional differences such as soil type and climate also had to be considered. Therefore, there was a need for applying the following calculation rules to scale up:

1. Calculate the EU crop-specific average yield reduction based on all the relevant case studies of the crop concerned: EU (crop, average case studies).

2. Determine which MS of the case studies match best MS(i): MS(cs, i).

3. Calculate the yield reduction for $\mathrm{MS}(\mathrm{i})$ as $\mathrm{y} \_$red_MS(i) $=0.5 \mathrm{EU}$ (crop, average case studies) $+0.5 \mathrm{MS}(\mathrm{cs}, \mathrm{i})$.

These calculation rules are also applied for the case countries. This implies that the values of the case countries applied in the macro analysis do not correspond to the figures of the case in that country. 
The consequence of this procedure is that the variety in the results between the cases is reduced. For grapes, the two cases in Italy have been combined by taking the average of both cases, which have equal weight. In Spain, we have assumed that $80 \%$ of the grapes are grown in dry areas, whereas $20 \%$ of the grapes for wine production are grown in wet areas. Therefore, both cases are combined on the basis of those weighting factors.

\section{Scenario 2: $50 \%$ nutrient loss reduction and $20 \%$ reduction of fertiliser use}

As the Gross Nitrate Balance (GNB) surplus ( $\mathrm{kg} / \mathrm{ha}$ ) needs to be reduced to comply with F2F targets, the intensity of the adjustments needed to be related to the GNB surplus. As such, ideally one would prefer to weigh the case study results according to the GNB surplus that MSs have. ${ }^{5}$ However, this information includes the contributions from all sectors, including livestock. Because the GNB-surplus is a 'summary' statistic comprising various sectoral origins of nitrate, the information was deemed not conclusive enough to use as a scaling factor for farm, crop and country specific results. Moreover, whereas EU objectives are defined at MS level, there is no specific information available to measure implementation and the regional modalities that will be applied. For this reason a rough rule of thumb has been used, according to the following procedure (e.g. yield reduction of MS(i) example), which corresponds to the procedure followed under Scenario 1:

1. Calculate EU crop-specific average yield reductions based on all the relevant case studies of the crop concerned: EU (crop, average case studies);

2. Determine which MS of the case studies is best matched MS(i): MS(cs, i);

3. Calculate the yield reduction for $\mathrm{MS}(\mathrm{i})$ as $\mathrm{y} \_$red_MS(i) $=0.5 \mathrm{EU}$ (crop, average case studies) $+0.5 \mathrm{MS}(\mathrm{cs}, \mathrm{i})$.

The calculated yield reductions are dependent on the overall EU average found (50\% and on the result from the 'mirroring' MS that has been selected out of the case study countries. The matching of an individual MS to one of the case study MSs is done by expert judgment, using certain criteria such as geographical proximity and similarities with respect to agronomic conditions as well as farming practices/conditions.

It should be noted that the case studies come from MSs that have average or low GNB surpluses. When extrapolating their results, it might be that for countries with relatively high GNB surpluses the adjustments that have to be made (and the associate impacts on yields) are under-estimated. This is likely to particularly hold for the four high GNB surplus countries: The Netherlands, Belgium, Malta and Greece. However, in most cases the contribution of these countries to EU production is in general low, but not always (e.g. Netherlands and fresh tomato production, Greece and olives/citrus production, Belgium and Netherlands and sugar beet production). But this implies that the approximation error made by the chosen shock extrapolation rule over MS is likely to be small, with limited market impacts expected. The advantage of the chosen approach is that extreme-case bias is likely to be avoided as the case studies come from a sample of MSs with an average or low GNB surplus. Nevertheless, the conditionality of the market outcomes on the used 'aggregation rule' should be recognised.

\section{Scenario 3: increasing the area for organic agriculture to $25 \%$}

This has been simulated by taking the current share of area under organic production per MS as the starting point. Subsequently, the level of organic area to be increased is estimated by taking the difference of the current level with respect to the $25 \%$ objective. This is the gap determining the MS specific increase (e.g. a MS which has a current rate of $5 \%$ will have to increase this by 20 percentage points in order to arrive at the $25 \%$ policy objective). From the case countries, information has been obtained indicating the yield differences between conventional and organic crops. The yield evolution of the crops has been adjusted based on the evolving shares of conventional and organic crop areas. The general pattern is that the increase in organic area will lead to lower yields, relative to the current baseline, which then will affect total crop supply as well as other markets elements (i.e. prices, demand and trade). Within the modelling exercise, it was only possible to apply the price premium that organic products face in a stylised way since the AGMEMOD model represents 'homogeneous goods' which implicitly capture the existing organic/conventional mix without providing individual

\footnotetext{
5 Information about GNB surplus is available at MS level (see European Commission COM(2020)486.
} 
representation to each production variant. Therefore, the model is not well-equipped to distinguish quality differentials between product categories and associated price premiums.

\section{Scenario 4 Is a Combination of Scenario 1, 2 and 10\% of the land under high-diversity landscape features}

In this scenario, the same procedure is applied as outlined in Scenarios 1 and 2 extended with the objective to have at least $10 \%$ of the agricultural land under high-diversity landscape features.

\section{Assessment of economic impacts: AGMEMOD modelling}

The study of the potential impacts of achieving the objectives of the F2F strategy by 2030 in the case of wheat, maize, rapeseed, sugar beet, apples and tomatoes for processing relied on the AGMEMOD model. ${ }^{6}$ AGMEMOD stands for 'AGricultural MEmber states MODelling'. In 2001, the model was developed by the AGMEMOD Partnership, a consortium of national university institutes and research agencies from several EU MSs and potential accession countries (Chantreuil et al., 2011). AGMEMOD is a dynamic, partial, multi-country, multi-market equilibrium system which solves in a GAMS environment (Van Leeuwen et al., 2008). It can provide significant detail concerning the main agricultural sectors in each EU MS, with most equations being estimated econometrically at the individual MS level. In cases which econometric analysis is not feasible or meaningful, e.g. due to lack of long time series, the equations are calibrated. The individual country models contain the behavioural responses of economic agents to changes in prices, policy instruments and other exogenous variables, e.g. world market prices, macroeconomic developments, etc., on the agricultural market. Within AGMEMOD, all commodity prices clear all the markets that are included.

The current AGMEMOD version covers the EU-27 MSs, the United Kingdom, North Macedonia, Turkey, Russia and Ukraine (AGMEMOD Consortium; 2010, 2011). Recently, some attempts of introducing a regional disaggregation were made in the case of Germany and Ukraine. Within AGMEMOD, a bottomup approach is used to integrate the different country models into the general 'structure' of the sectoral model. For each commodity in each country, agricultural production as well as supply, demand, trade, stocks and domestic prices are derived from a combination of equations and identities. One element of the supply and demand balance for each commodity is used as a closure variable to make the balance consistent. For a closer representation of the dynamics of the market, the specification of the equations that are used for a given commodity can differ across countries, allowing this to capture country-specific elements. AGMEMOD's projections combine econometric results and expert knowledge, i.e. the baseline projections of the models are validated by standard econometric methods and several rounds of consultation with experts who are familiar with the agricultural market in each of the regions included. ${ }^{7}$

The simulation of the four scenarios that have been explored in the context of this project reflects the potential development of the market by 2030, after applying certain shocks on yields and commodity prices at farm level. These shocks are assumed to progressively 'enter' into the model over the period 2021-2030, being the 'total' shock cumulatively implemented by 2030 . The size of the shocks that were applied in each case has been derived from a generalisation of the findings of the case studies conducted in an early stage of the project. As regards the yields, it should be noted that the application of the yield shock does not affect the dynamic yield evolution as it is already included in the AGMEMOD model based on empirical estimation (e.g. autonomous yield growth due to genetic progress and management improvements) but is used as an add-on to this already existing yield development. In the case of Scenario 4, changes in the proportion of land set-aside are also included.

\footnotetext{
6 In the case of the tomato for processing and apple markets only the five key producer countries are included in AGMEMOD. This is equivalent to more than $94 \%$ and $78 \%$ of the total EU production for tomato and apple respectively.

7 In terms of the product coverage, AGMEMOD provides specific representation of the following agricultural commodities: (i) cereals (soft wheat, durum wheat, barley, maize, rye, other grains); (ii) oilseeds (rapeseed, sunflower seed, soybeans, cotton seeds, vegetables oils and meals); (iii) livestock and meat (beef and veal, pork, poultry, sheep and goats); (iv) milk and dairy products (butter, skimmed milk powder and cheese); ( $v$ ) fruits and vegetables sector (tomatoes, apples); (vi) industrial crops (sugar beets tobacco and cotton) and potatoes; and (vii) bioethanol (from grains) and biodiesel (from oilseeds). Further details on the general model 'architecture' and recent applications of AGMEMOD are available at the model's website (https://agmemod.eu/).
} 
When interpreting the results, the reader should be aware that in the scenarios no price shocks (reflecting quality deterioration or 'organic' premium) were applied to sugar beet. This approach has been taken since within the model architecture the developments of the sugar beet market are 'linked' to the ones of the sugar market, while there is no individual representation of a farm-gate price for sugar beet. As the sugar processing industry is a highly capital intensive production activity, it has been assumed that the industry will source as much product as needed to run their business at normal capacity. This was also included in the model architecture, where sugar beets used as an input for the sugar beet processing industry are a function of the need for sugar which is not covered from imports, and follow from domestic uses (e.g. bioenergy, human demand for sugar) and sugar exports. The farm gate price equals the cost of production and has an impact on sugar beet yield, but most of the adjustment is made by the adjustment in the area grown with sugar beet. As a consequence, potential negative quality impacts on the sugar beet price will not show up as there is no yield-quality pricetrade-off for sugar beet included in the model.

\section{Assessment of economic impacts: Equilibrium displacement modelling}

For the crops which are not included in AGMEMOD, i.e. olives, wine, citrus and hops, crop-specific tailormade models were developed for this specific project. These 'tailor-made' models rely on the equilibrium displacement modelling (EDM) methodology. More specifically, equilibrium displacement models are partial equilibrium models that provide a simplified and stylised representation of a sectoral (related) market-setting. The economic theory behind the equilibrium displacement model assumes a competitive structure of the market under consideration (Pathiraja et al., 2017). In the EDM context, elements such as changes of government policies, climate change and other regulations are considered exogenous shocks and provoke movements of the supply/demand curve. EDMs date back to the work of Muth in the 1960s (Piggot, 1992) and have since found many applications in international literature (e.g. Wohlgenant, 1993, 2011; and Lusk et al.,. 2011).

Focusing on the conceptual framework, an EDM is a modelling 'tool' that provides a representation of the current market situation (equilibrium), which is defined by the supply and demand functions of a particular commodity (olives, wine, citrus and hops in this specific case). See Figure 2.2 for a graphical illustration of the general structure of the developed EDMs. The left panel of the graph represents the EU market by both EU demand and supply functions. In the figure they are presented in an aggregate way, but in the EDMs that are used EU MSs (key producers) or regions are distinguished, which together represented EU total supply and demand. The interaction with non-EU countries (aggregated as the Rest of the World, RoW) is via trade. As the right panel shows there are two curves which characterise the RoW-market. The first one is the EU's excess supply, which simply follows from a horizontal aggregation of the EUs supply and demand curves (where ES = S-D). The second curve is the other side of the market, which captures the Rest of the World's excess demand. The interaction of both curves determine the world price, which in turn also fixes the price in the EU. As is indicated in Figure 2.2, the EU is a net exporter while the RoW is a net importer based on the initial world market equilibrium being $E_{0}$, with a price $\mathrm{p}_{0}$ ). Due to $\mathrm{EU}$ declines in crop yields resulting from the implementation of the F2F and BD strategies, an inward shift of the supply curve of the EU is observed in the EDM (e.g. from $S_{0}$ to $S_{1}$ ). As a result, EU's excess supply curve also shows an inward shift (from $E S_{0}$ to $E S_{1}$ ). As a consequence of this shift, a new (world) market equilibrium will emerge $\left(E_{1}\right)$, and market prices in the RoW and the EU will increase. As observed in the graph, the EU remains a net exporter to RoW, but its exports will have declined. EU producers (farmers) produce less volume, but get a higher price. Due to these counteracting forces, the impact on farmer revenues may be ambiguous and will depend on the market specificities (in Figure 2.2 these are reflected in the slopes and curvature of the supply and demand curves) as well as the magnitude of the (yield) ${ }^{8}$ shock. ${ }^{9}$

\footnotetext{
8 Also other type of shocks can be taken into account in this framework. An important one which has been considered in this study is a negative price shock (to producers) due to a deterioration on product quality. This is modelled as a (negative) price wedge for the product grown in the EU relative to that grown outside the EU (where the F2F and BD strategies do not apply and quality has been assumed to be unchanged). This type of impact is not shown in the graph, but has been included in the EDMs.

9 Note that the mechanism how markets will adjust to F2F and BD shocks, as represented here for an EDM, is similar to what happens in the AGMEMOD model, with the main difference being that the AGMEMOD model is more refined and detailed.
} 


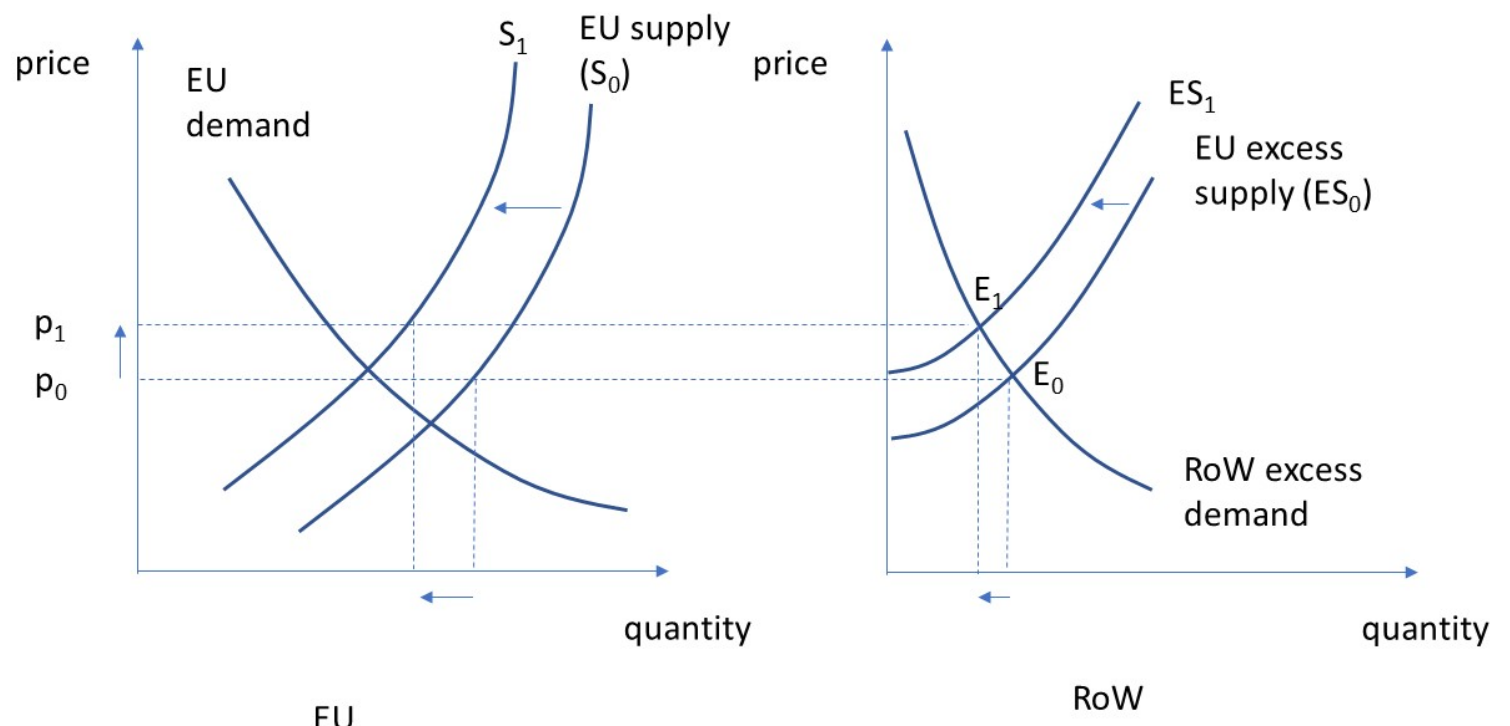

Figure 2.2 Generic example of an EDM for one commodity and two regions and its use to assess F2F- and BD-related shocks

Source: Authors.

EDMs use demand and supply elasticities to describe the relationship between changes in the quantity demanded or quantity supplied and the price of a commodity (e.g. supply elasticity, own-price elasticity of demand, cross-price elasticities of demand). Table 2.2 provides and overview of the elasticities as they have been used in the EDM models. The elasticities are estimated by the researchers, which are informed by empirical elasticity estimates from the literature. The information from the literature was incomplete, although specific elasticity estimates were also found in MSs (this is reflected in the table by indicating a range of elasticities). Note that in general, EU demand and supply elasticities are (own) price inelastic. This is quite a general characteristic for agricultural and food products, but holds even more for perennial crops. In contrast, the excess demand or supply elasticities of the RoW (see most right column of the table) are elastic, which reflects the depth of the world market, the responsiveness of world demand and supply, and the EU's share in world supply and demand. Note that due to the 'approximate nature' of these calibrated EDMs their results should be seen as indicative and be interpreted with caution.

Table 2.2 Price elasticities as they have been applied in the EDMs used for the F2F and BD assessment

\begin{tabular}{lccc} 
crop & EU Demand & $\begin{array}{c}\text { Price elasticities used in EDMs } \\
\text { EU Supply }\end{array}$ & $\begin{array}{c}\text { Rest of the World (excess } \\
\text { demand }(-) \text { or excess } \\
\text { supply }(+) \text { elasticity }\end{array}$ \\
Olives & $-0.35--0.09$ & 0.1 & -5.0 \\
\hline Wine & $-1.00--0.07$ & 0.1 & -5.6 \\
\hline Citrus & $-1.00--0,50$ & 0.4 & +5 \\
\hline Hops & -0.10 & 0.7 & -2 \\
\hline
\end{tabular}

Source: Authors.

Figure 2.3 provides a brief overview of the key mechanisms as they play a role in assessing the economic impacts of the F2F and BD strategies with a focus on the crop sector, as this is pursued in this research. The F2F and BD strategies affect both the yields (fertiliser and pesticide targets) as well as the area (organic agriculture, landscape elements) and potentially also product quality. These factors in turn negatively impact on supply, where in the market a reduced supply while the demand stays unchanged will lead to increasing scarcity of product. As a result, prices tend to rise. The extent 
to which this happens will depend on the initial yield and/or quality, and derived supply shocks, where the negative quality shock is likely to counteract the market price increase, at least at farm gate level. The model accounts for a number of second order effects: due to the price increase, farmers may look for ways to further improve their yields (quality) using other techniques than the restricted inputs, which may reduce the negative initial yield shock to some extent.

(+)

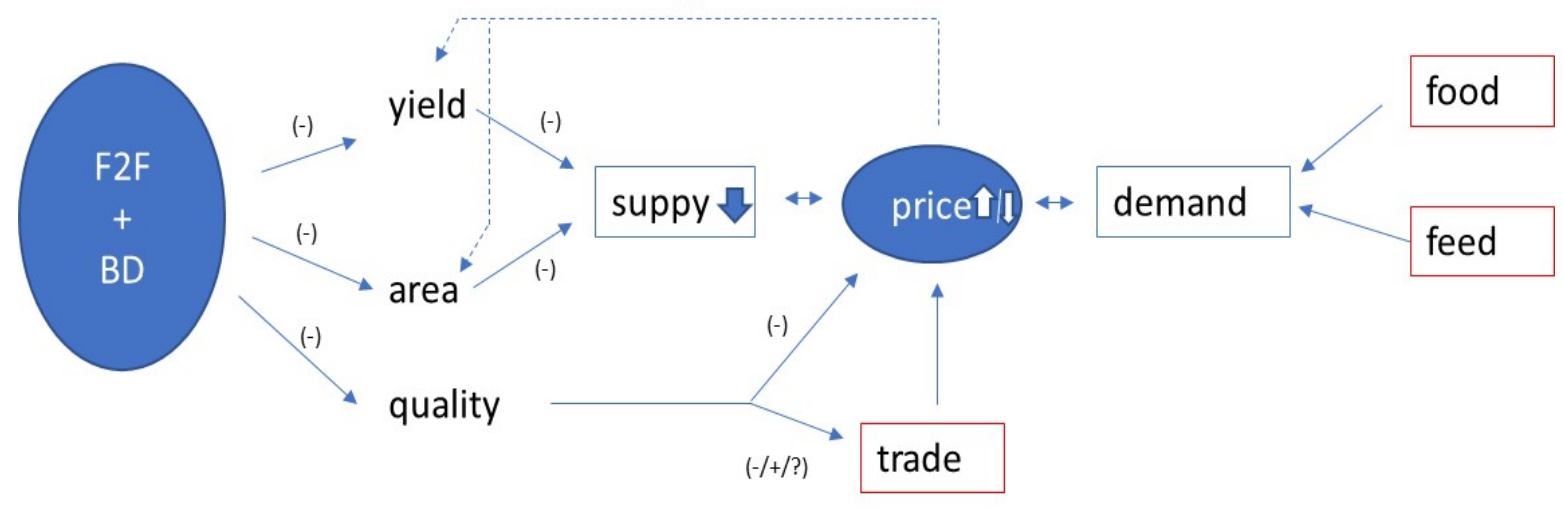

Figure 2.3 The basic agronomic-economic mechanisms playing a role in market and farmer responses to the shocks caused by the F2F and BD strategies

Source: Authors.

As Figure 2.3 makes clear, the market impacts will be co-determined by what happens to EU food and feed demand, as well as by responses from the trade side. Several outcomes are possible here. For example, in the F2F strategy, one objective is to reduce food waste, which could contribute to a lower crop demand. As regards to the demand for feed, this will be affected by the impact that the F2F and BD strategies have on livestock production in the EU. If this would be limited or decline (see estimates from the recent JRC study (Barreiro Hurle et al., 2021)) then this may negatively affect the demand for feed. A reduction in the demand for food and feed will lower the 'scarcity' of crops and counteract the price increase. It also is likely to have an impact on the trade and related indirect land use change (ILUC) figures. Moreover, the price increase projected due to the negative supply shock will also depend on the trade regime. When markets are open, an increasing scarcity caused by domestic supply may lead to a surge of imports, which could occur at a limited price increase.

Figure 2.3 helps not only to better understand the macro-economic results that may be expected, but also indicates the limitations of our results. Since the impacts of the F2F and BD strategies on EU food and feed demand and the derived demand for crops are not taken into account this study may overestimate the market impacts (price, import and export volume changes). 


\section{Results at farm level}

\subsection{Introduction}

In this chapter we present and discuss the results of the twenty-five case studies that have been completed for ten crops in seven countries. We start with a description of the case farms as defined by the expert, which is a common farm type in a large production region. Afterwards, we discuss the results of each scenario. Scenarios 1 and 2 are discussed per crop while Scenarios 3 and 4 for all crops together. We finalise this chapter with a description of the results of the tomato case from Morocco. Tomatoes were selected as they represent an important import product of the European Union. The tomatoes case from Morocco was completed in correspondence with the European case studies to get an impression of the consequences, should exporters to the EU have to comply with the same objectives as European producers.

\subsection{Typical crop farms}

\subsubsection{Overview}

Table 3.1 presents an overview of the farms that are selected for the case studies. This overview shows that the case farms cover a wide variety of farm types, ranging from very small farms in the Valencia region in Spain (citrus), Sicily and Calabria in Italy (olives and grapes) and modern family farms to very large farms such as the wheat case in Poland and the farm producing wheat and maize in Romania. For the scaling up to MS and EU level, it is important that variety exists among the case farms.

Table 3.1 Overview of typical farms per country per crop

\begin{tabular}{|c|c|c|c|c|c|c|}
\hline Country & Crop & Region & Soil-type & $\begin{array}{l}\text { Farm size } \\
\text { (ha) }\end{array}$ & Rotation & $\begin{array}{l}\% \text { set } \\
\text { aside }\end{array}$ \\
\hline Finland & $\begin{array}{l}\text { Wheat, } \\
\text { Rapeseed }\end{array}$ & South-western Finland & Clay & 70 & $\begin{array}{l}\text { Spring wheat - spring } \\
\text { barley - winter wheat - } \\
\text { oats - spring oilseeds }\end{array}$ & 7 \\
\hline \multirow[t]{3}{*}{ France } & Wheat & $\begin{array}{l}\text { Poitou-Charentes (West } \\
\text { of France) }\end{array}$ & $\begin{array}{l}\text { Shallow stony } \\
\text { limestone soil } \\
\text { of clay and } \\
\text { loam }\end{array}$ & 184 & $\begin{array}{l}\text { Rapeseed } \\
\text { soft wheat } \\
\text { sun flower }\end{array}$ & 6 \\
\hline & Sugar beet & Picardie & Deep silt & 143 & $\begin{array}{c}\text { soft wheat - winter barley - } \\
\text { spring barley - maize - } \\
\text { rapeseed - protein peas - } \\
\text { potato - vegetable - sugar } \\
\text { beet }\end{array}$ & 6 \\
\hline & Grapes & Not specified & Not specified & 20 & - & 10 \\
\hline \multirow[t]{2}{*}{ Germany } & Wheat & Northwest-Germany & Loam & 140 & $\begin{array}{c}\text { winter wheat, winter } \\
\text { barley, Rapeseed }\end{array}$ & 5 \\
\hline & Rapeseed & Northeast-Germany & Loam & 500 & $\begin{array}{c}\text { winter wheat, winter } \\
\text { barley, rapeseed }\end{array}$ & 5 \\
\hline
\end{tabular}




\begin{tabular}{|c|c|c|c|c|c|c|}
\hline Country & Crop & Region & Soil-type & $\begin{array}{l}\text { Farm size } \\
\text { (ha) }\end{array}$ & Rotation & $\begin{array}{l}\% \text { set } \\
\text { aside }\end{array}$ \\
\hline & Sugar beet & $\begin{array}{l}\text { different regions with } \\
\text { high productivity around } \\
\text { sugar factories }\end{array}$ & Loam & 180 & $\begin{array}{l}\text { winter wheat, winter } \\
\text { barley, rapeseed, sugar } \\
\text { beet }\end{array}$ & 5 \\
\hline & Hops & $\begin{array}{l}\text { Hallertau, Tettnang, } \\
\text { Elbe-Saale, Spalt }\end{array}$ & Sandy loam & 19 & - & 7 \\
\hline \multirow[t]{6}{*}{ Italy } & Apples & Trentino Alto Adige & Loamy soil & 3.5 & - & 10 \\
\hline & Tomatoes & Emilia Romagna & $\begin{array}{l}\text { Medium } \\
\text { texture }\end{array}$ & 10 & Wheat, tomatoes & 3 \\
\hline & Grapes & Trentino Alto Adige & $\begin{array}{l}\text { sandy/loam } \\
\text { silty }\end{array}$ & 2.5 & - & 10 \\
\hline & & Veneto & $\begin{array}{c}\text { Silty } \\
\text { clay/loam }\end{array}$ & 6 & & 3 \\
\hline & Olives & $\begin{array}{l}\text { Apulia, Calabria and } \\
\text { Sicily }\end{array}$ & $\begin{array}{l}\text { Sand: } 45 \text { to } \\
65 \% \text {; Silt: } 10 \\
\text { to } 35 \% \text {; Clay: } \\
10 \text { to } 35 \%\end{array}$ & 2 & - & 1 \\
\hline & Citrus & $\begin{array}{l}\text { Sicily, Calabria, } \\
\text { Basilicata, Puglia, } \\
\text { Sardegna }\end{array}$ & $\begin{array}{l}\text { sandy; sandy } \\
\text { loam; clay; } \\
\text { heavy clay }\end{array}$ & 10 & - & 20 \\
\hline \multirow[t]{4}{*}{ Poland } & Rapeseed & $\begin{array}{c}\text { Southern Poland - Opole } \\
\text { voivodship }\end{array}$ & Silty loam & 1400 & $\begin{array}{c}\text { Wheat, Rapeseed, Sugar } \\
\text { Beet, Potato, Beans, Maize, } \\
\text { Soy bean }\end{array}$ & 5 \\
\hline & Sugar beet & Łódzkie Voivodeship & $\begin{array}{l}\text { soil mosaic } \\
\text { (sandy, loamy } \\
\text { and loess } \\
\text { soils) }\end{array}$ & 40 & Sugar beets, wheat, maize & 3 \\
\hline & Apples & $\begin{array}{l}\text { Centre of Poland region } \\
\text { of Grójec in } \\
\text { mazowieckie voivodship }\end{array}$ & $\begin{array}{l}\text { Sandy loam } \\
\text { soil }\end{array}$ & $5-10$ & - & 6 \\
\hline & Hops & Lublin region & Mud & 3 & - & 6 \\
\hline Romania & Wheat, maize & $\begin{array}{l}\text { South Romania - The } \\
\text { Romanian Plain on } \\
\text { chernozem soil }\end{array}$ & Loam & 450 & $\begin{array}{c}\text { Wheat, rapeseed, barley, } \\
\text { maize, sunflower }\end{array}$ & 5 \\
\hline \multirow[t]{5}{*}{ Spain } & $\begin{array}{l}\text { Tomatoes } \\
\text { (open field) }\end{array}$ & Andalusia & $\begin{array}{l}\text { Solochanks, } \\
\text { clayey }\end{array}$ & 24 & $\begin{array}{c}\text { Tomato, Chard, Onion } \\
\text { Upland cotton }\end{array}$ & 6 \\
\hline & Grapes & $\begin{array}{l}\text { Several wine regions, } \\
\text { except coastal areas }\end{array}$ & Loam & 40 & - & 12 \\
\hline & & Galicia & Sand & 1 ha & & 2 \\
\hline & Olives & $\begin{array}{c}\text { Jaén, Córdoba, Sevilla, } \\
\text { Granada and Málaga }\end{array}$ & Clay & 6 & & 1 \\
\hline & Citrus & Valencia & Clay - Ioam & 1 & & 10 \\
\hline
\end{tabular}

Source: Authors.

\subsubsection{Wheat}

Wheat is one of the most important crops grown in the EU, with a large geographical spread over the entire Union, and constitutes one of the major ingredients in our daily food intake. The focus in this case is soft wheat. We have selected four countries for wheat case studies with a large geographical spread: Finland, Germany, France and Romania. The farm size in the Finnish case (70 ha) is the lowest. In the German and French cases, farm sizes are considerably bigger (140 ha and 184 ha respectively). The biggest farm size can be observed in the Romanian case with a size of 450 ha. This farm is oriented at exporting products, and distinguishes itself from many other farms in Romania of a few hectares, used for subsistence farming. In the Finnish case the crop is grown in a rotation scheme with oilseeds and other grains, such as barley. In the French, German and Romanian cases, the rotation consists of cereals and oilseeds such as oilseed rape in all three countries and sunflower in the French and the Romanian cases. The average yield per ha varies from 4.5 tonnes in the Finnish case 
to 10 tonnes in the German case. Differences in yield per ha are mainly caused by differences in climatic conditions and differences between spring wheat and winter wheat.

\subsubsection{Rapeseed}

Rapeseed is mainly produced in the northern half of Europe for oil and feed. The focus in this case is on oilseed rape (Brassica napus), not on turnip rape (B. rapa). Three countries have been selected: Finland, Poland and Germany. The farm size in the Finnish case (70 ha) is significantly lower than in the Polish case (1,400 ha) and the German case (500 ha). In all countries rapeseed is produced in rotation with cereals and other arable crops. Yields vary from 1.3 tonnes per ha in the Finnish case to 4.5 tonnes per ha in the Polish case.

\subsubsection{Sugar beet}

Sugar beets are produced for the production of sugar. Production takes place in large parts of the EU but predominantly in the northern half. The selected case countries are Poland, Germany and France. The average farm size ranges from 40 ha in the Polish case to 180 ha in the German case. The crop is cultivated in rotation with other arable crops, such as cereals and potatoes. The yield varies from 75 tonnes per ha in the Polish case to 87 tonnes per ha in the French case.

\subsubsection{Maize}

Maize is an important crop that is produced for livestock and bio-energy production. We have selected two countries for maize: France and Romania. In the French case, the farm size is 184 ha and 450 ha in the Romanian case. This farm is oriented at production for export, and distinguishes itself from subsistence farming. In the Romanian case, the rotation consists of cereals and oilseeds such as oilseed rape. In the French case, the rotation scheme consists of 4 years producing maize and one year producing durum wheat. The average production is 11 and 8 tonnes per ha in the French and Romanian cases respectively.

\subsubsection{Apples}

Apples are mainly produced for the fresh market, but also used in the processing industry for juice and compote production. In our case study, we focus on the fresh market. Poland and Italy are chosen as case countries. The average farm size is 5 to 10 ha in the Polish case and 3.5 ha in the Italian case. The Italian case farm is located in the region of Trentino Alto Adige, a mountainous region in the north of Italy. Production circumstances between both regions such as soil type, climatic conditions and height differ. Production per ha varies from 40 tonnes per ha in the Polish case to 60 tonnes per ha in the Italian case.

\subsubsection{Tomatoes}

Spain and Italy are the selected countries for tomatoes. Both cases refer to open field production of tomatoes cultivated for the processing industry. Tomatoes are cultivated in rotation with wheat in the Italian case and with onions, chard and upland cotton in the Spanish case. The average farm size varies from 10 ha in the Italian case to 24 ha in the Spanish case. The yields in the reference scenario is 90 tonnes per ha in the Italian case and 125 tonnes per ha in the Spanish case. ${ }^{10}$ In the Spanish case, fertigation is applied which can explain the differences in yield per ha between the two cases.

\footnotetext{
${ }^{10}$ The yield per ha is for tomatoes produced in the open field. A large part of the tomatoes produced in Spain are produced in greenhouses for the fresh market, with a much higher yield per ha.
} 


\subsubsection{Grapes $^{11}$}

For grapes we have selected France, Italy and Spain as case countries. The grapes are used for wine production. Because of the diversity in growing conditions, we have selected two regions in Italy and two in Spain. The size of the selected case farms varies considerably from 1 ha in coastal areas in Spain, 2.5 ha and 6 ha in the Italian cases to 20 ha in the French case and 40 ha in the Spanish case in dry areas. The average yields are 7 tonnes per ha in France, 13 and 17 tonnes per ha in Trentino Alto Adige and Veneto in Italy respectively and 7.5 and 11 tonnes per ha in the dry and wet areas in Spain respectively. In general, the quality of the wine will increase when the yield is limited, to ensure that the remaining vines are of good quality containing sufficient sugar. Therefore, in part of the wine producing regions, the yield is limited voluntarily. By consequence, compared to other crops, yields have limited value as an indicator relative to farm performance.

\subsubsection{Olives}

The selected countries for olives are Spain and Italy and are produced for olive oil. The case study in Italy is about 2 ha, which is a common farm size in the South of Italy, Sicily and Calabria. In the Spanish case, the farm size is $6 \mathrm{ha}$. Both farms are not irrigated. The reported yields are 1,000 kg of olive oil per ha in the Spanish case ${ }^{12}$ and 5 tonnes olives per ha in the Italian case respectively. This corresponds to roughly $1,000 \mathrm{~kg}$ of olive oil per ha.

\subsubsection{Citrus}

Like apples, citrus such as oranges and mandarins are produced for the fresh market, but also for the processing industry. Italy and Spain have been chosen as case countries with oranges as case crop. Both case farms differ in farm size: 10 ha in the Italian case versus 1 ha in the Spanish case, which does not provide a full income for the farmer. The average yield is 45 and 30 tonnes per ha in these cases respectively.

\subsubsection{Hops}

Hops is a relatively small perennial crop that is grown for beer production. The selected countries are Poland and Germany. The cases differ in farm size: 3 ha in Poland versus 19 ha in Germany for these cases, with a yield per ha of 2.5 and 2.3 tonnes per ha respectively.

\subsection{Scenario 1 - Reduction pesticide use and risk}

\subsubsection{Overview}

In this section we describe the results per crop taking into account the realisation of the objectives in Scenario 1: $50 \%$ reduction in the overall use and risk of pesticides and $50 \%$ reduction in the use of more hazardous pesticides. An overview of estimated yield losses in Scenario 1 is presented in Table 3.2, estimated price changes in Scenario 1 in Table 3.3 and the values of the HRI I in the reference scenario in Table 3.4 .

\footnotetext{
${ }^{11}$ The Italian case has been selected from a small region in the North. Therefore, an additional case study will be executed representing a large production region in Italy. In Spain, the case study has been selected from the dry production regions. An additional case study will be selected from a more wet region in the coastal zones.

${ }^{12}$ The largest share of olive production in Spain is not irrigated (approximately $75 \%$ ). There are a significant number of groves where the yield is lower than the one used in this report, especially in mountainous areas with high slopes. Although a transition is ongoing from an extensive, non-irrigated way of production to an irrigated way of production, with more technology applied and higher yields per ha.
} 
Table 3.2 Estimated yield changes per crop per country in Scenario 1 (\%)

\begin{tabular}{|c|c|c|c|c|c|c|c|c|}
\hline & Finland & France & Germany & Italy & Poland & Romania & Spain & Average \\
\hline Wheat & 0 & -5 & -10 & & & -7 & & -6 \\
\hline Rapeseed & 0 & & -10 & & -13 & & & -8 \\
\hline Maize & & 0 & & & & -4 & & -2 \\
\hline Apples & & & & -8 & -20 & & & -14 \\
\hline Grapes & & -28 & & $-20 /-6$ & & & $0 /-18$ & -15 \\
\hline Olives & & & & -30 & & & -13 & -21 \\
\hline Citrus & & & & -7 & & & -10 & -8 \\
\hline Hops & & & -20 & & -8 & & & -14 \\
\hline
\end{tabular}

Source: Authors.

Table 3.3 Estimated price changes per crop per country in Scenario 1 (\%)

\begin{tabular}{|c|c|c|c|c|c|c|c|c|}
\hline & Finland & France & Germany & Italy & Poland & Romania & Spain & Average \\
\hline Wheat & 0 & 0 & 0 & & & -5 & & -1 \\
\hline Rapeseed & 0 & & -5 & & 0 & & & -2 \\
\hline Maize & & 0 & & & & 0 & & 0 \\
\hline Apples & & & & -6 & 0 & & & -3 \\
\hline Grapes & & 0 & & $-5 / 0$ & & & $0 / 0$ & -1 \\
\hline Olives & & & & 0 & & & 0 & 0 \\
\hline Citrus & & & & 0 & & & 0 & 0 \\
\hline Hops & & & -10 & & -1.5 & & & -6 \\
\hline
\end{tabular}

Source: Authors.

Table 3.4 Values of Harmonised risk indicator in reference scenario

\begin{tabular}{|c|c|c|c|c|c|c|c|}
\hline & Finland & France & Germany & Italy & Poland & Romania & Spain \\
\hline Wheat & 20 & 52 & 21 & & & 4 & \\
\hline Rapeseed & 5 & & 22 & & 27 & & \\
\hline Sugar beet & & 56 & 42 & & 37 & & \\
\hline Maize & & 20 & & & & 4 & \\
\hline Apples & & & & 486 & 457 & & \\
\hline Tomatoes & & & & 105 & & & 27 \\
\hline Grapes & & 273 & & 341 / 601 & & & $43 / 203$ \\
\hline Olives & & & & 91 & & & 188 \\
\hline Citrus & & & & 232 & & & 67 \\
\hline Hops & & & 189 & & 222 & & \\
\hline
\end{tabular}

Source: Authors.

\subsubsection{Wheat}

The conventional crop protection strategy in the four wheat cases mainly relies on the use of pesticides, in some cases (Finland, Germany) guided by decision support systems to minimise the applied dosages. Other methods applied to prevent and control pests, diseases and weeds include seed treatment, crop rotation, the use of biocontrol methods in the French case, and the use of seed varieties which are tolerant against the most prevalent pests and diseases (the Romanian case). Mitigation measures that have been applied in the case studies to prevent the emission of pesticides to the environment include buffer zones (all cases) and the use of drift reducing nozzles (the German and French case). 
We expect that glyphosate will be no longer available but some selective compounds against couch will have to replace it. Risk group 3 insecticides can be replaced. Risk group 3 compounds for seed dressing can be replaced with Thermo seed and with bio-based fungicides (e.g. Cerall). No major need to adjust doses but the frequency of fungicide and insecticide applications may reduce as a result of improved warning systems, risk models and more diverse crop rotation.

When we compare the spraying schemes in the reference scenarios between the cases, we observe that although some active ingredients have been applied in all schemes, the spraying schemes largely differ from each other. The emphasis in crop protection in all case countries is on weed and disease control. In all case countries, only one insecticide is applied. Examples of active ingredients that are applied in multiple case countries are: (i) $M C P A$, which is the herbicide reported in the Finnish and German cases; (ii) benzovindiflupyr, which is the fungicide indicated in the German and French cases; and (iii) tebuconazole, which is the fungicide reported in the Finnish and Romanian cases. The spraying schemes between the Finnish and German cases have the largest degree of similarity with five fungicides applied in both reference scenarios. When we compare the values of HRI I for the reference scenarios, we see a variation from a score of 4 in the Romanian case, around 20 in the Finnish and German cases to 52 in the French case. In the Romanian case, only a few pesticides (mainly herbicides) are applied. In the adjusted spraying scheme in Scenario 1, not only the dosages, but also the composition of the spraying scheme is adjusted, indicating that both the use and the risk of the applied pesticides are adjusted. In very few cases, active ingredients that are applied in the reference scenario and replaced in one case are applied as an alternative in Scenario 1 in another case. An example is the use of flufenazet (herbicide, Candidate for Substitution) in the reference scenario in the German case that has been applied in Scenario 1 in the French case. The adjusted spraying schemes in Scenario 1 leads to yield losses ranging from $0 \%$ in the Finnish case to $10 \%$ in the German case.

In the Finnish case, yield losses can be prevented by replacement of pesticides from risk category 3 (candidates for substitution) to risk category 2 (see Textbox 3.1). Furthermore, a systems approach is applied. Chemical fungicide seed treatment has been replaced by thermal seed treatment and biological fungicides are applied. In other cases yield losses occur due to the fact that the damage caused by pests, diseases and weeds cannot be fully prevented (as indicated in the French and Romanian cases). Another reason is the replacement of the current variety by varieties that are more resistant, but have lower yields (as reported in the German and French case). Furthermore, the German expert points to the risk of herbicide resistance of certain weeds, which could lead to increased yield losses in the long term. In this case, mechanical weeding needs to be applied to reduce additional yield losses.

In the Romanian case, quality problems caused by specific diseases have also been reported, which leads to negative consequences for the price of the harvested product (see Textbox 3.2). Fusarium can produce mycotoxins that cause harm to human health if consumed. No major changes in the costs have been reported for any of the cases. However, in the French case, higher costs have been reported for pesticides, which explains the reason why farmers currently apply the spraying scheme elaborated in the reference scenario.

Textbox 3.2 Explanation of quality loss - Romanian case

The yield quality could be affected significantly especially because of the attack of some pests such as Eurygaster spp. (the grains stung by Eurygaster lose their quality for bakery, respectively for bread production), but also because of the development of some diseases such as Fusarium graminearum (the grains become inappropriate for human and animal consumption because of the mycotoxins presence).

When we compare the cases, we observe a number of differences. The reader should not forget that the farms are located in different countries and are not representative of the whole country. This has 
an impact on several aspects. Firstly, the climatic conditions differ, which has consequences on the presence of host plants, pests and disease pressure. Secondly, the availability of pesticides at MS level can differ. This may have led to the use of different seed varieties. Finally, the farm structure, size of the farm, crop rotation scheme and available technologies for farmers to control pests, diseases and weeds can differ. In this project, an extensive comparison of the cases of the same crop in different countries with involvement of all experts was not considered.

Based on the case studies, for wheat we expect yield losses varying from 0 to $10 \%$. Some quality problems are expected in the Romanian case, when the objectives to reduce the use and risk of pesticides by $50 \%$ and to reduce the use of more hazardous pesticides by $50 \%$ are applied at farm level. However, other aspects can also contribute to the expected yield in the year 2030 under this scenario. In the Finnish case, new varieties are expected to become available that will have higher yields and which are less susceptible to pests and diseases. Weather conditions can have impact on pest, disease and weed pressure leading to risks of significantly higher yield and/or quality losses in years with bad weather, or increased costs (see Textbox 3.3).

Textbox 3.3 Examples of increased risks - Germany and Finland

- Mechanical weeding (harrowing) is not included here but could be an option if weed infestation is high.

- Considerable difference in price between bread-quality wheat and wheat for feed. This will affect the net return. Annual variations in quality which determines whether the wheat meets the quality requirements for bread production.

\subsubsection{Rapeseed}

Like wheat, the crop protection strategy in conventional farming mainly relies on chemical pesticide use. Integrated Pest Management (IPM) techniques, such as pest monitoring and damage thresholds are applied to reduce the use of pesticides. Furthermore, competitive varieties are selected in the Finnish and Polish cases. The spraying schemes in the reference scenario of the cases partly match. No active ingredients are selected that are applied in all three case countries. The dosages of pesticides that are applied in different countries vary. An example is the application of metazachlor (herbicide, category 2) that is applied in $0.4 \mathrm{~kg} / \mathrm{per}$ in the German case and in $1.0 \mathrm{~kg} / \mathrm{ha}$ in the Polish case.

Values of HRI I vary from 5 in the Finnish case to 27 in the Polish case. In the adjusted spraying scheme in Scenario 1, not only the dosages, but also the composition of the spraying scheme is adjusted, indicating that both the use and the risk of the applied pesticides are adjusted. However, in all cases the volume is also reduced by at least $50 \%$, which means that the targets of the objective to reduce the overall use and risk of pesticides are fully met by the reduction of the volume of the applied pesticides. The reduction can be implemented in the Finnish case by replacing fungicides more diverse crop rotation, resistant cultivars and with thermo seed treatment. Furthermore application of advanced risk models can help to reduce the number of applications of both fungicides and insecticides, and thus reducing the volume. In the German and Polish cases, the reduction takes place by reducing the application of fungicides, whereas in the Finnish case the reduction concerns the application of both fungicides and insecticides.

The reported yield losses from the rapeseed case studies varied from 0 to $13 \%$. In the Finnish case, no yield loss is reported. A main driver for this is expected breeding progress, which is higher $(1.53 \%$ per annum) for $B$. napus than for the Brassica rapa $(0.85 \%$ per annum currently predominantly grown in Finland). Application of new seed varieties may even increase the yield levels in the near future significantly. No major changes have been reported in the costs. Both the German and the Polish cases point to increased risks such as bad weather, which can cause higher yield or quality losses. 


\subsubsection{Sugar beet}

In the Polish and French cases, the crop protection strategy consists of pesticide use, the application of decision support systems, and mechanical weeding. In the German case study, no mechanical weeding is applied in the conventional cultivation system. The spraying schemes in the reference scenarios largely differ between the case countries. The HRI I in the reference scenarios varies from 37 in the Polish case and 42 in the German case to 56 in the French case. However, in the German case, much fewer pesticides are applied (6) than in the Polish case (16), but in higher volumes. The French case has an intermediate position (11 active ingredients applied). The volume of the active ingredients applied vary from $4.3 \mathrm{~kg} / \mathrm{ha}$ in the Polish case to 5.1 and $5.2 \mathrm{~kg} / \mathrm{ha}$ in the German and French cases respectively. In both the French and German cases, the objectives are largely met by reducing the volume, whereas in the Polish case, some pesticides are replaced. In the German case, the reduction of herbicide use is compensated by increased mechanical weeding. The yield losses vary from $3 \%$ in the French case, to $10 \%$ in the Polish case and $15 \%$ in the German case, due to an increase in disease pressure in the French case, an increased weed competition in the German case or due to both reasons in the Polish case. In the French case, the increased risk of yield loss due to climate change is mentioned, depending mainly on disease pressure (see, Textbox 4). In both the German and Polish cases, quality loss is also reported. This results in a price decline of $15 \%$ in the Polish case due to damage caused by fungal diseases and a price decline of $5 \%$ in the German case due to loss of sugar content. Furthermore, all cases report additional costs for mechanical weed control, predominantly for additional labour input.

\subsubsection{Maize}

In both maize case study countries, no alternative crop protection techniques are applied in the reference crop protection strategy, so the main crop protection management relies on the use of pesticides. When we compare the spraying schemes in the reference scenarios between the cases, we observe some active ingredients applied in all schemes but also some differences. In both cases nicosulfuron (category 3 ) is applied in the reference scenario and excluded in Scenario 1 . The value of the HRI I in the reference scenario is 4 in the Romanian case and 20 in the French case. In both cases, volumes have been reduced and replaced by pesticides containing active substances from a lower risk group in Scenario 1. In the French case, no negative impacts of pesticide use and risk reduction on yield and quality have been reported, because the spraying scheme in Scenario 1 has the same efficacy as the spraying scheme in the reference scenario. In the Romanian case, $4 \%$ yield reduction is reported due to higher weed pressure, resulting from the reduction of herbicide use (see Textbox 3.4). However, the costs in Scenario 1 for both cases are somewhat higher than in the reference scenario due to additional labour input and more expensive pesticides.

\section{Textbox 3.4 Increased impact due to climate change - France}

Fungicides reduction impact will depend on climate. Cercospora development tends to be more severe with climatic change (temperature increase).

However, other aspects can also contribute to the expected yield in the year 2030 under this scenario. Weather conditions can have an impact on pests, diseases and weed pressure with risks to yields and/or quality losses being significantly higher in years with bad weather, or increased costs. Furthermore, the absence of efficacious pesticides can create a risk of significant losses in certain years. This is the case for Tanymecus dilaticollis + Agriotes spp. in the Romanian case. If the farmers' toolbox will continue to diminish, this risk will increase and also enlarge due to the development of resistance to pesticides.

Textbox 3.5 Explanation of difference between the reference scenario and Scenario 1 - Romania

The herbicide used for tembotrione control both monocotyledonous and dicotyledonous, but with a limited control of perennial monocotyledonous, which leads to a decrease of the obtained yield in the case of presence of such weeds. It was kept one pest treatment and one seed treatment with a similar effect as in the reference scenario. 


\subsubsection{Apples}

Both case farms in Poland and Italy apply IPM techniques such as mating disruption and application of nets against insects as reported in the Italian case. In both cases, a long list of active substances (almost 40) is applied to control pests and diseases. Many pesticides are applied in both countries. Only a few herbicides (MCPA and glyphosate) are applied to control weeds. The value of the HRI I varies from 457 in the Polish case to 486 in the Italian case. In the Polish case, the use of fungicides such as captan, fosetyl-al and sulfur in high volumes contribute to the value of the HRI. In the Italian case, the use of Paraffin oil used to control infestation by insects contributes significantly to this value. In Scenario 1, this insecticide is excluded. The reduction is implemented by omitting some sprayings and reducing the number of active substances applied. Implementation of the objectives to reduce the use and risk of pesticides results in both cases result in in yield reductions: $20 \%$ in the Polish case and $8 \%$ in the Italian case, due to a higher infestation by pests and diseases in the former case. Quality problems have also been reported in the Italian case resulting in a $6 \%$ lower price per unit. Fruits which have marks of infestation by pests or diseases are less desired in the market.

\subsubsection{Tomatoes}

The conventional crop protection strategy mainly relies on the use of pesticides in both the Italian and Spanish cases. In the Italian case, the use of chromotropic and pheromone traps is used as well as electronic monitoring.

The number of pesticides applied in the reference scenario differs slightly between both cases ( 9 in the Spanish case and 12 in the Italian case), but the pesticides applied vary to a large extent. The value of the HRI I also differs greatly: 105 in the Italian case versus 27 in the Spanish case. The applied volumes of the pesticides also differ: $11 \mathrm{~kg} / \mathrm{ha}$ in the Italian case versus $2 \mathrm{~kg} / \mathrm{ha}$ in the Spanish case. In the Italian case, the application of sulfur and copperhydroxide especially contributes to the high value of the HRI I. The higher use of fungicides in the Italian case can be explained by the differences in climatic conditions. In the Italian region of Emilia Romagna, more rainfall in the summer compared to the Spanish region Andalusia creates higher disease pressure. For Scenario 1 in the Italian case, the biopesticide Bacillus thurigiensis is applied. In both cases, implementation of the objectives is done by reducing both the volumes and types of pesticides, which results in a yield reduction of $20 \%$ in both cases. An example is the replacement of the herbicide pendimethalin (Candidate for Substitution) by rimsulfuron (group 2). In the Italian case, quality reduction caused by higher rot due to the reduction in fungicide use is also reported resulting in $10 \%$ lower prices.

\subsection{8 $\quad$ Grapes $^{13}$}

The conventional crop protection strategy as applied in the reference scenario relies solely on pesticide use in the case of France. In the Italian (Trentino Alto Adige) and Spanish (dry area) cases, mating disruption is also applied. In the Italian case in Veneto, also alternative measures such as the use of beneficial organisms are applied. Mechanical weeding takes place in the Italian cases and the Spanish case in the wet area, and monitoring traps in the Spanish dry area case.

\section{Textbox 3.6 Crop protection strategy in Scenario 1 - France}

The reduction of pesticide use and risk is obtained:

- $25 \%$ by mixture with biocontrol product

- $25 \%$ by using models and improve spaying system

This solution increases the risk of impact on yield in a critical year (diseases pressure).

The value of the HRI I is 273 in the French case, 341 and 601 in the Italian cases in Trentino Alto Adige and Veneto and 43 and 203 in the Spanish cases in the dry and wet areas respectively, showing a huge variation. The differences can be explained by the use of the fungicides Bordeaux mixture (as

\footnotetext{
${ }^{13}$ Additional cases for Italy (main production region) and Spain (wet production region) will be added.
} 
reported in the Italian case) and sulfur (as indicated in the Italian and French cases) to control fungal iseases. In the dry Spanish climate the disease pressure is lower. In all cases, the implementation of the objectives is achieved by both reducing the volume and replacing pesticides, which results in a yield reduction of $28 \%$ in the French case, $20 \%$ in the Italian case in Trentino Alto Adige, $6 \%$ in Veneto and $18 \%$ in Galicia, the case in the wet area in Spain. In the French case, the crop protection strategy under Scenario 1 is to apply biocontrol, and make use of decision support systems to spray at the right moment (see Textbox 3.6). In the Spanish case located in a dry production area, no yield loss is reported, since the volume of the applied pesticides can be reduced in the spring, and the pesticides from higher risk categories can be replaced by pesticides of a lower risk category. In the Italian case, no alternative measures are applied. Furthermore, the risk of lower yield in years with bad weather is reported in the French case. No significant changes in costs have been reported.

\subsubsection{Olives}

In both the Italian and Spanish cases, IPM techniques are applied as part of the conventional crop protection strategy. Besides the pesticide application, resistant seed varieties and monitoring traps are applied. In the Spanish case, qualified technicians are involved to assist the farmers and execute tasks such as field controls, checking traps and registration of the pesticides applied. Both spraying schemes in the reference scenario show some parallels. The use of copper based active ingredients are important pesticides in both countries.

The values of the HRI I are 188 in the case in Spain and 91 in the case in Italy, with relative high contributions of the copper based active ingredients. In the Spanish, case no fungicides are applied in the reference scenario. The objectives of Scenario 1 are realised by reduction of the volume of the applied pesticides in both cases, although in the Spanish case substitution of higher with lower risk pesticides is also applied. Implementation of the F2F targets results in $30 \%$ yield loss in the Italian case and $13 \%$ yield loss in the Spanish case. The yield losses can be reduced in the Spanish case by harvesting earlier under supervision of the technicians: farm advisors play a role in the execution and supervision of the crop protection strategy. The farmers in the Italian case with a very small farm size ( $1 \mathrm{ha}$ ) have little crop protection options to reduce yield loss, and are vulnerable to parasitic attacks. The case farm is located in a region where Xylella fastidiosa (a devastating bacteria) is not present. ${ }^{14}$ The expert in the Spanish case reports also an increased risk for higher yield losses in years with bad weather conditions.

\subsubsection{Citrus}

The conventional crop protection strategy in the Italian and Spanish cases consists mainly of pesticide use. The crop protection strategy in the Spanish case takes into account the use of natural predators. In the Italian case, monitoring and alert services based on weather information is applied to control pests and diseases at the right moment. The spraying schemes consisting of 16 pesticides in the Italian case and 20 in the Spanish case partially match. The value of the HRI I is 232 in the case of Italy and 67 in Spain, mainly caused by the application of higher dosages of pesticides in the Italian case compared to the Spanish case (28 versus $8 \mathrm{~kg}$ active ingredients applied per ha). This result is remarkable, since the case farm in Spain is quite small ( $1 \mathrm{ha}$ ). The F2F targets are realised by reduction of the volume of the applied pesticides in the Italian case and by reduction of use and risk of pesticides in the Spanish case by leaving 7 herbicides and insecticides out of the spraying scheme. In the case of Spain, tryclopyr has been replaced by hand thinning and herbicides by mechanical weed control. This results in a yield loss of $7 \%$ in the Italian case and $10 \%$ in the Spanish case, which is comparable. No negative consequences for fruit quality are mentioned. The changes in costs are related to additional labour required in both cases.

\subsubsection{Hops}

The crop protection strategy in the German and Polish cases consists both the use of pesticides and mechanical weed control. The spraying schemes partly match. The value of the HRI I is roughly the

\footnotetext{
${ }^{14}$ If infestation with $X$. fastidiosa, a quarantine organism, takes place, olive trees need to be eradicated.
} 
same: 223 in the case in the Poland and 189 in the case of Germany. High dosages of fosetyl-al and sulfur contribute to these values in both countries. The objectives are realised by both reducing the volume and replacing pesticides by less risky alternatives. Manual stripping and adding biostimulants are applied in the Polish case as alternative measure. Meeting the objectives in Scenario 1 results in an estimated yield loss of $8 \%$ in the case of Poland and $20 \%$ in the German case. Furthermore, quality losses due to lower content of bitter acids result in lower prices: $1.5 \%$ in the Polish case and $10 \%$ in the case of Germany due to fungal diseases. The costs in the case of Germany increase by manual stripping and increased mechanical and thermal weed control.

Textbox 3.7 Quality problems in Scenario 1 - Poland

The quality of the product (bitter acid content) may be reduced due to the increased severity of the symptoms of diseases and pests on hop cones.

\subsection{Scenario 2 - Reduction nutrient losses and fertiliser use}

\subsubsection{Overview}

In this section, we describe per crop the results of the assessments of the objectives in Scenario 2: $50 \%$ reduction of nutrient losses, which requires a reduced fertiliser use of at least $20 \%$. The reduced fertiliser use has been applied as an operational objective in the assessment of the consequences of these objectives. We pay attention to the volumes of the fertilisers $\mathrm{N}$ and $\mathrm{P}_{2} \mathrm{O}_{5}$ applied in the reference scenario, the type of fertiliser (organic or artificial) and the way the objectives of Scenario 2 are met. Next we present the consequence for the yield and the quality. Finally we describe which measures are applied to prevent nutrient losses and to support soil fertility in both the reference scenario and Scenario 2. An overview of the nitrogen and phosphate dosages applied (both organic and artificial) is provided in Tables 3.5 and 3.6.

Table 3.5 Dosage applied Nitrogen ( $k g$ per ha) in the reference scenario

\begin{tabular}{|c|c|c|c|c|c|c|c|}
\hline & Finland & France & Germany & Italy & Poland & Romania & Spain \\
\hline Wheat & 120 & 189 & 180 & & & 120 & \\
\hline Rapeseed & 110 & & 180 & & 210 & & \\
\hline Sugar beet & & 146 & 140 & & 170 & & \\
\hline Maize & & 220 & & & & 130 & \\
\hline Apples & & & & 60 & 80 & & \\
\hline Tomatoes & & & & 200 & & & 338 \\
\hline Grapes & & 60 & & 45 / 60 & & & 35 / 59 \\
\hline Olives & & & & 70 & & & 98 \\
\hline Citrus & & & & 320 & & & 275 \\
\hline Hops & & & 250 & & & & \\
\hline
\end{tabular}

Source: Authors. 
Table 3.6 Dosage applied Phosphate ( $k g$ per ha) in the reference scenario

\begin{tabular}{|c|c|c|c|c|c|c|c|}
\hline & Finland & France & Germany & Italy & Poland & Romania & Spain \\
\hline Wheat & 23 & 30 & 80 & & & 80 & \\
\hline Rapeseed & 23 & & 80 & & 90 & & \\
\hline Sugar beet & & 97 & 90 & & 70 & & \\
\hline Maize & & 79 & & & & 80 & \\
\hline Apples & & & & 20 & 13 & & \\
\hline Tomatoes & & & & 75 & & & 63 \\
\hline Grapes & & 20 & & $15 / 27$ & & & $12 / 68$ \\
\hline Olives & & & & 40 & & & 0 \\
\hline Citrus & & & & 335 & & & 100 \\
\hline Hops & & & 46 & & 60 & & \\
\hline
\end{tabular}

Source: Authors.

\subsubsection{Wheat}

In all cases, artificial fertilisers are applied in the reference scenario. The volumes applied for the German and French cases are higher than in the Finnish and Romanian cases (see, Tables 3.5 and 3.6). In all cases, the objectives have been met by reducing the volume of artificial fertilisers by at least $20 \%$. In the French case, the artificial $\mathrm{P}_{2} \mathrm{O}_{5}$ are also replaced by organic fertilisers. The experts report estimated yield losses varying from 3\% in the French case and 5\% in the Finnish case, $10 \%$ in the German case and $20 \%$ in the Romanian case (see Table 3.7). Furthermore, almost all experts report the risk of lower protein content, which may result in lower prices, see Textbox 3.88. In the German case, the expert estimates a price decline of $10 \%$ (see Table 3.8). In the reference scenario, buffer zones are applied to prevent nutrient losses in the Finnish and German cases, with the addition of catch and cover crops in Scenario 2. Furthermore, split application of fertilisers is applied in the Finnish and the French cases. In the French case, nutrients with urease inhibitor are added to Scenario 2. In Romania, subsidies are available for mitigation measures preventing nutrient losses such as buffer strips, use of winter crops, etc., see Textbox 3.8. With respect to the increase of soil fertility, intercropping, rotation and the use of organic fertilisers are mentioned in all cases.

Textbox 3.8 Available subsidies - Romania

Subsidies are conditioned, as for example: water protection strips with a minimum width of $1 \mathrm{~m}$ on lands with a slope of up to $12 \%$ and $3 \mathrm{~m}$ on lands with a slope greater than $12 \%$.

Table 3.7 Estimated yield changes per crop per country in Scenario 2 (\%)

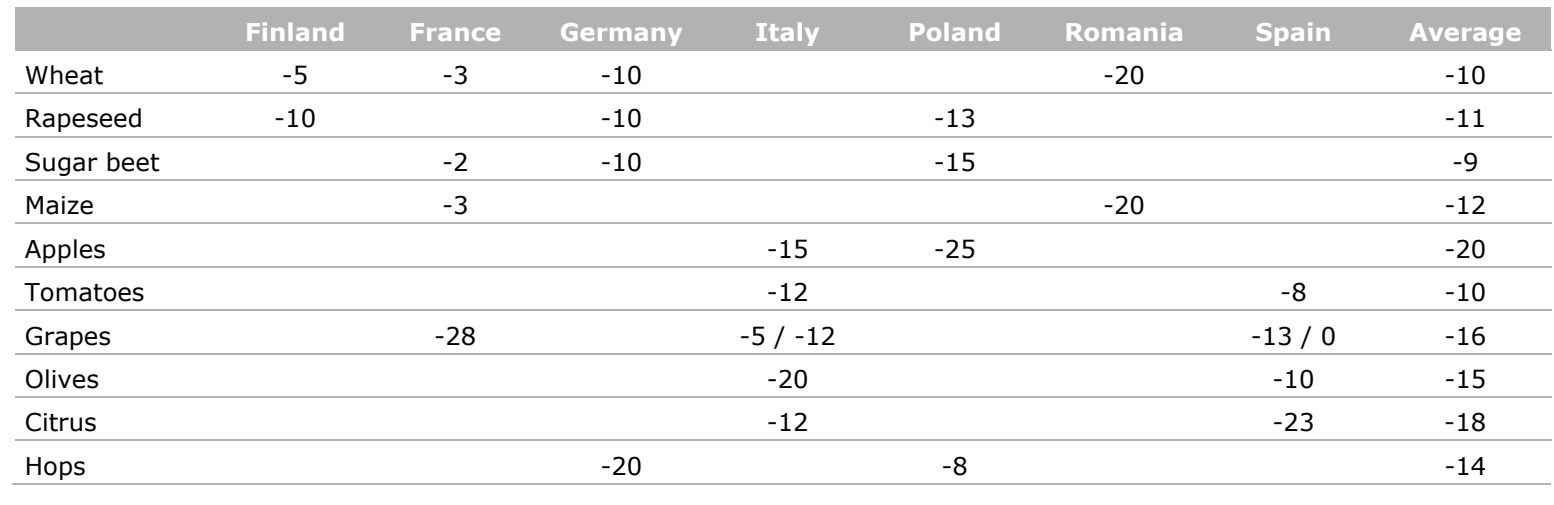

Source: Authors. 


\subsubsection{Rapeseed}

In the Finnish and German cases, only artificial fertilisers have been applied in the reference scenario. In the Polish case, organic and artificial fertilisers are both used. In all cases, the objectives have been met by reducing the volume of artificial fertilisers. Expected yield losses are $10 \%$ for both the Finnish and German cases, and $13 \%$ in the Polish case. Furthermore, a price decline of $10 \%$ is estimated in the German case due to a lower oil content in the seed. With respect to the prevention of nutrient losses and increasing soil fertility, comparable measures are applied as in wheat cases. The logic is that in many cases, both crops are part of the same rotation scheme, and measures are not applied at the level of single crops but for the purpose of the entire rotation scheme.

Table 3.8 Estimated price changes per crop per country in Scenario 2 (\%)

\begin{tabular}{|c|c|c|c|c|c|c|c|c|}
\hline & Finland & France & Germany & Italy & Poland & Romania & Spain & Average \\
\hline Wheat & 0 & 0 & -10 & & 0 & 0 & & -3 \\
\hline Rapeseed & 0 & & -10 & & 0 & & & -3 \\
\hline Maize & & 0 & & & & 0 & & 0 \\
\hline Apples & & & & 5 & -50 & & & -23 \\
\hline Grapes & & 0 & & $0 / 0$ & & & $5 / 0$ & 1 \\
\hline Olives & & & & 0 & & & 5 & 3 \\
\hline Citrus & & & & 0 & & & -5 & -3 \\
\hline Hops & & & 0 & & -2 & & & -1 \\
\hline
\end{tabular}

Source: Authors.

\subsubsection{Sugar beet}

In the German case only artificial fertilisers have been applied in the reference scenario. In the Polish and the French cases, organic and artificial fertilisers are combined. In the German and the Polish cases, the objectives have been met by reducing the volume of artificial fertilisers. In the French case, the volumes of both organic and artificial fertilisers have been reduced. Meeting the reduction objectives results in estimated yield losses of $2 \%$ in the French case, $10 \%$ in the German case and $15 \%$ in the Polish case. No effects on crop quality have been reported.

Sugar beet is also one of the crops that rotate with other arable crops. Measures applied in both the reference scenario and Scenario 2 oriented at the prevention of nutrient losses and increasing fertility corresponds for other crops such as wheat and rapeseed.

\subsubsection{Maize}

In all cases, artificial fertilisers are applied in the reference scenario. The volumes applied in the French case are higher than in the Romanian case (see Tables 3.5 and 3.6). In all cases, the objectives have been met by reducing the volume of artificial fertilisers by at least $20 \%$. No organic fertilisers are applied in Scenario 2 . Yield losses range from $2 \%$ in the French case, to $20 \%$ in the Romanian case. This can be explained by the significantly higher volumes of fertilisers applied in the French case compared to the Romanian case. In all cases, artificial fertilisers are applied in the reference scenario. The volumes applied in the German and French cases are higher than in the Finnish and Romanian cases (see, Tables 3.7 and 3.8). In all cases, the objectives have been met by reducing the volume of artificial fertilisers by at least $20 \%$. Measures applied in the Romanian case in both the reference scenario and Scenario 2 oriented at the prevention of nutrient losses and increase of soil fertility is related to the use of cover crops, crop rotation and the application of green fertilisers such as legumes. In the French case, residual organic product applied to the crop before maize cultivation is mentioned as a measure to increase soil fertility in both scenarios. 


\subsubsection{Apples}

In the Italian case, only artificial fertilisers have been applied in the reference scenario. In the Polish case, organic and artificial fertilisers are both used. In both countries, the objectives have been met by reducing the volume of artificial fertilisers. In the Italian case, artificial fertilisers have been partly replaced by organic fertilisers following a common practice aimed to sustain organic matter in the soil, when it is declining, or to enhance soil biological fertility. Soil fertility is in both countries and both scenarios enhanced by the application of organic fertilisers. Meeting the reduction objectives results in estimated yield losses of $25 \%$ in the Polish case and $15 \%$ in the Italian case. Both positive and negative effects on the quality have been reported. The Polish case reports negative effects on fruit size and colour of the peel resulting in a price decline of $50 \%$ but also a slightly improved storability of the fruit. The Italian experts do not expect negative consequences for the quality of the fruit, but a slight increase of the fruit size. With respect to reducing emissions, permanent grass cover crop is mentioned in the Polish and Italian case in both scenarios and in the two countries. Organic fertilisers, which characterise Scenario 2, are less effective in infiltrating into the soil with respect to the best mineral fertiliser, but ammonia emissions are not expected to increase because mature manure is chosen and the grass cover is effective in slowing wind speed close to the soil.

\subsubsection{Tomatoes}

In the Spanish case, only artificial fertilisers have been applied in the reference scenario. The objectives to reduce fertiliser use and nutrient losses have been met by reducing the volume of artificial fertilisers. In the Italian case, organic and artificial fertilisers are combined in the reference scenario. To meet the F2F targets, only organic fertilisers are applied which will drastically increase fertilisation costs. Meeting the reduction objectives results in estimated yield losses of $8 \%$ in the Spanish case where fertigation is applied and $12 \%$ in the Italian case. No effects on the quality of the crop have been reported for both countries. In the Italian case, fertilisation input remains sufficiently high to avoid a reduction in soil fertility. Measures applied to reduce nutrient losses and to increase soil fertility are comparable to other annual crops: prompt tillage after organic fertiliser distribution, use of stable organic input. Green manuring could also be efficiently introduced in the long time between wheat harvest (July) and the following spring time, when tomatoes are transplanted.

\subsubsection{Grapes}

In the French case only artificial fertilisers have been applied in the reference scenario. In the Spanish and the Italian cases, organic and artificial fertilisers are combined. In all countries, the objectives have been met by reducing the volume of artificial fertilisers and partly by replacing artificial with organic fertilisers. In all countries, the volumes of fertilisers applied is relatively low in comparison to other products. The low volumes of fertilisers are applied to reduce the vigour of the plant and to increase the quality of the wine. Meeting the reduction objectives results in estimated yield losses of $5 \%$ in the Italian case in Trentino Alto Adige; $12 \%$ in the case in Veneto, $13 \%$ in the Spanish case in the dry areas; $0 \%$ in the case in Galicia and $28 \%$ in the French case. In the Italian case, a slight reduction in the quality of the crop is expected by reducing the level of yeast assimilable nitrogen in the fruit, resulting in a price decline of $5 \%$. In most cases, no specific measures are applied to prevent nutrient losses. In the case in Veneto, Italy, the use of slow release fertilisers is mentioned as a measure to prevent nutrient losses.

In Scenario 2, organic fertilisers are applied early in the season to increase plant availability. Green manure is also applied in the French, Italian, and the Spanish cases to increase the soil fertility. In the hilly environments where grapes cultivation usually occurs, green manure will play an important role in terms of preventing soil erosion.

Textbox 3.9. Measures to increase soil fertility - Spain, dry areas

Increase of organic fraction of fertilisers; the use of slow release fertilisers and fractioning of applications (particularly if fertigation is available). 


\subsubsection{Olives}

In the Spanish case, only artificial fertilisers have been applied in the reference scenario. The objectives to reduce fertiliser use and nutrient losses have been met by reducing the volume of artificial fertilisers. In the Italian case, both organic and artificial fertilisers are applied in the reference scenario. To meet the objectives, the volumes of both artificial and organic fertilisers are reduced. Estimated yield losses in Scenario 2 are $10 \%$ in the Spanish case and $20 \%$ in the Italian case. Both cases report an increase of the quality of the crop when a reduced amount of fertilisers are applied, however, no impacts on the price were reported. Measures to prevent nutrient losses in Scenario 2 include the application of fertilisers before rain (as reported in the Spanish case). Measures to increase soil fertility in both scenarios include early application of fertiliser, prior to the rain season, to increase plant availability. Green manure is not often applied in olive trees cultivation areas, due to water deficit.

\subsubsection{Citrus}

In both the Italian and Spanish cases, artificial and organic fertilisers are applied in the reference scenario. The objectives to reduce fertiliser use and nutrient losses have been met by reducing the volume of artificial fertilisers in the Italian case, and both artificial and organic fertilisers in the Spanish case. Estimated yield losses are $12 \%$ in the Italian case and $23 \%$ in the Spanish case. In the Spanish case, quality losses are also expected due to a reduced fruit size and different ripening, with a $5 \%$ price decline as a consequence. No reduction in quality and therefore in price is expected for the Italian case. Grass cover crops and green manure are added in Scenario 2 to increase soil fertility in the Italian case. In the Spanish case, the application of precision drip irrigation and fertigation is mentioned as a measure to reduce nutrient losses.

\subsubsection{Hops}

In both the Polish and German cases, artificial and organic fertilisers are applied in the reference scenario. The objectives to reduce fertiliser use and nutrient losses have been met by reducing the volume of artificial fertilisers in the Polish case, with both artificial and organic fertilisers used in the German case. The reduction in nutrient use results in an estimated $8 \%$ yield loss in the Polish case and $20 \%$ yield loss in the German case. A slight quality loss is expected in the Polish case, resulting in a $2 \%$ lower price. Both countries report the use of cover crops and organic manure to increase soil fertility. Fertigation is mentioned in the German case as a measure to reduce nutrient losses.

\subsection{Scenario 3 - Expansion of organic area}

All experts have been requested to give a description of a typical organic farm, on which the case crop is grown. When we compared organic producers with conventional producers, we observed a number of differences. For example, the farm size of organic farms in most cases is comparable or slightly lower. In annual crops, the rotation contains more crops, in order to maintain soil fertility and increase resilience against pests and diseases. No synthetic pesticides or artificial fertilisers are allowed to be applied as stipulated in the EU organics regulation. Therefore, the nutrient management relies on the use of organic fertilisers, sourced from organic livestock farmers and green manure. The crop protection strategy is based on a mix of cultivation measures, mechanical weed control, biocontrol, application of pesticides derived from natural sources and the use of seed varieties that are more resistant to pests and diseases. Yield levels are considerably lower in organic production compared to conventional production. Table 3.9 provides estimates for the yield levels per crop that are expected for organic crops, demonstrating yield levels being lower from 7 to $50 \%$ compared to the conventional production. Estimates for organic production are not provided for all cases. This is due to the fact that in certain case countries, the share of organic versus conventional production is low, and no data are available that could be used as a basis for the estimations. The fluctuations in yield levels are also higher than in conventional production as farmers have access to much less crop protection tools. The lower yield levels can only be absorbed by producers if a higher price is paid for the produce.

Table 3.10 presents an overview of the estimated prices of organic products. The prices are related to 
the reduced yield levels. The higher the difference in yield between conventional and organic production, the higher the price levels for organic products. The fluctuations of prices for organic products are usually more prevalent than in conventional production for two reasons. Firstly, the yield fluctuations of organic production is higher, and the market size of organic products is much smaller than that of conventional production which reduces the capacity to cope with fluctuations in the supply of organic products.

In Table 3.11, an overview is provided of the values of the HRI I for organic production. Since pesticides of natural origin and biopesticides follow the same procedure for registration as synthetic pesticides, they are also included in the calculation of the Harmonised Risk Indicator. The values show that hardly any pesticides are applied in annual crops such as wheat, rapeseed and maize. In contrast, the values for perennial crops such as apples, grapes and olives, can be high. In some cases, especially in Mediterranean countries, the values of the HRI I can be even higher than in conventional production (values for these cases are presented in Italic). This is mainly caused by the use of copper based active ingredients, which is listed as a candidate for substitution (category 3 ) in high volumes to control disease. In those cases, a shift to organic production will have adverse consequences in terms of meeting the F2F and BD strategy target of reducing the use and risk of pesticides.

Table 3.9 Estimated yield changes per crop per country in Scenario 3 compared to the reference scenario (\%)

\begin{tabular}{|c|c|c|c|c|c|c|c|c|}
\hline & Finland & France & Germany & Italy & Poland & Romania & Spain & Average \\
\hline Wheat & -40 & -50 & -35 & & & -42 & & -42 \\
\hline Rapeseed & -50 & & -35 & & na & & & -42 \\
\hline Maize & & -23 & & & & -38 & & -31 \\
\hline Apples & & & & -25 & -50 & & & -38 \\
\hline Grapes & & -15 & & $-10 /-25$ & & & -27 / na & -20 \\
\hline Olives & & & & -50 & & & -30 & -40 \\
\hline Citrus & & & & -7 & & & -40 & -24 \\
\hline Hops & & & -18 & & -30 & & & -24 \\
\hline
\end{tabular}

$\mathrm{Na}$ - not available

Source: Authors.

Table 3.10 Estimated price increase per crop per country in Scenario 3 compared to the reference scenario (\%)

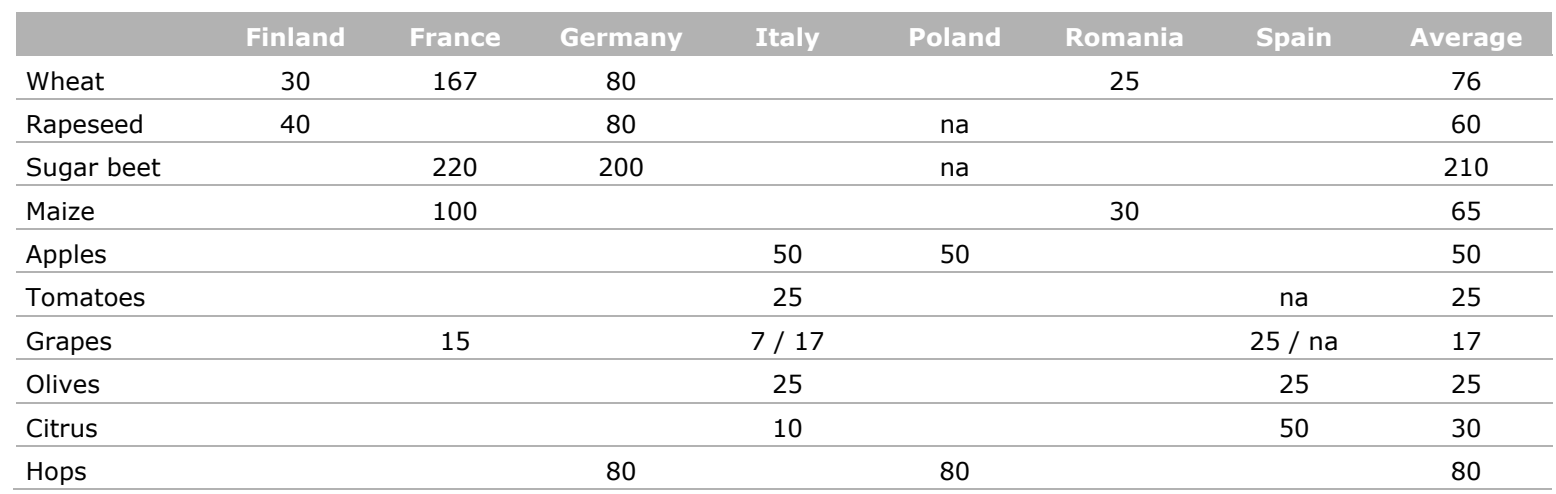

Source: Authors. 
Table 3.11 Values of Harmonised Risk Indicator in organic production

\begin{tabular}{|c|c|c|c|c|c|c|c|}
\hline & Finland & France & Germany & Italy & Poland & Romania & Spain \\
\hline Wheat & 0 & 0 & 0 & & & 8 & \\
\hline Rapeseed & 0 & & 0 & & $\mathrm{Na}$ & & \\
\hline Sugar beet & & & 0 & & $\mathrm{Na}$ & & \\
\hline Maize & & 0 & & & & 8 & \\
\hline Apples & & & & 799 & 320 & & \\
\hline Tomatoes & & & & 87 & & & $\mathrm{Na}$ \\
\hline Grapes & & 624 & & $517 / 174$ & & & $199 / \mathrm{Na}$ \\
\hline Olives & & & & 95 & & & 69 \\
\hline Citrus & & & & 296 & & & 141 \\
\hline Hops & & & 240 & & 103 & & \\
\hline
\end{tabular}

Source: Authors.

\subsection{Scenario 4 - Combined reduction of pesticide and risk, nutrient losses and fertiliser use and $10 \%$ set aside}

In Table 3.1 the percentage of the set aside has been presented per crop and country as estimated by the experts. Table 3.12 contains the estimated yield losses of the crops, when the objectives of Scenario 1 (reduction of use and risk of pesticides) and Scenario 2 (reduction of nutrient losses) and the objective to have at least $10 \%$ of the production area under high landscape features are combined. The last objective is calculated as the additional yield reduction when the $\%$ set aside as listed in Table 3.1 has to be increased to $10 \%$. When we compare the estimated yield losses with the relevant yield losses of Scenarios 1 and 2, taking into account the yield losses due to the increase of the percentage set-aside, we can conclude that in most cases, the yield losses estimated in Scenarios 1 and 2 add up to the yield loss in Scenario 4. However, in some cases, the estimated yield loss is lower than the sum. For example, this is the case in tomato production in the Italian case. The reason is that there can be a positive interaction between both objectives. Reduction of nutrient use can contribute to higher resilience against pests and diseases, which reduces the impacts of the objectives to reduce pesticide use and risk. The results show that the average yield losses for annual crops vary from $14 \%$ for rapeseed to $23 \%$ for tomatoes. For perennial crops, the yield losses vary from $21 \%$ for hops to $30 \%$ for olives and apples. Table 3.13 contains the price changes, which correspond to the highest price changes in Scenario 1 or 2.

Table 3.12 Estimated yield changes per crop per country in Scenario 4 (\%)

\begin{tabular}{|c|c|c|c|c|c|c|c|c|}
\hline & Finland & France & Germany & Italy & Poland & Romania & Spain & Average \\
\hline Wheat & -10 & -11 & -15 & & & -25 & & -15 \\
\hline Rapeseed & -10 & & -15 & & -18 & & & -14 \\
\hline Maize & & -7 & & & & -23 & & -15 \\
\hline Apples & & & & -20 & -50 & & & -30 \\
\hline Grapes & & -28 & & $-24 /-17$ & & & $-13 /-18$ & -21 \\
\hline Olives & & & & -40 & & & -20 & -30 \\
\hline Citrus & & & & -12 & & & -31 & -22 \\
\hline Hops & & & -26 & & -16 & & & -21 \\
\hline
\end{tabular}

Source: Authors. 
Table 3.13 Estimated price changes per crop per country in Scenario 4 (\%)

\begin{tabular}{|c|c|c|c|c|c|c|c|c|}
\hline & Finland & France & Germany & Italy & Poland & Romania & Spain & Average \\
\hline Wheat & 0 & 0 & -10 & & & -5 & & -4 \\
\hline Rapeseed & 0 & & -10 & & 0 & & & -3 \\
\hline Maize & & 0 & & & & 0 & & 0 \\
\hline Apples & & & & 0 & -50 & & & -25 \\
\hline Grapes & & 0 & & $-5 / 0$ & & & $3 / 0$ & 0 \\
\hline Olives & & & & 0 & & & 5 & 2 \\
\hline Citrus & & & & 0 & & & -5 & -2 \\
\hline Hops & & & -10 & & -2 & & & -6 \\
\hline
\end{tabular}

Source: Authors.

\subsection{The Moroccan case - fresh tomatoes}

The European Union has an open economy with much international trade. This triggers the question of what will be the consequences if exporters to the EU have to comply with the same requirements as European farmers. Morocco has been selected as a case country with fresh tomatoes selected as the case crop. The European Union is an important export destination for the Moroccan vegetable sector. We recruited a small team of experts in Morocco which have applied the same methodology on the production of tomatoes at the local level.

The case chosen is a farm that produces tomatoes in plastic tunnels in the Souss region located in the South of Morocco. Farm sizes range from 5 to 20 ha or more. The cultivation partly takes place in soil and partly in rockwool. The crop protection strategy mainly relies on chemical pesticide use on smaller farms, with the use of traps for monitoring. The larger farms apply IPM with monitoring by skilled technicians, the use of chemical, biological and microbial substances complying to the EU maximum residue level requirements for imported products. Weeds are controlled manually.

In the reference scenario, the spraying scheme mainly consists of 25 fungicides and insecticides. The HRI I value is 38. The objectives in Scenario 1 are met by reducing the number of pesticides to 19, adjusting volumes applied, and substituting higher risk category pesticides by pesticides with a lower risk category. The experts reported that they expect a yield loss of $20 \%$ in Scenario 1 . Furthermore, the level of damage to the crop due to pests and disease is expected to have an impact on the quality of the crops and subsequently lead to leading to a price decline of $15 \%$. Finally, a larger amount of the produce will not qualify for export due to quality problems.

In the reference scenario, $1,200 \mathrm{~kg}$ of nitrogen and $200 \mathrm{~kg}$ phosphate are applied per ha, predominantly as artificial fertilisers. The reduced application results in an average yield loss of $15 \%$ and a price decline of 5 to $10 \%$ due to reduced quality of the product. When these objectives are combined in Scenario 4, the yield loss varies from 20 to $30 \%$ while the prices are expected to be 5 to $10 \%$ lower. The scenario for organic production was not taken into account in this study.

\subsection{Conclusions}

Based on the analysis of the four scenarios the following conclusions can be drawn:

\section{Scenario 1 - Reduction of pesticide use and risk}

1. In most cases, the implementation of the F2F targets leads to yield losses. In addition, some of the local experts reported that greater variability in yield levels is expected dependent on weather conditions which can aggravate the yield loss effect for farmers. 
2. The yield losses are lower for arable crops $(\leq 15 \%)$ than for perennial tree crops $(\leq 30 \%)$.

3. The price decline varies on average from 0 to $7 \%$ per crop, mainly caused by quality problems such as rot and affected peels.

4. Differences in yield levels between case countries are limited in some crops (wheat, maize, citrus) and differ significantly in others (olives, rapeseed, grapes).

5. The value of HRI I is higher for perennial crops than for annual crops. The highest calculated HRI I for annual crops was 52, whereas this was tenfold for perennial crops. This is mainly caused by the higher number of applications and higher volumes of pesticides applied.

6. The reduction of the volume of pesticides plays a more important role in implementation of the F2F targets than substituting higher risk pesticides by pesticides from a lower risk category.

\section{Scenario 2 - Reduction of nutrient losses and fertiliser use}

7. For annual crops, the average yield loss in Scenario 2 is estimated at $10 \%$ and for perennial crops between 15 and $20 \%$.

8. Prices declines are in most cases limited (with the exception of apples and sugar beet) to less than $5 \%$. Quality problems mentioned are lower grading, less content such as protein level in wheat.

9. In a few cases, the reduced fertiliser use can also result in increased quality (i.e. grapes and olives).

10. In part of the cases, artificial fertilisers are replaced by organic fertilisers to reduce nutrient losses while maintaining soil fertility. However, it should be noted that the percentage nutrients of organic fertilisers available for the crop can be lower than of artificial fertilisers.

\section{Scenario 3: Expanding organic area}

11. The yield levels in organic production are significantly lower than in conventional production. Prices are significantly higher, but vary to large degree.

12. The values of HRI I for organically produced crops show that hardly any pesticides are applied in the case of annual crops. On the contrary, in perennial crops the values can be high. In some cases, especially in Mediterranean countries, the values of the HRI I can even be higher than in conventional production.

\section{Scenario 4: Combined reduction of pesticide and risk, nutrient losses and fertiliser use and $10 \%$ set aside}

13. When objectives for pesticides, nutrients and set-aside are combined, the yield losses vary from 14 to $23 \%$ for annual crops and from 22 to $30 \%$ for perennial crops.

14. Price changes vary from $-25 \%$ in apples to $+2 \%$ for olives. 


\section{$4 \quad$ Results at macro level}

\subsection{Introduction}

This chapter focuses on the results at macro level. In particular, domestic market, trade, and indirect land use change impacts are described for the four scenarios examined and discussed with respect to their agronomic impacts in Chapter 3.

\subsection{Scenario 1 - Reduction of pesticide use and risk}

\subsubsection{Production and prices}

The focus of this scenario is on assessing the macro-level impact of achieving the $50 \%$ reductions in the use and risk of pesticides target. This achievement is expected to have a negative impact on yields and quality (see previous chapter, Section 3.2 for details). In general terms, lower yields per hectare will reduce supply, which in turn will, at a given demand, induce increases in the price of the relevant crops. At the same time, a counteracting impact, i.e. a price decline, will result from the quality deterioration, as this will lower the farm gate price (see also Section 3.2 for further details on the price impact of quality changes). The final price response will depend on the magnitude of the mentioned price 'impacts', reflecting a price increase in those cases in which the shortage of supply caused by the decline in yields (i.e. scarcity-effect) dominates. As indicated in the case studies (Chapter 3), no price shocks (reflecting quality deterioration) are expected for maize, olives and citrus, while limited price shocks are anticipated for wine and wheat.

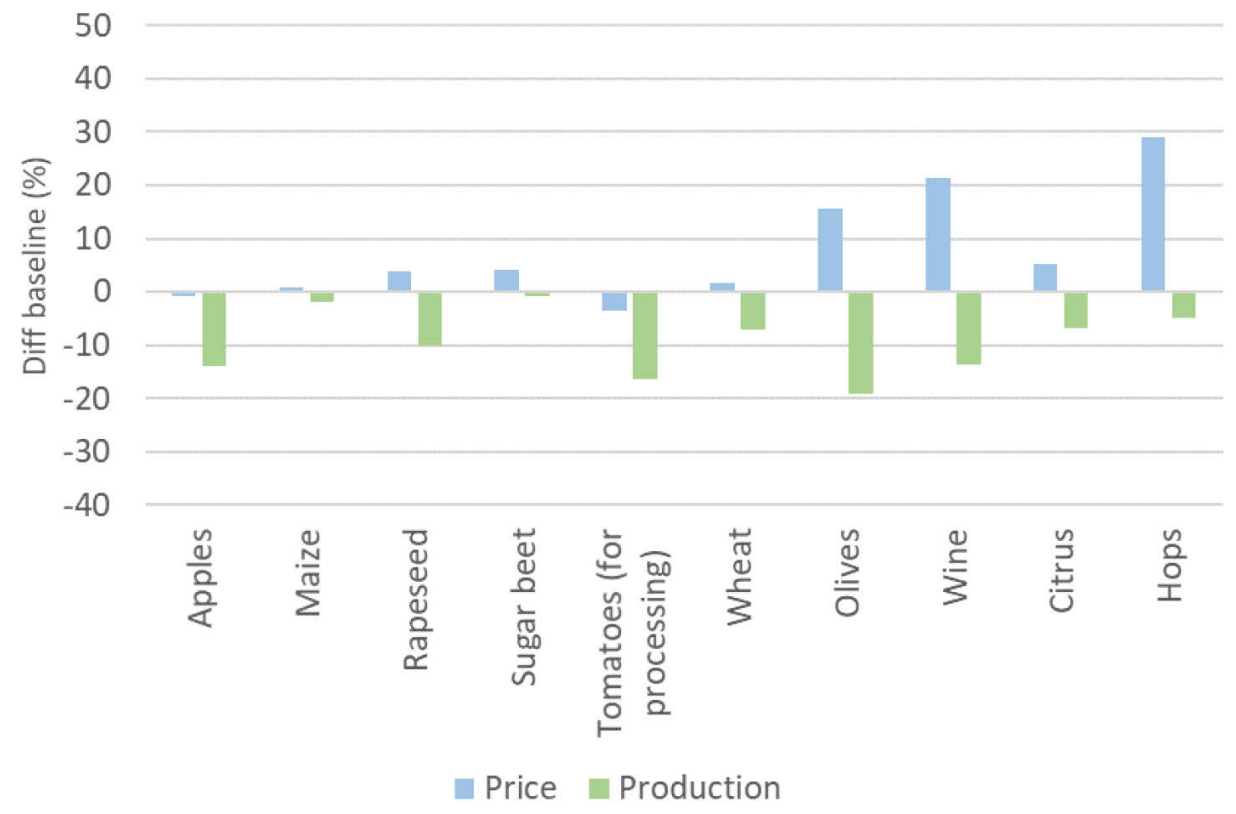

Figure 4.1 Scenario 1 - Overview of production and price impacts (\%), EU-27

Notes: The impacts reported for apples and tomatoes (for processing) refer to the key producers within the EU-27. In 2020, the key apple producers (DE, PL, FR, HU and IT) represents around $75 \%$ of total apple supply within the EU-27; while the four key tomato producers (ES, IT, PT and GR) amount to $97 \%$ of total tomato for processing supply at the EU-27 level.

Source: AGMEMOD based on input from the analysis presented in Chapter 3. 
Figure 4.1 summarises the impacts on production and prices related to the implementation of the two pesticide targets. They are measured as the difference between the scenario and the baseline values (all in 2030). For the mechanism behind the identified impacts, the reader is directed to Figure 2.3 provided in the methodology-chapter. As shown in Figure 4.1, the overall production impacts are limited (declines below or equal to $-5 \%$ ) in the case of maize, sugar beet and hops. In 8 out of the 10 cases, the net price effect turns out to be positive. However, the overall impacts on price are also limited (below 5\%) in the case of apples, sugar beet and wheat. Significant price increases could be expected for wine, olives and hops (increases of at least $16 \%$ ).

For a better understanding of the price impacts (and their underlying causes), Figure 4.2 brings together the expected price impacts as reported in the case studies with the total expected price effects as simulated by the AGMEMOD model. The former exclusively reflects the expected quality deterioration due to the measure, while the latter provides the net price effect that could be expected when considering both quality deterioration and price increases caused by increased commodity scarcity due to declining yields. The scarcity impact seems to dominate in most cases, with tomatoes for processing and apples being exceptions.

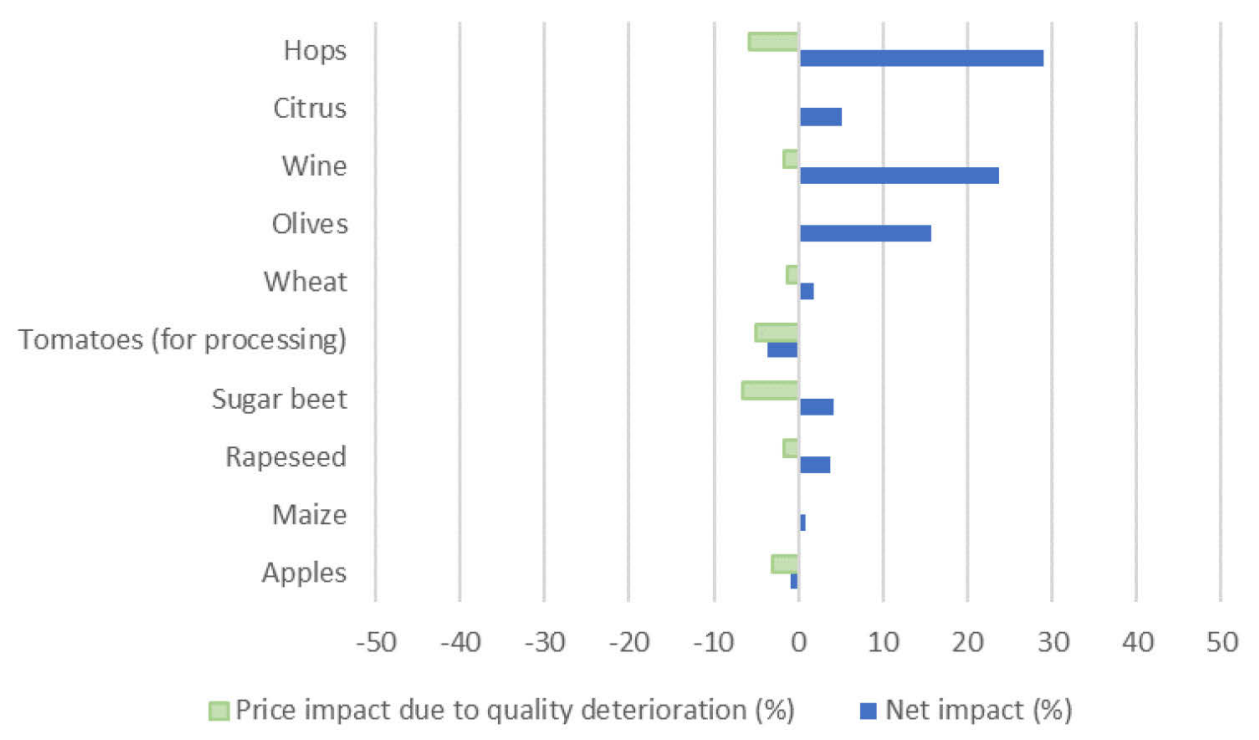

Figure 4.2 Scenario 1 - Net price impacts (\%) EU-27

Notes: The impacts reported for apples and tomatoes (for processing) refer to the key producers within the EU-27.

Source: AGMEMOD based on input from the analysis presented in Chapter 3.

\subsubsection{Trade impacts}

Table 4.1 Scenario 1 - Net trade impacts, EU-27

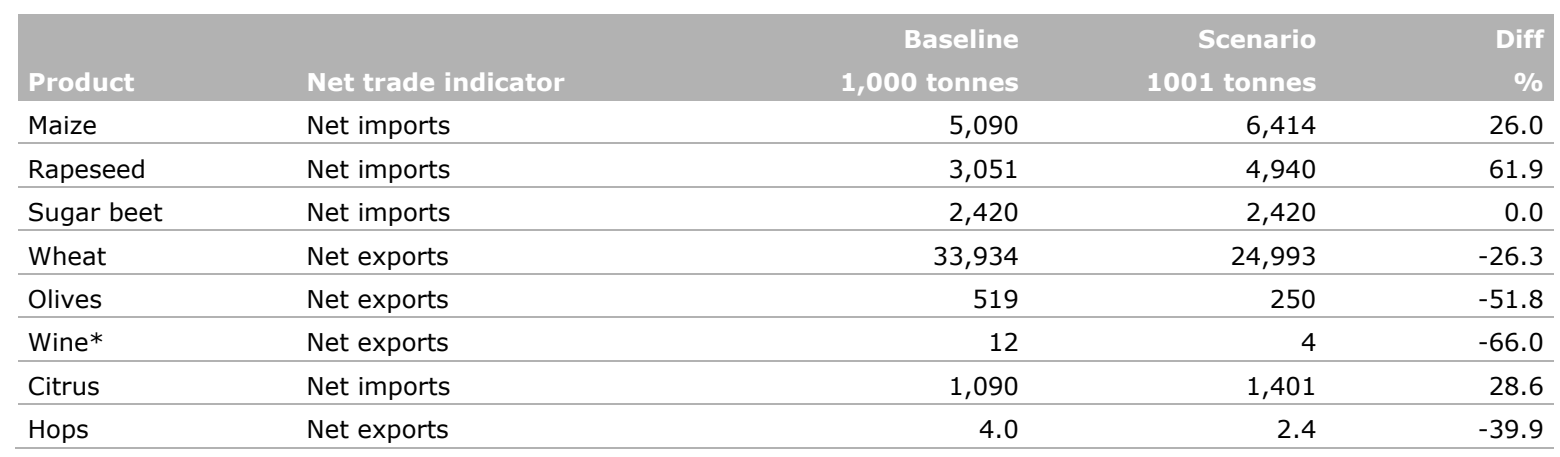

Note: * means $1,000 \mathrm{hl}$.

Source: AGMEMOD based on input from the analysis presented in Chapter 3. 
Table 4.2 Scenario 1 - Net trade impacts, key producers

\begin{tabular}{llrrrr} 
Member States & Product & Net trade & $\begin{array}{c}\text { Baseline } \\
1,000 \text { tonnes }\end{array}$ & $\begin{array}{c}\text { Scenario } \\
\text { indicator }\end{array}$ \\
Germany, Hungary, Poland, France, Italy & Apples & Net exports & 1,314 & 1,885 & 43.5 \\
\hline Spain, Greece, Italy, Portugal & Tomatoes for processing & Net exports & 5,321 & 3,244 & -39.0 \\
\hline
\end{tabular}

Source: AGMEMOD based on input from the analysis presented in Chapter 3.

Tables 4.1 and 4.2 show the net trade flows (expressed in 1,000 tonnes) that have been simulated in the case of the Baseline and Scenario 1. Focusing on the impacts of this measure, the AGMEMOD simulation indicates that net imports are expected to increase in the case of maize (26\%), rapeseed $(62 \%)$ and citrus (29\%). Net exports are expected to decline in the case of tomatoes for processing $(-39 \%)$, olives $(-52 \%)$, wine $(-66 \%)$ and hops $(-40 \%)$. Focusing on the five key producer countries, the simulation indicates that the net exports of apples from this region could also grow. This trend also reflects the loss of competitiveness of local fresh production as raw input for the processing industry, which might, in the longer run, induce them to adjust their production capacity.

\subsubsection{Indirect land use change}

Another dimension to explore when assessing the impacts of the F2G and BD strategy targets is the Indirect land use change (ILUC). As defined by the Council of the European Union (2018), 'Indirect land-use change occurs when the cultivation of crops for biofuels, bioliquids and biomass fuels displaces traditional production of crops for food and feed purposes. This additional demand may increase the pressure on land and can lead to the extension of agricultural land into areas with high carbon stock such as forests, wetlands and peat land causing additional greenhouse gas emissions'. ${ }^{15}$ Here, it is recognised that not only changes in imports, but also in exports can lead to indirect land use change. More broadly speaking, indirect land use change can be also defined as 'land whose ultimate purpose is essentially changed from its previous use'. In this context, 'indirect land use change' is defined as opposed to 'direct land use change' which reflects 'a situation in which a field was being converted from corn-for-ethanol to switchgrass production, as in both cases the land would ultimately be used to grow crops for biofuel production'. ${ }^{16}$ Keeping in mind this definitions and leaving aside the specific biofuel purpose, in the context of this report a broad definition of ILUC is adopted using this term to reflect: (i) the changes in land use that occur outside the EU due to the substitution of local (EU) production with imported (non-EU) production (this is the so-called 'ILUC1') which is eventually consumed within the EU; and (ii) the changes in land use that occur outside the EU to produce additional commodities that compensate the 'loss' of EU production that is not exported to the EU (this is the so-called 'ILUC2'). The notion of 'use' that is behind the 'ILUC' definition used in this report goes beyond 'bioenergy/biomass production' and considers use as a broad 'EU demand' regardless it being domestic demand (i.e. local consumption) or foreign (non-EU) demand (i.e. exports).

Table 4.3 concludes the expected changes in production volumes and the associated ILUC indicators. More specifically, ILUC due to increased EU imports (ILUC1) is estimated to be around 826 thousand ha EU equivalents and is exclusively related to maize, rapeseed and citrus. Moreover, the estimated ILUC related to replace the EU export decline gap (ILUC2) is almost 1.7 million ha EU equivalents, with around $90 \%$ being attributable to wheat. In the case of sugar beet, the indirect land use change is marginal. This latter effect is driven by the assumption on existing capacity utilisation by the sugar beet processing industry, which is likely to hold in the short and medium run, but could face further adjustments when time proceeds.

\footnotetext{
${ }^{15}$ This information has been retrieved from: https://www.iscc-system.org/how-to-deal-with-indirect-land-use-change/.

${ }^{16}$ Further discussion and full definition are available at: https://farm-energy.extension.org/what-is-direct-land-use-ordirect-land-use-change/.
} 
Table 4.3 Scenario 1 Indirect Land Use Change (ILUC) impacts (x 1,000 ha)

\begin{tabular}{|c|c|c|c|c|}
\hline Product & Volume change ( 1,000 tonnes) & Average yield (tonnes/ha) & ILUC1 (imports) & ILUC2 (exports) \\
\hline Apple & 571.6 & 22.3 & 0.0 & 25.6 \\
\hline Maize & $-1,323.6$ & 7.1 & -186.8 & 0.0 \\
\hline Sugar beet & 0.0 & 73.1 & 0.0 & 0.0 \\
\hline Tomatoes & $-2,077.1$ & 89.0 & 0.0 & -23.3 \\
\hline Olives & -268.8 & 452.3 & 0.0 & -0.6 \\
\hline Wine* & $-8,123.9$ & 51.1 & 0.0 & -159.0 \\
\hline Citrus & -311.3 & 20.5 & -15.2 & 0.0 \\
\hline Hops & -1.6 & 2.0 & 0.0 & -0.8 \\
\hline
\end{tabular}

Notes: * stands for $\mathrm{hl} / \mathrm{ha}$ and $1,000 \mathrm{hl}$ in the case of yield and volume respectively. Negative volume changes in the case of net importer sectors (i.e. maize, rapeseed, sugar beet and citrus) should be interpreted as an increase in imports. The average yields used in the calculations are those of the EU (which is a highly productive agricultural area). Therefore, land use changes could be even larger if average yields at global level (or for the rest of the world) are assumed.

Source: AGMEMOD based on input from the analysis presented in Chapter 3.

It should be noted that the reported trade and ILUC impacts are conditional on what happens to the livestock sector, changing consumer diets and the reduction of food waste (see also the discussion around Figure 2.3 in the Methodology chapter). The assessment of the F2F and BD strategy target on EU animal production was beyond the scope of this project, which only focuses on the crop production sectors. A recent JRC study concludes that livestock production is likely to be negatively affected (lower production), which will introduce a decline in feed demand and as a result most likely also lower trade and ILUC impacts that are reported in this study (Barreiro Hurle et al., 2021).

\subsubsection{Production value}

Quantity impacts could be translated into value impacts to give an indication of the magnitude of the effects in monetary terms. In other words, a value indicator can be used to characterise the economic loss that could be related to the implementation of a particular measure. This type of indicator gives the monetary value of the loss of production, evaluated at baseline prices. We noted that the scenario specific price movement may counteract its volume reduction which may lead to a lower value loss than the one provided by our indicator. However, we have to accept that there are some limitations to the market (and derived price) impacts as we estimate these and also learn from other studies that there still is a large uncertainty about future prices. For that reason, we chose to use the baseline situation as a reference, which provides at least an indication about the financial cost or gain due to the change in production evaluated at the prices that are in line with the current EU outlook.

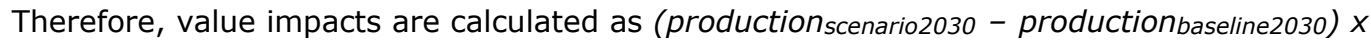
price baseline2030.

The assessment of the value impacts is provided in Table 4.4. For all the sectors under consideration, value losses could be expected to following the previously presented results on lower production volumes. The mentioned losses could reach nearly EUR 1.5 billion in the case of wheat. In total, implementing the targets could lead to a value loss of around EUR 6 billion. 
Table 4.4 Scenario 1 - Impact on the value of projected changes in production (EU-27 and key producers, $x$ million EUR)

\begin{tabular}{|c|c|c|c|}
\hline Product & $\begin{array}{l}\text { Volume change } \\
(1,000 \text { tonnes) }\end{array}$ & Price (EUR/100 kg) & $\begin{array}{l}\text { Value change } \\
\text { (EUR million) }\end{array}$ \\
\hline Apples & $-1,328.7$ & 34.6 & -459.7 \\
\hline Maize & $-1,373.1$ & 13.5 & -184.7 \\
\hline Rapeseed & $-2,452.0$ & 32.1 & -787.3 \\
\hline Sugar beet & $-1,148.5$ & 2.5 & -28.9 \\
\hline Tomatoes (for processing) & $-1,984.9$ & 85.7 & $-1,701.8$ \\
\hline Wheat & $-9,435.9$ & 15.3 & $-1,447.8$ \\
\hline Olives & -397.1 & 192.9 & -765.8 \\
\hline Wine* & $-22,570.7$ & 4.3 & -95.9 \\
\hline Citrus & -741.1 & 80.0 & -592.9 \\
\hline \multirow[t]{2}{*}{ Hops } & -3.1 & 400.0 & -12.2 \\
\hline & \multicolumn{2}{|c|}{ Total (EUR million) } & $-6,077.1$ \\
\hline
\end{tabular}

Notes: The impacts reported for apples and tomatoes (for processing) refer to the key producers within the EU-27.* stands for *1,000 $\mathrm{hl}$ and EUR/hl. Value impacts have been evaluated by taking into account AGMEMOD baseline 2030 prices. Volume changes are based on the trade indicator.

Source: AGMEMOD based on input from the analysis presented in Chapter 3.

\subsection{Scenario 2 - Reduction of nutrient losses and fertiliser use}

\subsubsection{Production and prices}

Scenario 2 explores the potential impacts of reducing nutrient losses by $50 \%$, together with a $20 \%$ decline in fertiliser use. The expected developments related to the implementation of the targets are similar to those expected in the case of Scenario 1. The decline in fertiliser use could lead to declining yields, while the subsequent decline in supply could induce a rise in the prices of the relevant agricultural commodities. At the same time, the reduction in fertiliser application is likely to affect the quality of the agricultural outputs which will be translated into lower prices at farm-gate level. The net price impact will depend on the magnitude and direction of these conflicting forces (price increase due to scarcity versus price decline due to quality deterioration).

Figure 4.3 presents the impacts on production and prices related to the achievement of the fertiliser target, reported as differences between the scenario and the baseline values in 2030 (see, Figure 2.3 for an overview of the general scenario mechanism). In general terms, production declines are below $15 \%$. However, apple production in the five largest apple producing countries in the EU-27 is expected to decline by more than $20 \%$ when comparing the scenario and the baseline situation. As shown in Figure 4.3, the largest price increases are expected in the case of wine and hops (around 20\%). Price impacts are marginal in the case of wheat and tomatoes for processing. 


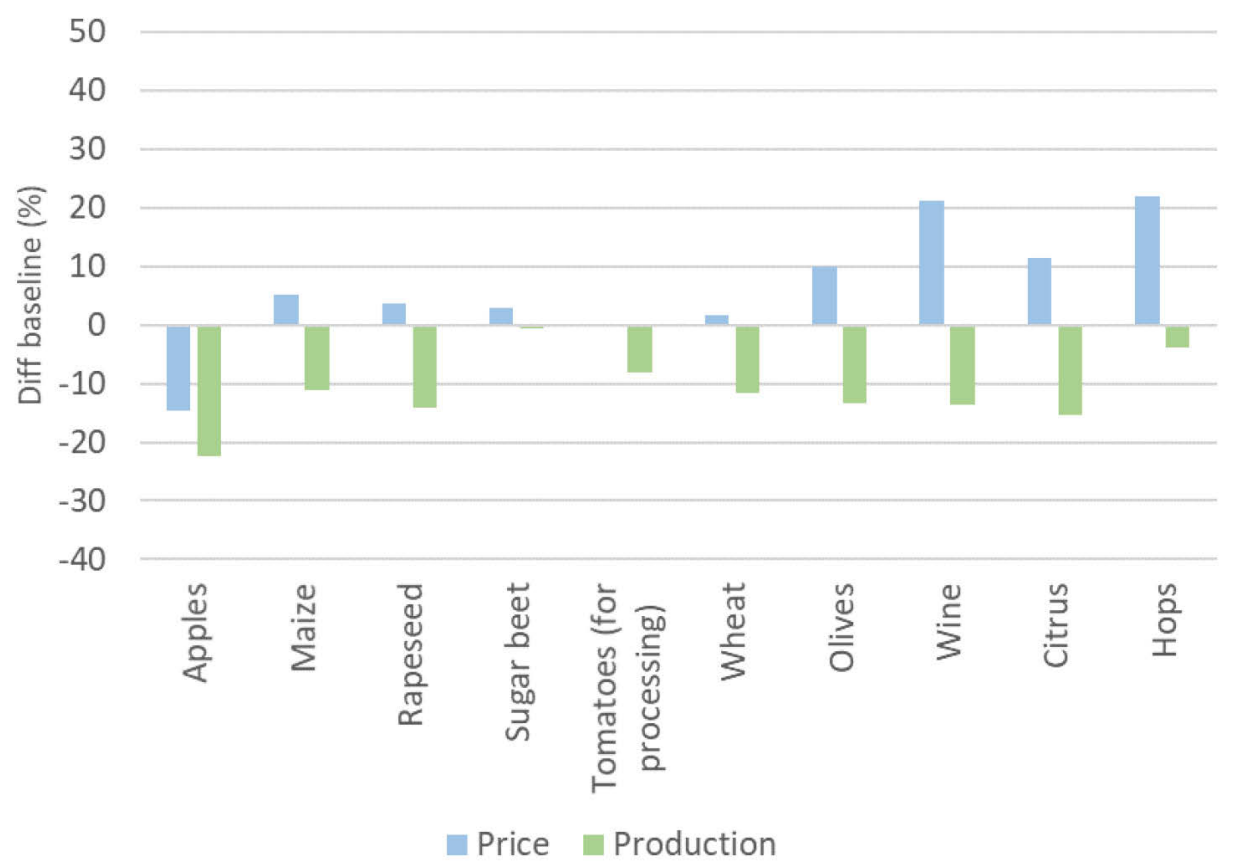

Figure 4.3 Scenario 2 - Overview of production and price impacts (\%), EU-27

Notes: The impacts reported for apples and tomatoes (for processing) refer to the key producers within the EU-27. In 2020, the key apple producers (DE, PL, FR, HU and IT) represents around $75 \%$ of total apple supply within the EU-27; while the four key tomato producers (ES, IT, PT and EL) amount to $97 \%$ of total tomato production for processing at the EU-27 level.

Source: AGMEMOD based on input from the analysis presented in Chapter 3.

Figure 4.4 combines the expected price impacts as reported in the case studies with the total expected price effects as calculated by AGMEMOD. As explained earlier, the expected price impacts suggested by the case studies exclusively reflect the expected quality deterioration resulting from the implementation of the target, while the total expected effect provide the net price impact resulting from considering both quality deterioration and price increases caused by declining supply. As in the case of Scenario 1 , the scarcity effect is dominant in the vast majority of cases.

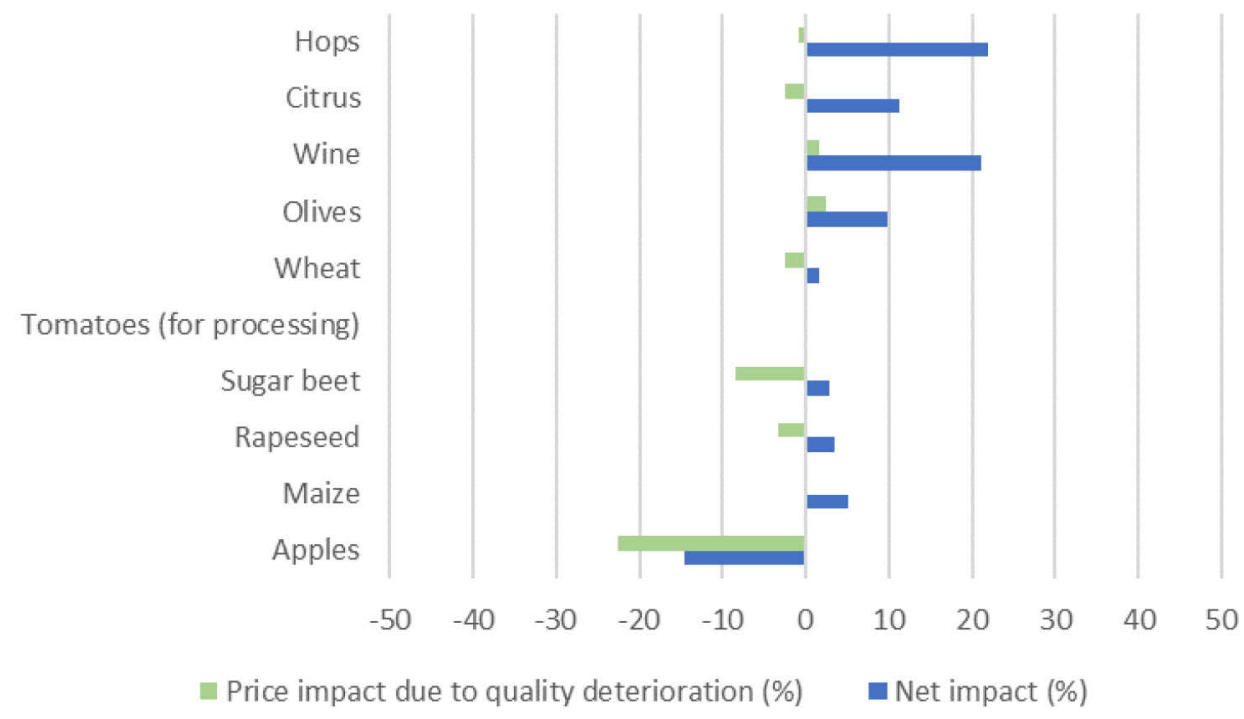

Figure 4.4 Scenario 2 - Net price impacts (\%) EU-27

Notes: The impacts reported for apples and tomatoes (for processing) refer to the key producers within the EU-27.

Source: AGMEMOD based on input from the analysis presented in Chapter 3. 


\subsubsection{Trade impacts}

Tables 4.5 and 4.6 show the net trade flows (expressed in 1,000 tonnes) that have been simulated in the case of the Baseline and Scenario 2. As suggested by the AGMEMOD simulation, implementing the targets proposed in this scenario could lead to an increase of net imports in the cases of maize $(162 \%)$, rapeseed $(75 \%)$ and citrus $(71 \%)$. The largest net exports declines are expected for wheat $(41 \%)$, olives $(37 \%)$ and wine $(67 \%)$. Drawing attention to key producer countries, the scenario outcomes indicate that for both groups of key producers net exports could decline.

Table 4.5 Scenario 2 - Net trade impacts, EU-27

\begin{tabular}{|c|c|c|c|c|}
\hline & & Baseline & Scenario & Diff \\
\hline Product & Net trade indicator & $1,000 \mathrm{t}$ & $1001 \mathrm{t}$ & $\%$ \\
\hline Maize & Net imports & $5,090.5$ & $13,326.3$ & 161.8 \\
\hline Rapeseed & Net imports & $3,050.9$ & $5,341.8$ & 75.1 \\
\hline Sugar beet & Net imports & $2,419.8$ & $2,419.8$ & 0.0 \\
\hline Wheat & Net exports & $33,934.1$ & $20,131.7$ & -40.7 \\
\hline Olives & Net exports & 519.0 & 325.2 & -37.3 \\
\hline Wine* & Net exports & 12.3 & 4.3 & -66.8 \\
\hline Citrus & Net imports & $1,090.0$ & $1,866.8$ & 71.3 \\
\hline Hops & Net exports & 4.0 & 2.7 & -32.8 \\
\hline
\end{tabular}

Note: * means $1,000 \mathrm{hl}$.

Source: AGMEMOD based on input from the analysis presented in Chapter 3.

Table 4.6 Scenario 2 - Net trade impacts, key producers

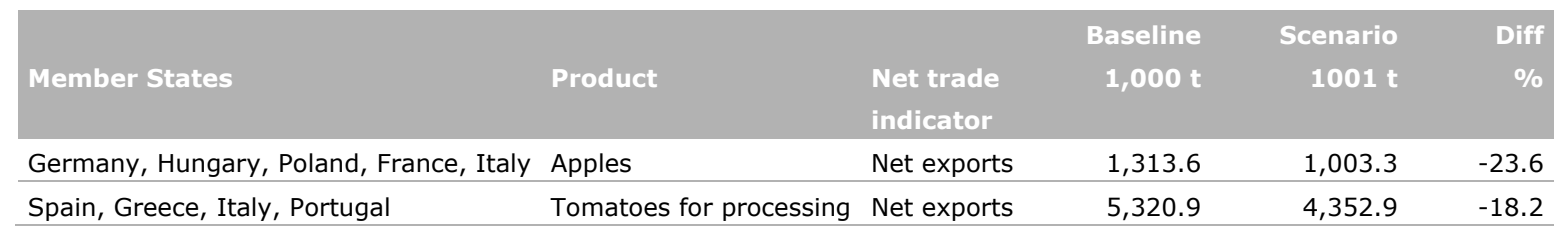

Source: AGMEMOD based on input from the analysis presented in Chapter 3.

\subsubsection{Indirect land use change}

Table 4.7 indicates the expected changes in the production volumes and the related ILUC indicators. In particular, ILUC due to increased EU imports (ILUC1) is calculated to be almost 2 million ha EUequivalents and is related to maize, rapeseed and citrus. The estimated ILUC related to replace the EU export decline gap (ILUC2) is more than 2.6 million ha EU equivalents, with the largest share being associated to wheat (93\%). As in the case of Scenario 1, the indirect land use change attributable to sugar beet is marginal. 
Table 4.7 Scenario 2 - Indirect Land Use Change (ILUC) impacts (x 1,000 ha)

\begin{tabular}{|c|c|c|c|c|}
\hline Product & $\begin{array}{r}\text { Volume change }(1,000 \\
\text { tonnes })\end{array}$ & $\begin{array}{l}\text { Average yield } \\
\text { (tonne/ha) }\end{array}$ & $\begin{array}{r}\text { ILUC1 } \\
\text { (imports) }\end{array}$ & $\begin{array}{r}\text { ILUC2 } \\
\text { (exports) }\end{array}$ \\
\hline Apples & -310.3 & 22.3 & 0.0 & -13.9 \\
\hline Rapeseed & $-2,290.9$ & 3.0 & -756.5 & 0.0 \\
\hline Sugar beet & 0.0 & 73.1 & 0.0 & 0.0 \\
\hline Wheat & $-13,802.4$ & 5.5 & 0.0 & $-2,490.9$ \\
\hline Olives & -193.7 & 452.3 & 0.0 & -0.4 \\
\hline Wine* & $-8,219.0$ & 51.1 & 0.0 & -160.9 \\
\hline Citrus & -776.8 & 20.5 & -37.9 & 0.0 \\
\hline
\end{tabular}

Notes: * stands for $\mathrm{hl} / \mathrm{ha}$ and $1,000 \mathrm{hl}$ in the case of yield and volume respectively. Negative volume changes in the case of net importer sectors (i.e. maize, rapeseed, sugar beet and citrus) should be interpreted as an increase in imports.

Source: AGMEMOD based on input from the analysis presented in Chapter 3.

\subsubsection{Production value}

Table 4.8 summarises the outcomes of the assessment of the impacts in value terms. Value losses due lower production volumes could be expected in all cases, amounting to almost EUR 8 billion. In absolute terms, the losses estimated for the wheat sector (around EUR 2.1 billion) are similar to the findings for Scenario 1.

Table 4.8 Scenario 2 - Impact on the value of projected changes in production (EU-27 and key producers, $x$ million EUR)

\begin{tabular}{|c|c|c|c|}
\hline Product & $\begin{array}{r}\text { Volume change }(1,000 \\
\text { tonnes })\end{array}$ & Price (EUR/100 kg) & $\begin{array}{r}\text { Value change (EUR } \\
\text { million) }\end{array}$ \\
\hline Apples & $-2,178.1$ & 34.6 & -753.6 \\
\hline Rapeseed & $-2,911.0$ & 32.1 & -934.7 \\
\hline Sugar beet & -769.6 & 2.5 & -19.4 \\
\hline Wheat & $-1,3870.8$ & 15.3 & $-2,128.3$ \\
\hline Olives & -277.3 & 192.9 & -534.8 \\
\hline Wine* & $-22,953.9$ & 4.3 & -97.6 \\
\hline Citrus & $-1,678.8$ & 80.0 & $-1,343.0$ \\
\hline
\end{tabular}

Notes: The impacts reported for apples and tomatoes (for processing) refer to the key producers within the EU-27. * stands for $* 1,000 \mathrm{hl}$ and EUR/hl. Value impacts have been evaluated by taking into account AGMEMOD baseline 2030 prices. Volume changes are based on the trade indicator.

Source: AGMEMOD based on input from the analysis presented in Chapter 3 . 


\subsection{Scenario 3 - Expansion of organic area}

\subsubsection{Production and prices}

This scenario simulates a progressive expansion of organic production, reaching $25 \%$ of the total agricultural area in the EU by 2030 . This scenario relies on the hypothesis that an expansion of organic agriculture would lead to lower average yields. On the price side, a larger share of organic production would imply higher average prices due the price premium that it is associated to organic products (assuming a sufficient demand for organic products). Unlike in Scenarios 1 and 2, a priori price increases could be expected since both forces (yields and price effects) moves on the same direction, i.e. price increases due to scarcity reinforce price increases due to the expansion of organic production. However, the net impact will also depend on how demand reacts, since higher prices could lead to a weaker demand which eventually activates a self-correction price mechanism.

Figure 4.5 shows the overall impacts on production and prices that could be expected when $25 \%$ of total harvested area is under organic production (once again the reader is referred to Figure 2.3 for a description of the logic of the scenario). In this case, the AGMEMOD simulation suggests price increases in most cases, with hops being the only exception (a price decline of around $7 \%$ is expected in this case). With regard to production effects, moderate declines in production could be expected in most cases (below 10\%). Limited production increases are anticipated for hops (2\%). The largest price increase is indicated for rapeseed $(13 \%)$, while the largest production decline is expected in the case of wheat $(-8 \%)$.

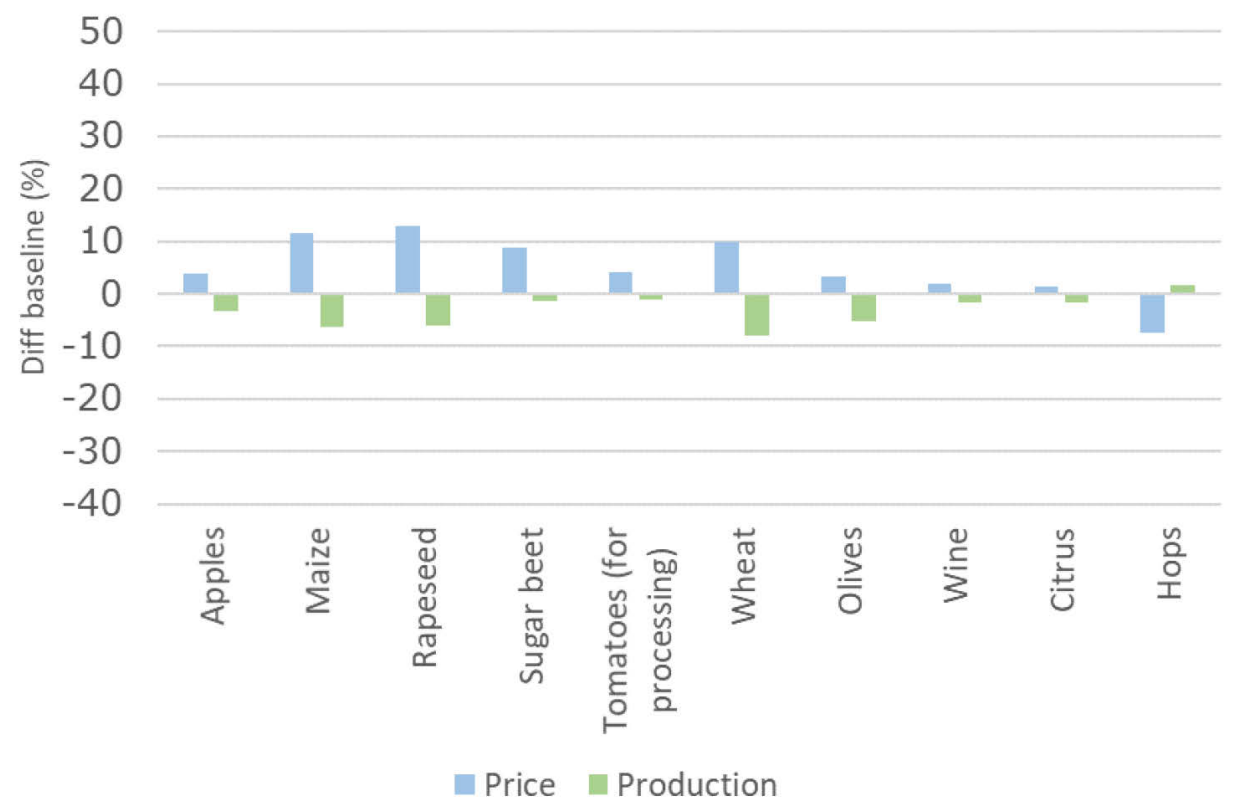

Figure 4.5 Scenario 3 - Overview of production and price impacts (\%), EU-27

Notes: The impacts reported for apples and tomatoes (for processing) refer to the key producers within the EU-27. In 2020, the key apple producers (DE, PL, FR, HU and IT) represent around 75\% of total apple supply within the EU-27; while the four key tomato producers (ES, IT, PT and EL) amount to $97 \%$ of total tomato for processing supply at the EU-27 level.

Source: AGMEMOD based on input from the analysis presented in Chapter 3.

Figure 4.6 links the expected price increases suggested by the case studies to the total expected price effects as simulated by AGMEMOD. The expected price impacts suggested by the case studies reflect the price premium associated with organic production, while the total expected effect provide the net price impact resulting from considering both the price premium and price increases caused by declining yields, as well as the potential decline in demand due to higher prices. With the expectation of hops, there is a positive net impact on prices. 


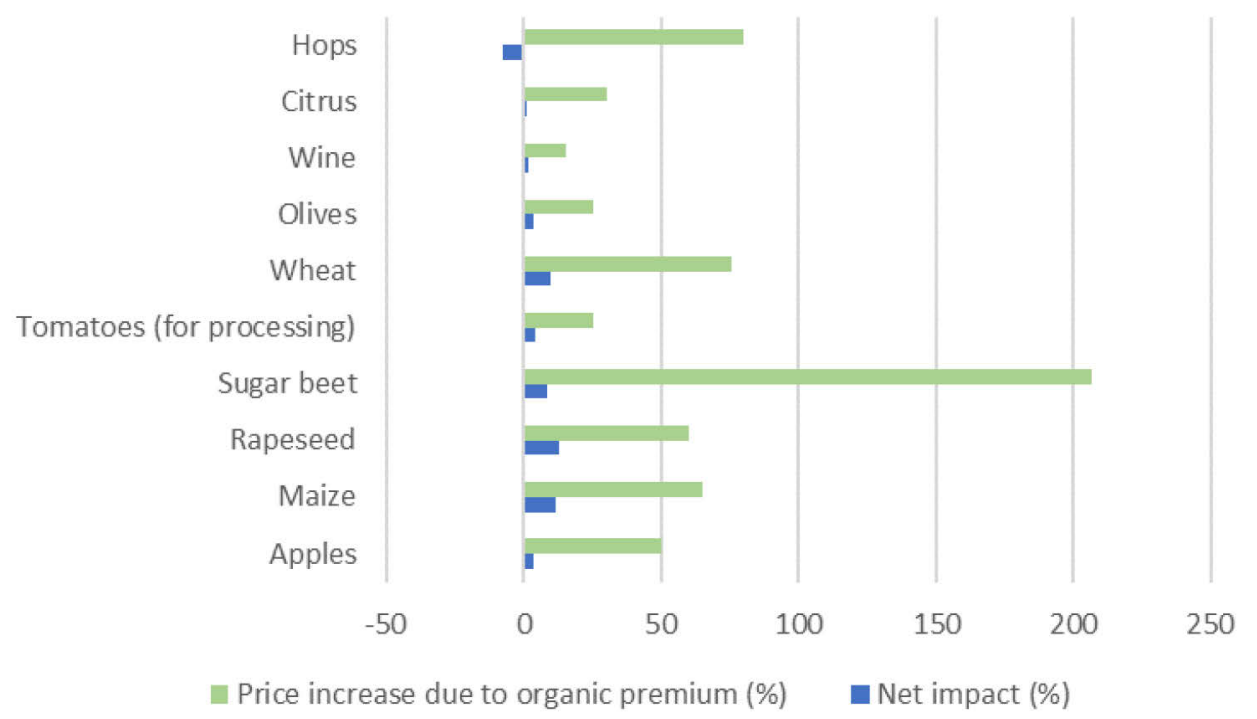

Figure 4.6 Scenario 3 - Net price impacts (\%) EU-27

Notes: The impacts reported for apples and tomatoes (for processing) refer to the key producers within the EU-27.

Source: AGMEMOD based on input from the analysis presented in Chapter 3.

The reader should be aware that the price increases due to the organic premium reported above (green bars, Figure 4.6) represent the price premium associated to organic production (compared to conventional) as estimated by the experts. Since our assessment has taken into account the current level of organic production, the actual price shocks imposed to the model are actually lower than the ones reported in the figure. The net expected market impacts (blue bars, Figure 4.6) represent the average price impacts taking into account the relative shares of organic/conventional product, as well the price impacts related to yield changes.

\subsubsection{Trade impacts}

Tables 4.9 and 4.10 report the net trade flows (expressed in 1,000 tonnes) that have been simulated in the case of the Baseline and Scenario 3. As in the previous cases, achieving the targets proposed in this scenario could lead to an increase of net imports in the case of maize (51\%) and rapeseed (18\%), although increases would be much weaker than in the case of Scenario 2 (162\% and 75\% respectively). A similar outcome could be expected for the citrus sector, with an increase of around $6.5 \%$. In terms of net exports, the scenario results indicate a decline in the olive and wine cases (by $15 \%$ and $10 \%$ respectively), while increases in net exports are indicated for hops (17\%). Note that this implies that in the case of hops the price premium effect $(20 \%$ price premium) is so large that it outpaces the yield reduction impact. As a result the impact on hops production even lightly increase (by about $1.5 \%$ relative to the baseline), whereas due to the price increase EU demand declines somewhat (by about $1 \%$ relative to the baseline). The net result is that exports increase. When focusing on the key tomato producers, the expansion of organic agricultural would have a limited impact on net trade ( $1.2 \%$ decline compared to the Baseline situation). 
Table 4.9 Scenario 3 - Net trade impacts, EU-27

\begin{tabular}{|c|c|c|c|c|}
\hline & & Baseline & Scenario & Diff \\
\hline Product & Net trade indicator & $1,000 t$ & $1001 t$ & $\%$ \\
\hline Maize & Net imports & $5,090.4$ & $7,702.1$ & 51.3 \\
\hline Sugar beet & Net imports & $2,419.7$ & $2,419.7$ & 0.00 \\
\hline Wheat & Net exports & $33,934.1$ & $24,732.3$ & -27.1 \\
\hline Wine* & Net exports & 12.3 & 11.1 & -10.0 \\
\hline Citrus & Net imports & $1,090.0$ & $1,161.2$ & 6.5 \\
\hline Hops & Net exports & 4.0 & 4.7 & 16.6 \\
\hline
\end{tabular}

Note: * means $1,000 \mathrm{hl}$.

Source: AGMEMOD based on input from the analysis presented in Chapter 3.

Table 4.10 Scenario 3 - Net trade impacts, key producers

\begin{tabular}{|c|c|c|c|c|c|}
\hline & & & Baseline & Scenario & Diff \\
\hline Member States & Product & $\begin{array}{l}\text { Net trade } \\
\text { indicator }\end{array}$ & $1,000 t$ & $1001 \mathrm{t}$ & $\%$ \\
\hline Germany, Hungary, Poland, France, Italy & Apples & Net exports & $1,313.6$ & 2,588.5 & 97.1 \\
\hline Spain, Greece, Italy, Portugal & Tomatoes for processing & Net exports & $5,320.9$ & $5,254.8$ & -1.2 \\
\hline
\end{tabular}

Source: AGMEMOD based on input from the analysis presented in Chapter 3.

\subsubsection{Indirect land use change}

Table 4.11 provides an overview of the expected changes in production volumes and the relevant ILUC indicators. As shown in the table, due to increased EU imports, the indirect land use (ILUC1) is expected to be around 0.5 million ha EU equivalents and is mainly related to maize and rapeseed. The estimated ILUC related to replacement of the EU export decline gap (ILUC2) is around 1.6 million ha EU equivalents, with the largest contribution associated to wheat (similarly as in the previous scenarios).

Table 4.11 Scenario 3 - Indirect Land Use Change (ILUC) impacts (x 1,000 ha)

\begin{tabular}{|c|c|c|c|c|}
\hline Product & $\begin{array}{l}\text { Volume change } \\
\text { (1,000 tonnes) }\end{array}$ & $\begin{array}{r}\text { Average yield } \\
\text { (tonne/ha) }\end{array}$ & ILUC1 (imports) & ILUC2 (exports) \\
\hline Apple & $1,274.9$ & 22.3 & 0.0 & 57.1 \\
\hline Maize & $-2,611.6$ & 7.1 & -368.6 & 0.0 \\
\hline Rapeseed & -532.8 & 3.0 & -176.0 & 0.0 \\
\hline Sugar beet & 0.0 & 73.1 & 0.0 & 0.0 \\
\hline Tomatoes for processing & -66.1 & 89.0 & 0.0 & -0.7 \\
\hline Wheat & $-9,201.8$ & 5.5 & 0.0 & $-1,660.7$ \\
\hline Olives & -77.1 & 452.3 & 0.0 & -0.2 \\
\hline Wine* & $-1,234.5$ & 51.1 & 0.0 & -24.2 \\
\hline Citrus & -71.2 & 20.5 & -3.5 & 0.0 \\
\hline \multirow[t]{2}{*}{ Hops } & 0.7 & 2.0 & 0.0 & 0.3 \\
\hline & \multicolumn{2}{|c|}{ TOTAL (1,000 ha) } & -548.0 & $-1,628.3$ \\
\hline
\end{tabular}

Notes: * stands for $\mathrm{hl} / \mathrm{ha}$ and $1,000 \mathrm{hl}$ in the case of yield and volume respectively. Negative volume changes in the case of net importer sectors (i.e. maize, rapeseed, sugar beet and citrus) should be interpreted as an increase in imports.

Source: AGMEMOD based on input from the analysis presented in Chapter 3. 


\subsubsection{Production value}

Table 4.12 focuses on the value impacts that could emanate from achieving the target set in terms of organic agriculture. The main loss is expected in the case of wheat, estimated to be at around EUR 1.7 billion. For all considered crops the expected loss is around EUR 3.4 billion.

Table 4.12 Scenario 3 - Impact on the value of projected changes in production (EU-27 and key producers, $x$ million EUR)

\begin{tabular}{|c|c|c|c|}
\hline Product & $\begin{array}{l}\text { Volume change } \\
\text { ( } 1,000 \text { tonnes) }\end{array}$ & Price (EUR/100 kg) & $\begin{array}{l}\text { Value change } \\
\text { (EUR million) }\end{array}$ \\
\hline Apples & -354.9 & 34.6 & -122.8 \\
\hline Maize & $-4,388.4$ & 13.5 & -590.3 \\
\hline Rapeseed & $-1,499.1$ & 32.1 & -481.4 \\
\hline Sugar beet & $-2,913.9$ & 2.5 & -73.3 \\
\hline Tomatoes (for processing) & -104.8 & 85.7 & -89.8 \\
\hline Wheat & $-10,763.6$ & 15.3 & $-1,651.5$ \\
\hline Olives & -106.4 & 192.9 & -205.2 \\
\hline Wine* & $-2,734.6$ & 4.3 & -11.6 \\
\hline Citrus & -181.0 & 80.0 & -144.8 \\
\hline \multirow[t]{2}{*}{ Hops } & 1.1 & 400.0 & 4.5 \\
\hline & & Total (EUR million) & $-3,366.3$ \\
\hline
\end{tabular}

Notes: The impacts reported for apples and tomatoes (for processing) refer to the key producers within the EU-27. * stands for $* 1,000 \mathrm{hl}$ and EUR/hl. Value impacts have been evaluated by taking into account AGMEMOD baseline 2030 prices. Volume changes are based on the trade indicator.

Source: AGMEMOD based on input from the analysis presented in Chapter 3.

\subsection{Scenario 4 - Combined reduction of pesticide use and risk, nutrient losses and fertiliser use and $10 \%$ set aside}

\subsubsection{Production and prices}

Scenario 4 presents a combination of Scenarios 1 and 2, together with an expansion of the share of the land under high-diversity landscape features reaching $10 \%$ by 2030 . The general mechanism of this scenario is very similar to what was described previously for Scenarios 1 and 2. Overall supply and prices would reflect a decline in yields due to lower application of plant protection products, as well as the associated quality deterioration which eventually would lead to lower prices. Once again, the net price impact would depend on the dominant element (price increase due to scarcity versus price decline due to quality deterioration).

A summary of the impacts on prices and production related to the implementation of the pesticides, fertilisers and set-aside targets is provided in Figure 4.7. As in the previous cases, the impacts are measured as the difference between the scenario and the baseline values in 2030 . As shown in the figure below, in 7 out of 10 cases, production declines are around 10-20\%. A lower production decline is expected in the case of hops (decline by $6 \%$ ). In terms of price impacts, similarly as in the case of Scenario 1, significant price increases could be expected for olives, wine and hops (increases in the range of $26-42 \%$ ). More limited price impacts are expected in the case of maize, rapeseed, sugar beet and wheat (increases below $7 \%$ ). 


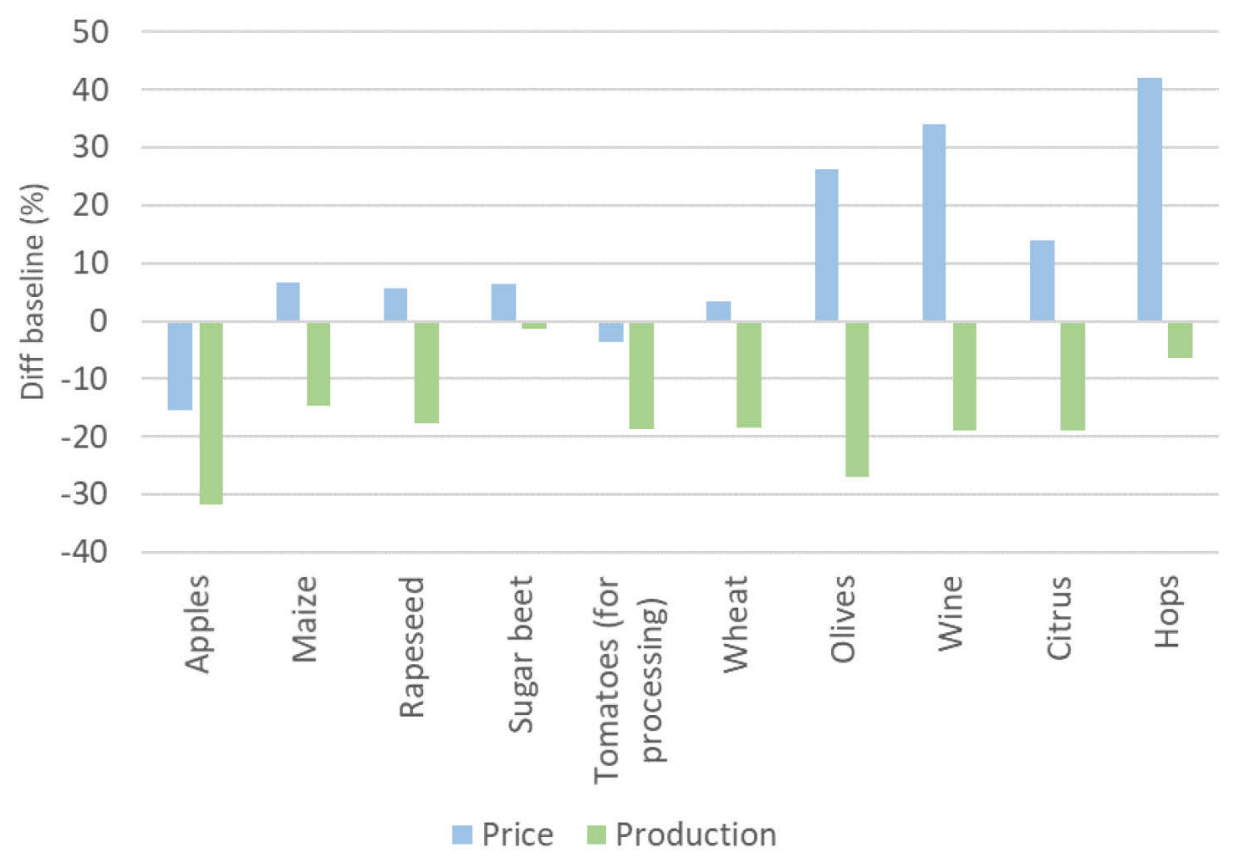

Figure 4.7 Scenario 4 - Overview of production and price impacts (\%), EU-27

Notes: The impacts reported for apples and tomatoes (for processing) refer to the key producers within the EU-27. In 2020, the key apple producers (DE, PL, FR, HU and IT) represent around 75\% of total apple supply within the EU-27; while the four key tomato producers (ES, IT, PT and EL) amount to $97 \%$ of total tomatoes for processing production at the EU-27 level.

Source: AGMEMOD based on input from the analysis presented in Chapter 3.

Figure 4.8 brings together the expected price impacts as reported in the case studies with the total expected price effects as indicated by the AGMEMOD model. As in the case of Scenarios 1 and 2, the former captures the expected quality deterioration due to the achievements of the targets, while the latter provides the net price effect that could be expected when considering both quality deterioration and price increases induced by lower supply. The scarcity impact is the one which prevails in most cases. Similarly as in Scenario 1, apples are the only exception to this general trend with a negative net price impact.

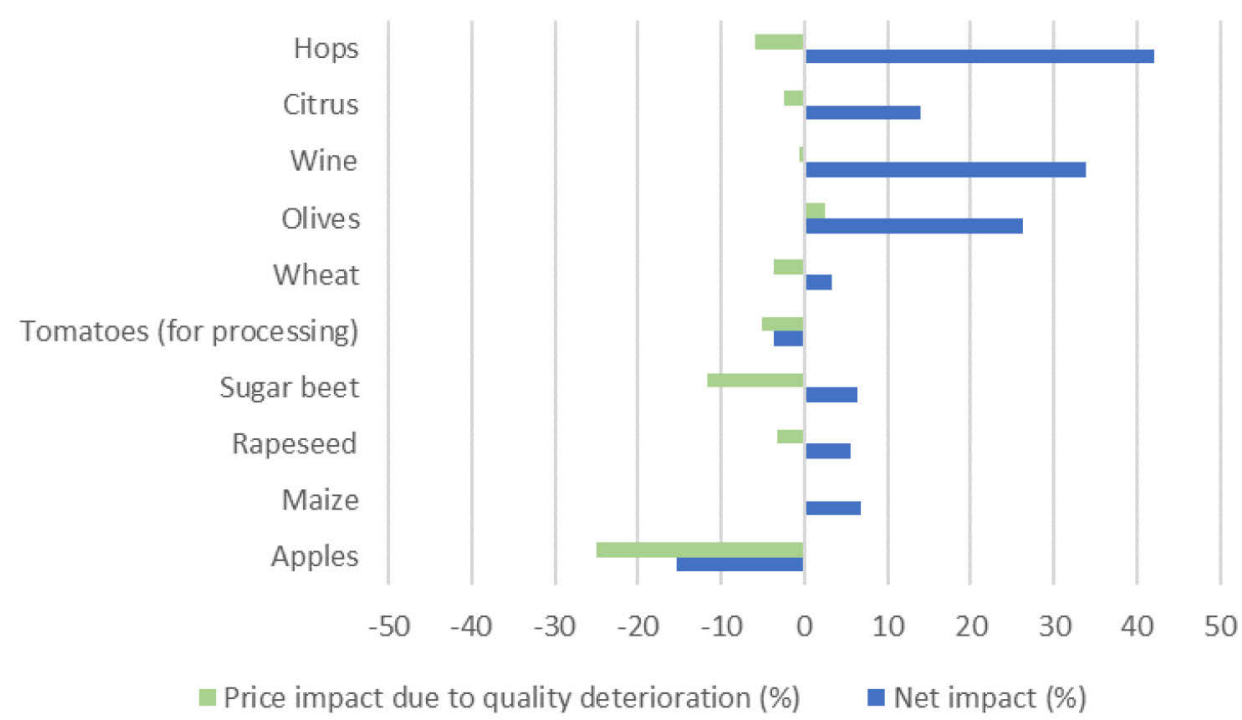

Figure 4.8 Scenario 4 - Net price impacts (\%) EU-27

Notes: The impacts reported for apples and tomatoes (for processing) refer to the key producers within the EU-27.

Source: AGMEMOD based on input from the analysis presented in Chapter 3. 


\subsubsection{Trade impacts}

Tables 4.13 and 4.14 summarise the net trade flows (expressed in 1,000 tonnes) that have been simulated in the case of the Baseline and Scenario 4. Achieving the intended targets for this scenario is expected to lead to a strong increase in net imports of maize, rapeseed and citrus, with increases by almost $209 \%, 98 \%$ and $92 \%$ respectively. Focusing on net exports, the AGMEMOD simulations indicate potential declines in the case of olives, wine and hops, with numbers higher than $50 \%$. Regarding horticulture, the outcomes in the case of the selected crops point to a potential decline by more than $44 \%$.

Table 4.13 Scenario 4 - Net trade impacts, EU-27

\begin{tabular}{|c|c|c|c|c|}
\hline & & Baseline & Scenario & Diff \\
\hline Product & Net trade indicator & $1,000 t$ & $1001 t$ & $\%$ \\
\hline Maize & Net imports & $5,090.5$ & $15,707.7$ & 208.6 \\
\hline Rapeseed & Net imports & $3,050.9$ & $6,041.3$ & 98.0 \\
\hline Sugar beet & Net imports & $2,419.8$ & $2,419.8$ & 0.0 \\
\hline Wheat & Net exports & $33,934.1$ & $11,110.5$ & -67.3 \\
\hline Olives & Net exports & 519.0 & 161.2 & -68.9 \\
\hline Wine* & Net exports & 12.3 & 2.4 & -80.5 \\
\hline Citrus & Net imports & $1,090.0$ & $2,094.3$ & 92.1 \\
\hline Hops & Net exports & 4.0 & 2.0 & -50.4 \\
\hline
\end{tabular}

Note: * means $1,000 \mathrm{hl}$.

Source: AGMEMOD based on input from the analysis presented in Chapter 3.

Table 4.14 Scenario 4 - Net trade impacts, key producers

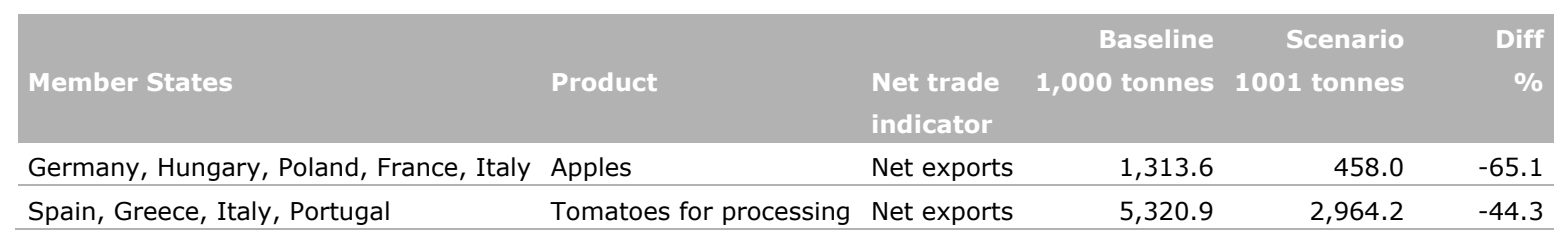

Source: AGMEMOD based on input from the analysis presented in Chapter 3.

\subsubsection{Indirect land use change}

Table 4.15 shows the expected changes in the production volume and the related ILUC indicators. On the one hand, indirect land use due to increased EU imports (ILUC1) is estimated to be around 2.5 million ha EU equivalents and is mainly due to changes in maize and rapeseed. On the other hand, the estimated ILUC related to replace the EU export decline gap (ILUC2) is around 4.4 million ha EUequivalents, with around $95 \%$ being attributable to wheat. 
Table 4.15 Scenario 4 - Indirect Land Use Change (ILUC) impacts (x 1,000 ha)

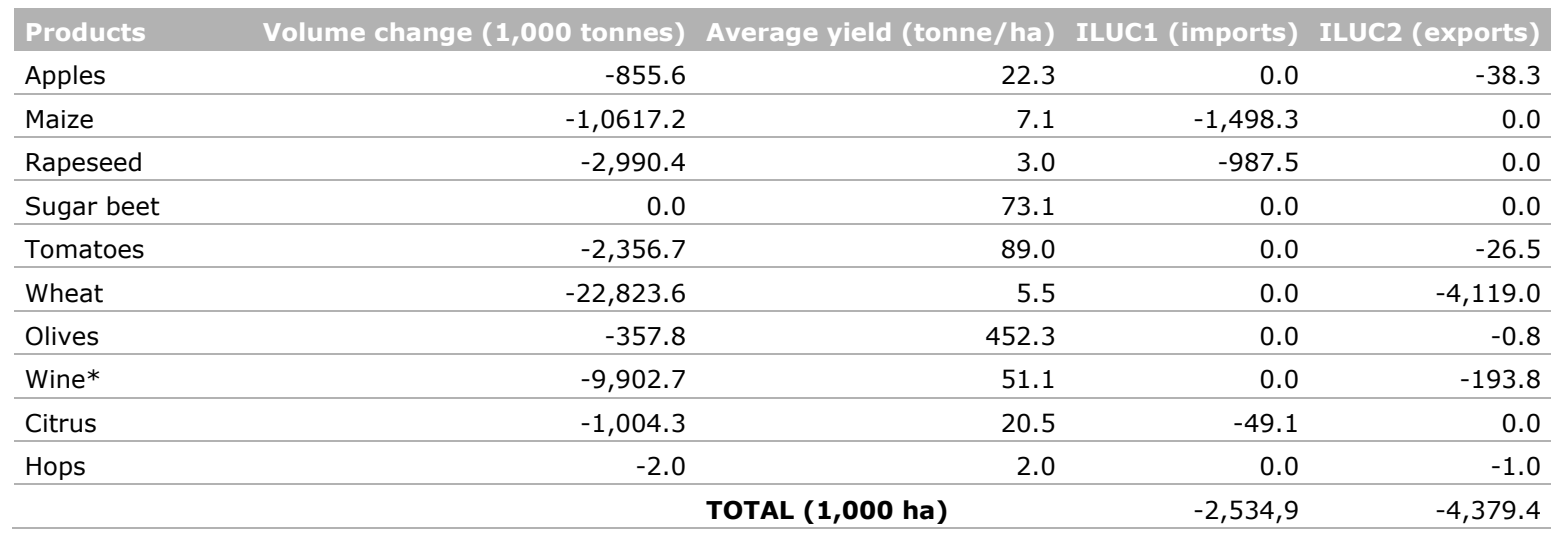

Notes: * stands for $\mathrm{hl} / \mathrm{ha}$ and $1,000 \mathrm{hl}$ in the case of yield and volume respectively. Negative volume changes in the case of net importer sectors (i.e. maize, rapeseed, sugar beet and citrus) should be interpreted as an increase in imports.

Source: AGMEMOD based on input from the analysis presented in Chapter 3.

\subsubsection{Production value}

Table 4.16 presents the simulated impacts in terms of value that could be associated to the targets/measures proposed in Scenario 4. Similarly as in the case of Scenarios 1 and 2, value losses due to lower production volumes could be expected for all crops. Across the various sectors, the largest loss is estimated for wheat (almost EUR 3.6 billion). Overall, losses could amount to almost EUR 12 billion.

Table 4.16 Scenario 4 - Impact on the value of projected changes in production (EU-27 and key producers, $x$ million EUR)

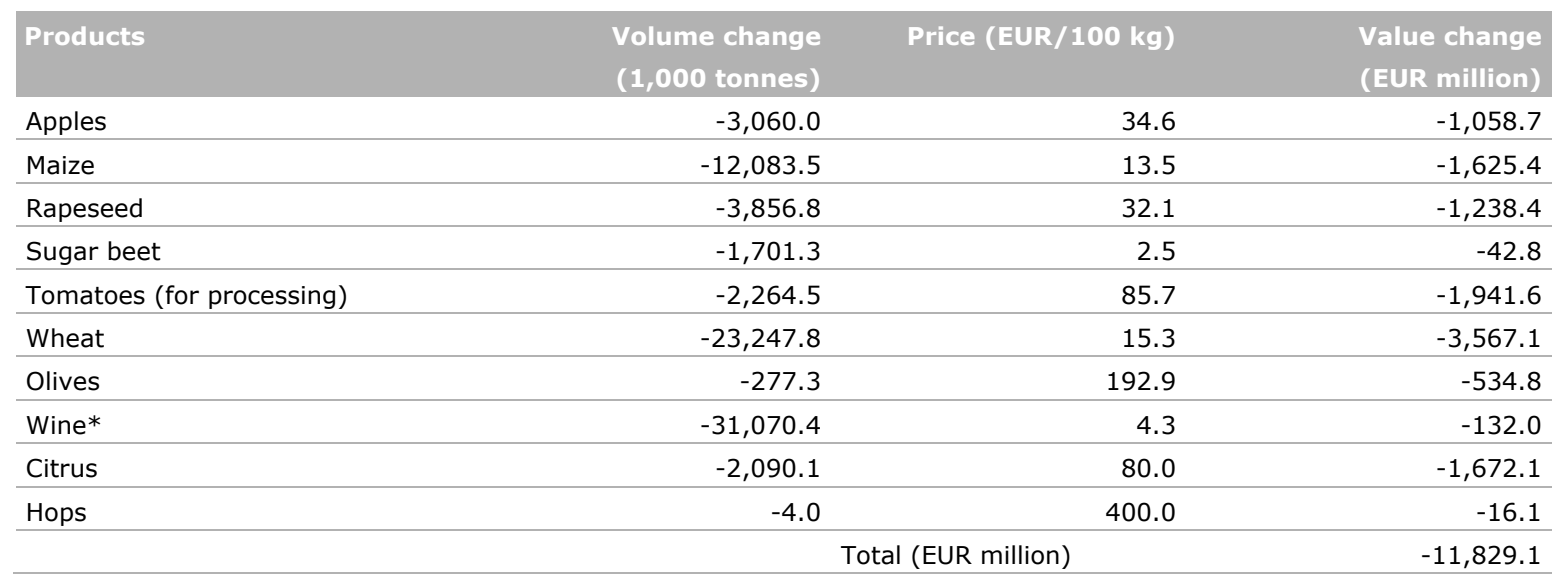

Notes: The impacts reported for apples and tomatoes (for processing) refer to the key producers within the EU-27. * stands for $* 1,000 \mathrm{hl}$ and EUR/hl. Value impacts have been evaluated by taking into account AGMEMOD baseline 2030 prices. Volume changes are based on the trade indicator.

Source: AGMEMOD based on input from the analysis presented in Chapter 3. 


\section{Discussion, conclusions and recommendations}

\section{$5.1 \quad$ Discussion}

\section{Scope of the impact assessment}

A comprehensive impact assessment is necessary to understand the links between different policies and their consequences. The impact assessment described in this report is to a large extent limited to the economic consequences. With respect to the environmental impacts, we have only assessed the effects on the indirect land use changes. Since no environmental impact assessment has been executed by the European Commission or other institutes as part of an ex ante evaluation, it was not possible to compare the economic impacts with all relevant environmental impacts. This comparison would contribute to a better political decision-making process. Furthermore, the F2F strategy contains objectives with the intention to contribute to the feasibility of the targets that have been assessed in this study. Examples are the initiative to improve the corporate governance framework including a requirement for the food industry to integrate sustainability into corporate strategies, the efforts to promote sustainable food consumption and facilitating the shift to healthy, sustainable diets, and the reduction of food loss and waste. However, the plans how to implement those initiatives are in development. A plan to support organic farming has been released in September 2021. Therefore, it was not possible to assess to what extent the economic impacts of the assessed targets could be compensated. In general, it can be concluded that plans which differentiate between food produced in the EU according to the assessed targets such as the promotion of sustainable food consumption and food which production does not comply with the assessed objectives will have a compensating effect. If this is not the case, it will not compensate the competitive disadvantage. An example is the objective to reduce food waste.

\section{Policy objectives and development}

The F2F and BD strategies include clear targets for crop producers to meet in 2030, although for this moment not binding. In this study, we have interpreted these objectives as targets that have to be fulfilled by farmers and growers. However, the European Parliament and the MS governments will also contribute. This is for example the case in meeting the objectives for the reduction of use and risks of pesticides by $50 \%$ in 2030 , as well as the reduction of the use of more hazardous pesticides by $50 \%$ in 2030. In this context, an important instrument will be the recategorisation of the pesticides. Especially the termination of the registration of pesticides that are listed in category 3 (candidates for substitution) will significantly contribute to these targets, irrespective if alternatives will be made available for farmers. In this study, we have assumed that all pesticides currently available will continue to remain in the farmers' toolbox.

Another example concerns the implementation of the targets to reduce nutrient losses. The focus is to reduce the excess use of nutrients measured by the gross nitrogen balance (GNB). There is a significant variation in the average GNB between MSs. The elaboration of the policy to meet these targets will be a joint responsibility of the European Commission and MS governments. Member States with a high GNB will have to contribute more than MSs with a low GNB. As a consequence, we expect that objectives for farmers will vary significantly across MSs. The case studies conducted in the present study have not taken into account these potential differences.

\section{Method used to measuring trends in the use and risk of pesticides}

The European Commission has adopted Harmonised Risk Indicator I as the method to measure progress in meeting the objectives to reduce the use and risk of pesticides at MS level. This method has subdivided all pesticides into four categories: (i) low-risk active substances; (ii) active substances; (iii) candidates for substitution; and (iv) pesticides that are not approved. The categories are given a weighting factor of $1,8,16$ and 64 respectively. The impact is calculated by multiplying the sold volume per year of each category by its weighting factor, and summing up the calculated values of all categories. In our study, we have applied this methodology at farm level. However, the European 
Commission can reassess the category of active substances. If this takes place, the values will then be recalculated retrospectively. This will have large consequences on the calculation of the trends, and therefore the progress made towards achieving the F2F and BD strategy targets, especially if candidates for substitution will lose their registration status, and move to the highest risk group (category 4). Unless farmers receive derogations by their MS government, farmers will no longer be allowed to use them, thus reducing the sold volume (almost) to zero, but also in previous years, this active substance will get a weighting factor of 64 , which enlarges the reduction of the environmental impact. This last step is not correct in our view. It creates unpredictability and double counting of the effect of such a decision. Therefore, we recommend the EC not adjust the weighting factor retrospectively.

\section{Method farm level}

The F2F and BD strategy targets have a time horizon of 2030. This implies that farmers and MSs are expected to meet these targets by 2030. In the meantime, subject to regulatory approval, farmers may invest in the purchase of new technologies, knowledge and experience which can enable them to meet these targets. This implies that the consequences for meeting the targets will not be experienced immediately, but gradually. The technological growth measured as the annual increase of yields will be reduced during this period or even become negative. In our case studies at farm level the immediate consequences for the yield and quality level are assessed, but compensated in the assessment of the effects at macro level by the normal technological growth until 2030.

This study deviates from the other impact assessments published by JRC and USDA (Barreiro-Hurle et al., 2021; Beckman et al., 2020) by including data collection and analysis at farm level. However, the results of the case studies need careful interpretation. Each case study contains an assessment by one or a few experts, based on their expertise and available data. However, the reader should be aware that conducting extensive studies or field trials is far beyond the scope of this study, and therefore, they were not carried out. Therefore, this study does not contain hard conclusions, and the results of the case studies are surrounded by a margin of uncertainty. The assessed impacts need to be interpreted as explorations of the potential impacts which require further research.

\section{Results}

For each crop, only one assessment per case country has been executed, with four cases at maximum. The only exception regards grapes in Italy and Spain with two cases per country. The results for each of the case crops vary across the case countries, and cannot be considered to be representative for the entire case country, as explained in chapter 2 . Multiple aspects contribute to the potential explanation of the differences. The described case farms differ from each other in terms of dimensions such as sizes, level of technology, structure of the farm, rotation (in the case of annual crops), location with differences in soil type, climatic conditions, pest and disease pressure, available active substances, performance etc. Furthermore, the assessment has been executed for a single crop. For annual crops, the crop protection and nutrient management strategies are developed for all crops in the rotation. This allows farmers to take measures that contribute to the entire rotation cycle such as the application of green manure and cover crops. Furthermore, they can focus on the reduction of the use of pesticides and nutrients of crops with the lowest margin and limit the reduction on cash crops.

In annual crops, there is more flexibility to adjust the crop protection strategy than in perennial crops. More management choices can be made on a yearly basis, and crops are in most cases part of a crop rotation. This further enlarges the grower's management toolbox. Also, the overall growing season is shorter so the risk of pest and disease build-up may be smaller and the carry-over risk lower.

Aspects that need further attention regard the yearly fluctuations in yields. If the use of pesticides is limited, the risk of yield reduction increases. In growing seasons with bad weather such as low temperatures and a lot of rain, the disease pressure will be high. Furthermore, if the number of active ingredients will be reduced, the risk of resistance development will increase, which limits the options for farmers to control pests, diseases and weeds. Therefore, we have conducted a limited sensitivity analysis. Results have been presented in Appendix 3. 


\section{Ways to meet the objectives}

In the case studies, we have requested the experts to assess the expected behaviour of farmers and growers. This deviates from what is technically feasible to meet the objectives of the F2F and BD strategies.

Farmers and growers have different options in their attempts to meet the F2F targets on pesticides. The most important option is to replace existing seed varieties by more resistant ones. The breeding sector contributes significantly to continuous growth of the yield level (Noleppa and Cartsburg, 2021). Especially the cultivation of perennial plants can benefit in the mid and long term. However, the impact can be enlarged, when new breeding techniques (NBTs) are allowed to apply. These techniques can significantly reduce the length of the breeding process. However, European legislation needs to be adjusted to allow the use of NBTs. Other options to meet the F2F targets are the increase of genetic diversity in the cultivation systems such as the use of functional agrobiodiversity, the use of mechanical and other alternative weed control methods. Furthermore, the use of cover crops and green manure, adjusted rotations, and the use of precision agricultural techniques for monitoring, early alert systems, advanced seed treatment techniques and biocontrol agents among others (Bremmer et al., 2021) can contribute to realise the targets of the F2F and biodiversity strategies. Some techniques such as the use of biostimulants need further fundamental research before largescale uptake can occur.

Other options include the increase of the knowledge and experience of farmers and growers by extension, training and participation in networks with other farmers and growers. The sizeable difference in strategies and performance of farms with comparable structures, rotation and acreage show the difference between reality and what is technical feasible. The comparison of the case studies in different countries also shows differences in crop protection strategies, spraying schemes and resulting values of the HRI I. In our methodology, it was out of scope to bring the experts of the same crop from the different case countries together. This would have enabled them to mutual reflect on their assessments and to analyse the differences in their estimations. Therefore, national and international cooperation can enlarge the options for farmers and growers to meet the targets.

\section{Organic production}

The European Commission has set the objective to have at least $25 \%$ of the agricultural land under organic production (including grassland), assuming organic production is more sustainable. When we compare the results of Scenario 3 to the case studies at farm level, we see a lower nutrient use. In annual crops we observe little or no pesticide use in the cultivation of annual crops. However, in the cultivation of perennial crops, we observe significant use of pesticides in organic production. In a number of cases such as wine production and citrus cultivation, we observe even higher values of the HRI I than in conventional production, mainly caused by the use of copper-based active substances, which are of natural origin, but classified as candidates for substitution. Additional research is required to investigate to what extent these findings are confirmed in practice. In these cases, this will create a disincentive to shift from conventional to organic production.

\section{Analysis at macro level}

At macro level, an increase of the area under organic production will contribute to meeting the environmental objectives such as the reduction of pesticide use and risk, and nutrient use, if the environmental impact of organic is lower than of conventional production. In that case, conventional growers can reduce their targets. However, in this macro analysis, the target for organic production has not been combined with the other targets, since we do not know to what extent an increase in organic crop production will contribute to meeting the reduction targets for conventional growers.

\section{Positioning the study}

For a better understanding of the findings of this assessment, a comparison with some recent studies exploring the impacts of the F2F strategy is due. More specifically, we refer to the USDA (Beckman et al., 2020) and JRC (Barreiro-Hurle et al., 2021) studies. In general terms, the estimated yield impacts (at market level) in this study for arable crops are comparable to those suggested by the JRC study, while in the case of perennials the present estimates for yield declines tend to be larger than those reported by the JRC. 
More specifically, a strength of the present study is that potential quality impacts are included. The farm perspective and the agronomic implications of using plant protection products are elements better represented in our assessment than in the other two. The expansion of organic production is a dimension that it is not considered in the USDA study, it is explored in the present assessment. The USDA and JRC studies both take on board the interactions with the livestock sector and have a more detailed coverage of world market dynamics.

\section{Limitations from the assessment}

Since no study is exempt from limitations, the reader should bear in mind some aspects of this study when considering the outcomes. First, it is important to remark that the trade and indirect land use change figures are assuming that EU demand for food and feed will remain unchanged. In other words, the presented results do not take into account the expected shocks that the F2F and BD strategies will impose on the EU livestock sector, which will be translated into further shocks on feed demand. By relying on the JRC study, it can be concluded that demand for crops is likely to decline due to projected declines in animal production. Therefore, our results might be overestimating the trade impacts.

Another important aspect is that the AGMEMOD model has an EU focus. Its EU scope makes the model less 'strong' for simulating world price impacts endogenously. This could lead to some underestimation of the price responses in our case relative to those obtained in the two other studies (JRC and USDA) mentioned before.

\subsection{Conclusions}

Table 5.1 summarises the outcomes of the four scenarios that were simulated to assess the implications of achieving the selected targets.

In general terms, we can conclude that the losses in production come from yield losses (i.e. negative yield shock) as well as quality losses (i.e. price decline) which in general reinforce each other. The impacts of the expected quality deterioration (i.e. the negative price shock) are counteracted by the general market impact of increasing prices due to increase 'scarcity' which results from a decline in supply. Overall, the impacts on EU trade are significant and in percentage terms larger than the shocks on production. The general pattern is that EU imports (e.g. maize, rapeseed) could substantially increase, while EU exports (e.g. wheat, olives, wine) are expected to decline.

Keeping in mind the above expected developments, one conclusion that can be drawn is that farmers are likely to face negative income impacts in the coming years. This is because revenues ( $p$ rice $x$ volume) tend to decline and are likely to outpace the reduction in costs, e.g. relative lower importance of fertiliser and pesticide costs in total costs of crop production.

On the basis of this study we present the following conclusions:

1. Reducing pesticide use and risk of pesticides by $50 \%$ and to reduce nutrient losses (50\%) have significant impact on yield level. Estimated yield losses vary:

- From 0 to $30 \%$ in Scenario 1 (reduction pesticide use and risk)

- From 2 to $25 \%$ in Scenario 2 (reduction fertiliser use)

2. Impacts of realisation of F2F objectives for permanent crops such as grapes, apples, olives, citrus are higher than for annual crops such as oilseed, rapeseed, wheat, maize and sugar beets.

This is so since for permanent crops there are less options available to reduce impacts than in the case of annual crops.

3. Our yield impacts (at market level) for arable crops are comparable to those of the JRC study; our yield loss impacts for perennials tend to be higher than those of the JRC study; potential quality impacts are ignored by all other studies, but explored in our study.

4. The losses in production come from yield losses (negative yield shock) as well as quality losses (price decline) which in general reinforce each other.

5. The quality loss impact (negative price shock) is partly counteracted by the general market impact of increasing prices due to increase 'scarcity' (resulting from a decline in supply). 
6. The impacts on EU trade are significant and in percentage terms larger than the shocks to production. The general pattern is that EU imports (e.g. maize, rapeseed) substantially increase, whereas EU exports (e.g. wheat, olives, wine) decline.

7. Estimated indirect land use effect of assessed crops is 2.5 (additional import) and 5.4 (reduced export) million ha (conditional on unchanged EU crop demands for food and feed).

8. Farm income is likely to suffer since revenues tend to decline, probably at a higher speed than expected cost reductions.

Table 5.1 Overview of expected impacts related to the achievement of the targets

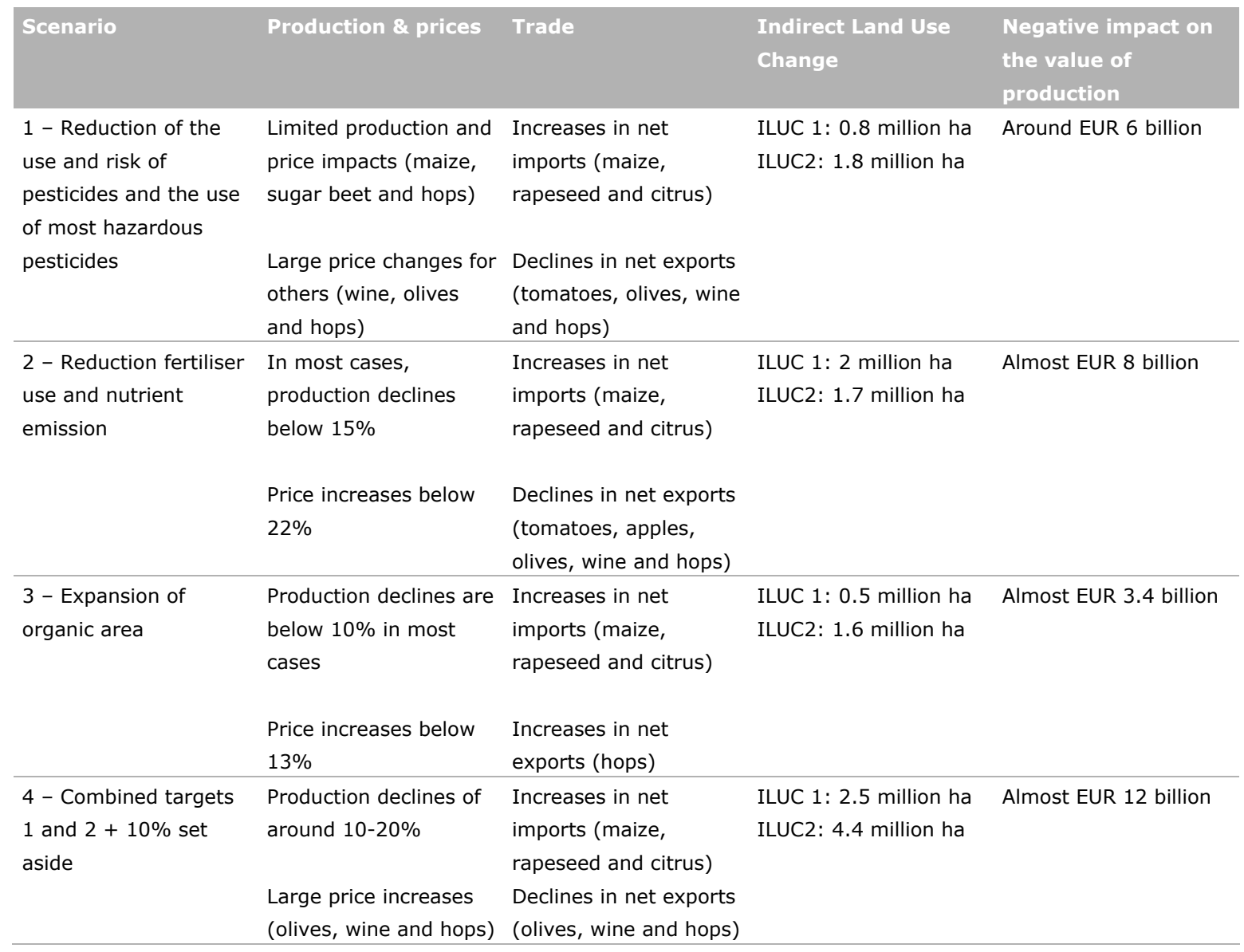

Source: Authors.

\subsection{Recommendations}

Finally, our policy recommendations are presented:

1. To help reduce/overcome the negative impacts of reduction of pesticides and nutrients, especially for permanent crops, there is an increased need for innovations in crop protection techniques, such as biocontrol, breeding, precision agriculture, biostimulants and other techniques that contribute to the resilience of crop production against pests, weeds and diseases. Removing legislative barriers to new breeding techniques, in order to shorten the breeding process significantly could help. To best achieve the ambition to reduce nutrient losses by half, the Nutrient Use Efficiency indicator developed by the EU Nitrogen Expert Panel should be endorsed and the application of tools to achieve this (e.g. variable rate application) must be incentivised. This will contribute to making crop production more sustainable in the medium term for annual crops and in the long term for permanent crops.

2. Consider the pros and cons of the use of the Harmonised Risk Indicator to measure the reduction of pesticide use and risk, since this measure is susceptible for decisions to change the category of an active substance. 
3. In addition to market challenges, the objectives to reduce pesticide use and nutrient emissions could be perceived as a disincentive to shift to organic production. This was found to be the case for permanent crops, which made use of copper-based active substances. Moreover, expanding organic production may face market constraints (e.g. insufficient demand growth) that could erode the current price premium for organic products and therewith their attractiveness/profitability: a price premium is needed to cover additional costs per unit of product. These aspects need further research.

4. The European Union, the MSs and private stakeholders should take into account the following potential trade-offs and combine efforts to develop mitigation strategies:
a. F2F/BD create a competitive disadvantage relative to EU imports (raises a level playing field issue, causing an increase in trade dependency),
b. indirect land-use effects (close to 10 million ha),
c. a likely farm income loss and
d. a reduced EU contribution to 'zero-hunger' SDG. 


\section{References and websites}

Barreiro Hurle, J., Bogonos, M., Himics, M., Hristov, J., Perez Dominguez, I., Sahoo, A., Salputra, G., Weiss, F., Baldoni, E., and Elleby, C. (2021). Modelling environmental and climate ambition in the agricultural sector with the CAPRI model, EUR 30317 EN, Publications Office of the European Union, Luxembourg, ISBN 978-92-76-20889-1 (online), doi:10.2760/98160 (online), JRC121368.

Beckman, J., Ivanic, M., Jelliffe, J.L., Baquedano, F.G., and Scott, S.G. (2020). Economic and Food Security Impacts of Agricultural Input Reduction Under the European Union Green Deal's Farm to Fork and Biodiversity Strategies. Economic Research Services, USDA.

Bremmer, J., Riemens, M., and Reinders, M. (2021). The future of crop protection in Europe. Panel for the Future of Science and Technology EPRS | European Parliamentary Research Service Scientific Foresight Unit (STOA) PE 656.330 - February 2021

Chantreuil, F., Hanrahan, K.F., and van Leeuwen, M. (2011). The Future of EU Agricultural Markets by AGMEMOD, Springer.

Council of the European Union. (2018). Interinstitutional File: 2016/0382 (COD), Brussels June 21.

Eurostat (2021) Methodology for calculating harmonised risk indicators for pesticides under Directive 2009/128/EC, 2021 edition. European Union.

Harvey, J. A. et al. International scientists formulate a roadmap for insect conservation and recovery. Nature Ecology \& Evolution (2020). DOI: 10.1038/s41559-019-1079-8

Lusk, J., Roosen, J., and Shogren, J.F. (2011). The Oxford handbook of the economics of food consumption and policy, edited by Jayson L. Lusk, Jutta Roosen and Jason F. Shogren: Oxford; New York: Oxford University Press.

Noleppa, S., and Cartsburg, M. (2021). The socio-economic and environmental values of plant breeding in the EU and for selected EU member states. HFFA Research,

Pathiraja, E., Griffith, G., Farquharson, R., and Faggian, R. (2017). Specifying and Testing an Equilibrium Displacement Model of the Coconut Market in Sri Lanka. Australasian Agribusiness Review 2017, Volume 25(4), 55-86.

Piggott, R.R. (1992). "Some old thrusts revisited", Australian Journal of Agricultural Economics, 36(2), 24.

Sánchez-Bayoa, F. and Wyckhuys, K.A.G. Worldwide decline of the entomofauna: A review of its drivers. Biological Conservation (2019). DOI: 10.1016/j.biocon.2019.01.020

Van Leeuwen, M., Tabeau, A., Dol, W., and Bouma, F. (2008). AGMEMOD Deliverable 8. Technical Report on the Combined Model.

Wohlgenant, M.K. (1993). Distribution of Gains from Research and Promotion in Multi-Stage Production Systems: The Case of the U.S. Beef and Pork Industries. American Journal of Agricultural Economics, 75(3), pp. 642-651.

Wohlgenant, M.K. (2011). Consumer Demand and Welfare in Equilibrium Displacement Models. In J.L. Lusk, J. Roosen, and J. F. Shogren (eds.) The Oxford Handbook of the Economics of Food Consumption and Policy. Oxford, Oxford University Press. 


\section{Appendix 1 Questionnaire}

\section{Sheet Instructions}

1 Fill in the sheets ' Generic questions' (description of farm, cultivation) and 'Elaboration of scenarios'. In the sheet 'Explanation of scenarios' the objectives of each scenario are explained.

$2 \quad$ Fill in only the white coloured cells with cell borders

3 Scenario 4 contains the combination of Scenario 1 and 2. By consequence, the pesticides applied in Scenario 1 and the nutrients applied in Scenario 2 are copied.

Scenario 4 contains the $10 \%$ set aside objective additionally, which need to be incorporated in the assessment of the consequences

4 The objectives have the time horizon of 2030. This means that the autonomous technical developments in the coming 10 years need to be included in the analysis!

5 In case of questions, don't hesitate to contact the involved project team member!

Sheet generic questions

Description of the typical farm that serves as an example for the analysis of the scenarios

Provide justification to explain why this is farm is "typical" for the selected crop and country:

\section{Question}

\section{Case crop}

What is the case crop?

What is the region where this type of farms are common?

Normal sowing and planting time?

Normal harvesting time?

\section{Description of the typical farm, crop and field:}

Which crops are grown at the farm in a typical rotation scheme?

What is the time period of this rotation scheme

Specify the relative share per crop summing up to $100 \%$ over the whole rotation period

Describe the complete rotation cycle

What is a typical farm size measured in ha?

What is the soil type?

What is the percentage of content of organic matter in the soil?

What is the level of acidity $(\mathrm{pH})$

\section{Set aside}

Which percentage of the agricultural land is out of production (set aside)?

\section{Labour input}

Family hours per year

Paid labour hours per year (contract work excluded)

\section{Which machinery is present for:}

Tillage?

\section{Crop protection?}

Mechanical weed control?

Fertilisation (manure, artificial fertilisers)?

precision agriculture?

Which cultivation operations are executed by a contract worker? 
Soil tillage and fertilisation

Which types of soil tillage is applied

What is the frequency of soil tillage?

Explain the answer, if necessary

\section{Description of crop protection for the case crop:}

List the main pests in the crop

List the main diseases in the crop

List the main weeds

What is the main crop protection strategy:

IPM-strategies? Please describe

\section{Chemical}

non-chemical measures: list machinery used, frequency, crop stage

application of buffer strips?

Other methods? Please describe

\section{Social importance}

How important is the crop, are the farms for:

the biodiversity (species richness) in the region?

the landscape?

the local economy? (contribution to welfare in the region)

employment?

the food provision in the region?

\section{Economic importance}

How important is the crop

as input for other agricultural production?

for the national economy? (contribution to gross national product)

for export?

for generation of farm income (profitability)

for self-sufficiency? 
Sheet Explanation of the scenarios

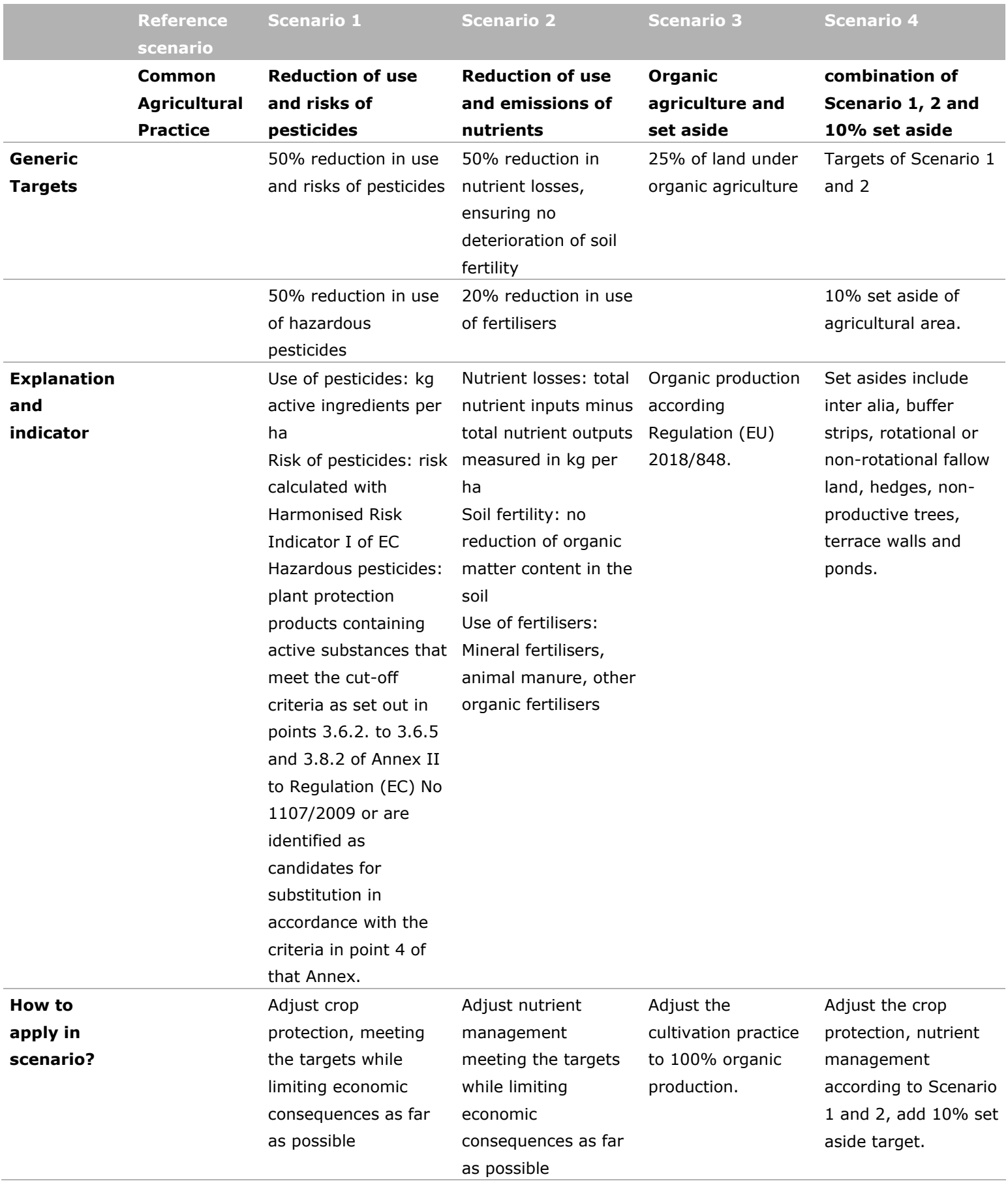




\section{Sheet elaboration of the scenarios}

\section{Specify the nutrient management}

List the fertilisers applied: dose, frequency

$\mathrm{N}$ (Organic)

P2O5 (Organic)

$\mathrm{N}$ (Artificial)

P2O5 (Artificial)

What is the share of the uptake of nutrients by the crop?

Which share is stored in the soil?

Which share is emitted to the soil water?

Which measures are applied to prevent emission and nutrient losses?

How effective are these measures?

\section{Specify the crop protection}

List the pesticides applied below (dropdown button)

\section{Total active ingredients per hectare}

\section{Total active ingredients per hectare in risk group 3}

\section{Value Harmonised Risk Indicator}

Which measures are applied to prevent emission to soil, air and water?

Which measures are applied to increase soil fertility?

Which measures are applied to increase resilience against pests and diseases?

What is the estimated yield in this scenario?

How do the scenarios affect the yield

How do the scenarios affect the quality of the product

List differences (fertilisers and pesticides used, adjusted doses, adjusted frequencies, alternative measures applied) of scenarios $1,2,3$ and 4 on the one hand compared with reference scenario

\section{Socio-economic questions:}

Employment for farmer

Employment for employees or contract workers

\section{Change in costs}

Labour

Machinery (energy, depreciation, maintenance)

Pesticides

Nutrients

Reduced land use

Yield

Price

Which other effects can be mentioned? 


\section{Appendix 2 Overview of institutes and experts involved in case studies}

\begin{tabular}{|c|c|c|}
\hline Case crop & Country & Institutes \\
\hline \multirow[t]{4}{*}{ Wheat } & Finland & $\begin{array}{l}\text { Natural Resources Institute Finland (Luke): Jukka Salonen, Erja Huusela, } \\
\text { Heikki Jalli, Marja Jalli, Lauri Jauhiainen, Jarmo Ketola, Antti Laine, } \\
\text { Pentti Ruuttunen, and Tapio Salo }\end{array}$ \\
\hline & France & Arvalis \\
\hline & Germany & Julius Kühn Institute (JKI): Arnd Verschwele \\
\hline & Romania & $\begin{array}{l}\text { University of Agricultural Sciences and Veterinary Medicine of Bucharest, } \\
\text { Viorel Ion }\end{array}$ \\
\hline \multirow[t]{3}{*}{ Rapeseed } & Finland & See wheat \\
\hline & Germany & Julius Kühn Institute (JKI): Arnd Verschwele \\
\hline & Poland & $\begin{array}{l}\text { National Association of Producers of Rapeseed and Protein Crops: } \\
\text { Krzysztof Gawęcki, Marcin Markowicz and Ewelina Spłocharska }\end{array}$ \\
\hline \multirow[t]{3}{*}{ Sugar beet } & France & Institut Technique de la Betterave, Rémy Duval \\
\hline & Germany & Julius Kühn Institute (JKI): Arnd Verschwele \\
\hline & Poland & KZPBC: Rafal Strachota and colleagues \\
\hline \multirow[t]{2}{*}{ Maize } & France & Arvalis \\
\hline & Romania & $\begin{array}{l}\text { University of Agricultural Sciences and Veterinary Medicine of Bucharest, } \\
\text { Viorel Ion }\end{array}$ \\
\hline \multirow[t]{2}{*}{ Apples } & Italy & $\begin{array}{l}\text { Fondazione Edmund Mach: Gino Angeli, Maurizio Bottura, Giorgio De Ros, } \\
\text { Claudio Ioriatti, Tommaso Pantezzi, Duilio Porro and Roberto Zanzotti }\end{array}$ \\
\hline & Poland & $\begin{array}{l}\text { The National Institute of Horticultural Research: Agata Broniarek-Niemiec, } \\
\text { Wojciech Piotrowski, Joanna Puławska, Małgorzata Sekrecka, } \\
\text { Wojciech Warabieda and Paweł Wójcik }\end{array}$ \\
\hline \multirow[t]{2}{*}{ Tomatoes } & Italy & Council for Agricultural Research and Economics (CREA): Alessandro Natalini \\
\hline & Spain & $\begin{array}{l}\text { Andalusian Institute of Agricultural and Fisheries Research and Training } \\
\text { (IFAPA): Pedro Cermeño Sacristán }\end{array}$ \\
\hline \multirow[t]{3}{*}{ Grapes } & France & Institut Français de la Vigne et du VinL Eric Chantelot \\
\hline & Italy & $\begin{array}{l}\text { Fondazione Edmund Mach (Trentino Alto Adige): Gino Angeli, } \\
\text { Maurizio Bottura, Giorgio De Ros, Claudio Ioriatti, Tommaso Pantezzi, } \\
\text { Duilio Porro and Roberto Zanzotti } \\
\text { Council for Agricultural Research and Economics (CREA) (Veneto): } \\
\text { Elisa Angelini and Vally Forte with assistance from Davide Granzotto }\end{array}$ \\
\hline & Spain & $\begin{array}{l}\text { Public University of Navarra: Gonzaga Santesteban and } \\
\text { Bárbara Sebastián Caumel (consultant) (dry areas) } \\
\text { Martin Codax: Cecilia Canda González (Galicia) }\end{array}$ \\
\hline \multirow[t]{2}{*}{ Olives } & Italy & $\begin{array}{l}\text { Council for Agricultural Research and Economics (CREA): Mario Riolo, } \\
\text { Pierluigi Rizzo, Elena Santilli, Veronica Vizzarri and Francesco Zaffina, }\end{array}$ \\
\hline & Spain & $\begin{array}{l}\text { Andalusian Institute of Agricultural and Fisheries Research and Training } \\
\text { (IFAPA): Javier Hidalgo }\end{array}$ \\
\hline \multirow[t]{2}{*}{ Citrus } & Italy & $\begin{array}{l}\text { Council for Agricultural Research and Economics (CREA): } \\
\text { Maria Concetta Strano, Simona Fabroni, Filippo ferlito, Michele Scirè, } \\
\text { Salvatore Panebianco }\end{array}$ \\
\hline & Spain & Politechnic University of Valencia: Carlos Mesejo Conejos \\
\hline \multirow[t]{2}{*}{ Hops } & Germany & Hop Research Center, Florian Weihrauch \\
\hline & Poland & $\begin{array}{l}\text { Institute of Soil Science and Plant Cultivation-State Research Institute, } \\
\text { Urszula Skomra }\end{array}$ \\
\hline
\end{tabular}




\section{Appendix 3 Sensitivity Analysis}

Several sensitivity analyses have been pursued in order to provide more insight into the potential impacts of weather shocks or variation in yield shocks. The reason for conducting analyses on the shocks was that it was signalled from the case studies that due to the reductions in pesticide and fertiliser applications the variability in yields results may increase. Since in the standard scenario analysis, the simulations are assuming 'normalised' weather conditions and the on average expected yield shock, the sensitivity analyses presented in Table A3.1, can add further insight into yield and market responses in case of more extreme conditions. Therefore scenarios have been elaborated. The values chosen for the yield shocks have been based on information from the case studies and expertise from Wageningen UR (see Table A3.1).

Table A3.1 Different yield shocks (relative to Scenario 1) and their motivation *)

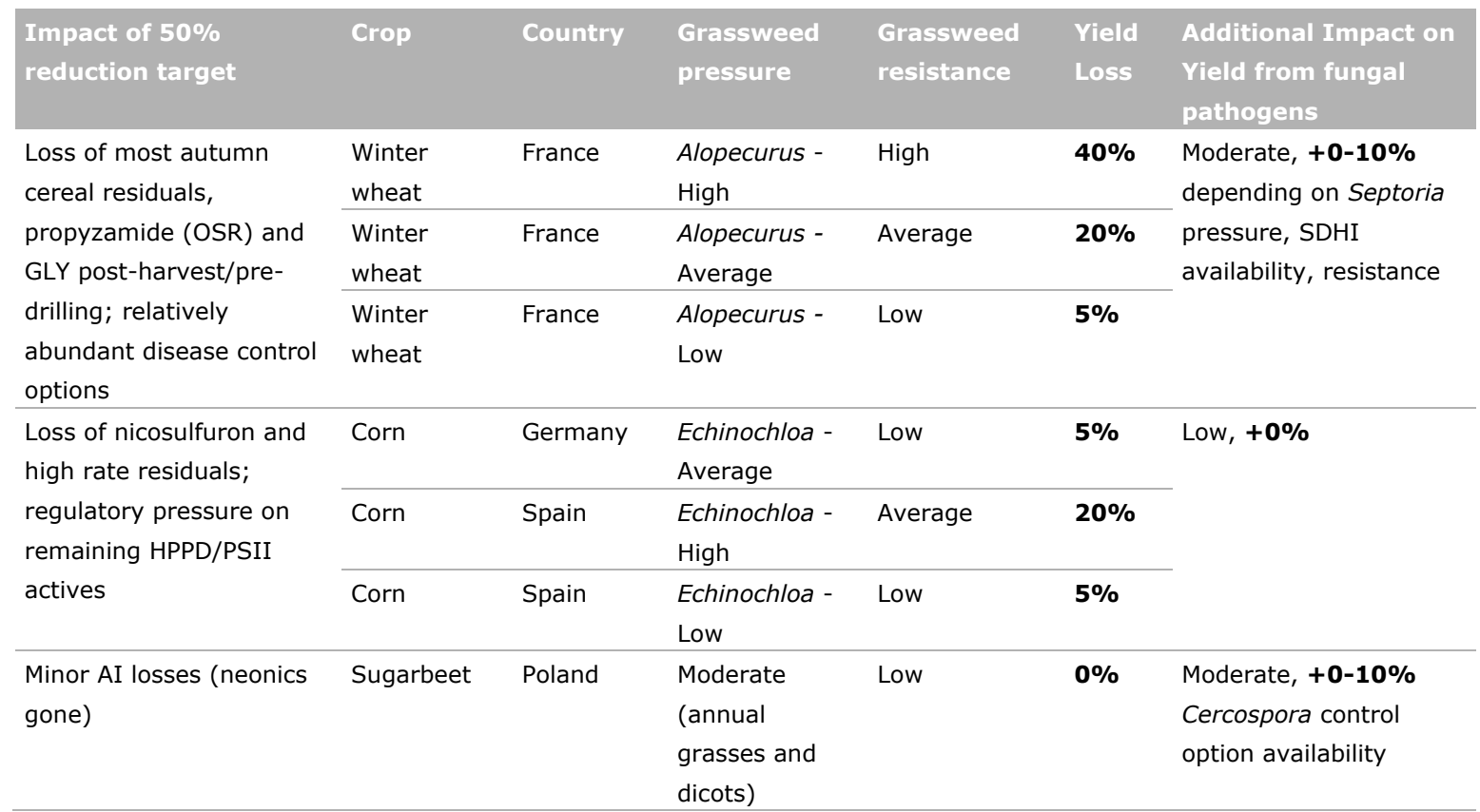

It should be noted that only a very limited number of sensitivity analyses have been done, which is sufficient to illustrate the impact of potential shocks, but is by far not sufficient to provide a more complete overview of the increased sensitivity of the cropping system.

The yield shock information as provided in Table A3.1 has been translated into 8 variants of the standard scenario that have been simulated (see, Table A3.2). Rather than providing full descriptions of all the results the scope has been limited to the impact of the yield shock of the EU MS where the shock is taking place, the impact on production and price in this MS, the impact on total EU-27 production and the impact on the market price in the EU. Variants 1 to 4 of the sensitivity analysis focus on different yield shocks for wheat in France. In the original situation (see Scenario 1) a yield shock of $-5 \%$ has been simulated. Adding a $5 \%$ additional yield reduction provides a negative yield shock of $-10 \%$. In the most extreme case, a yield shock of $40 \%$ (weed pressure, grassweed resistance) plus $10 \%$ (fungal pathogens), in addition to the original 5\% (Scenario 1), which aggregates to a 55\% yield shock. The simulated yield shocks for Scenario 1 to 4 are $-10,-25,-45$, and $-55 \%$ respectively. In all case the yield more or less directly translate into a decline in production in France. The decline in production induces an increase in the crop price, where the price increase is larger the larger is the negative yield shock. The impact of the decline in wheat production in France has a negative impact on total EU production, which is significant since France is one of the EU's key 
wheat producing MSs (the share of France in EU-27 wheat production is about 29\%). As a consequence also the price of wheat in the EU as a whole will increase, although not as much as in in France (imperfect price transmission). Although stronger declines in French wheat production have a negative impact on the EU's total wheat production, this impact is not linearly increasing with the increase in the yield shock. The reason is that the induced price increase in the EU stimulate other MSs to increase their wheat production. Another reason is that wheat exports will decline due to the wheat price increase in the EU making its wheat exports less competitive.

Table A3.2 Summary scenario outcomes

\begin{tabular}{|c|c|c|c|c|c|c|c|}
\hline & $\begin{array}{l}\text { Crop/ Country } \\
\text { affected by } \\
\text { shock }\end{array}$ & $\begin{array}{r}\text { Yield shock } \\
(\%)\end{array}$ & $\begin{array}{l}\text { Actual } \\
\text { impact on } \\
\text { yield }(\%)\end{array}$ & $\begin{array}{r}\text { Impact on } \\
\text { local } \\
\text { production } \\
(\%)\end{array}$ & $\begin{array}{r}\text { Impact on } \\
\text { local price } \\
(\%)\end{array}$ & $\begin{array}{r}\text { Impact on } \\
\text { EU-27 } \\
\text { production } \\
(\%)\end{array}$ & $\begin{array}{r}\text { Impact on } \\
\text { EU-27 Price } \\
(\%)\end{array}$ \\
\hline Variant 1 & Soft wheat/France & -10 & -10.0 & -10.9 & 3.4 & -7.2 & 2.3 \\
\hline Variant 2 & Soft wheat/France & -25 & -24.9 & -27.6 & 5.7 & -7.5 & 3.9 \\
\hline Variant 4 & Soft wheat/France & -55 & -54.9 & -59.0 & 10.1 & -7.9 & 7.0 \\
\hline Variant 5 & Sugar beet/Poland & -20 & -19.3 & -4.4 & 14.6 & -1.0 & 4.6 \\
\hline Variant 6 & Maize/Germany & -6 & -6.0 & -6.7 & 0.6 & -2.2 & 0.9 \\
\hline Variant 7 & Maize/Spain & -6 & -6.0 & -6.4 & $-*)$ & -2.3 & 0.9 \\
\hline
\end{tabular}

NB. \% differences are calculated with respect to the baseline. Impact on local (MS) production and EU-27 production are calculated looking only at the crop that is affected by the shock. Actual impacts are endogenously calculated by the model, taking into account all supply/demand interactions. Yield shocks are the exogenous shocks imposed to the AGMEMOD model.

*) Due to an overresponse to the change in a self-sufficiency degree the calculated price impact for Spain was considered not to be reliable, i.e. close to zero, whereas an price increase close to that of the EU level should be expected. Source: AGMEMOD model.

Variant 5 (Table A3.2) provides the outcome of $15 \%$ additional negative yield shock (10\% in addition to the already $10 \%$ yield reduction of Scenario 1) for sugar beet in Poland. Similarly to the wheat case, the additional yield reduction will lower both Polish and EU sugar beet production and induce increases in sugar beet prices ( $+15 \%$ in Poland and $+5 \%$ in the rest of the EU). The main difference with the wheat case is that the production impacts are relatively small. This is caused by the way the model deals with the high capital intensity of the sugar beet processing industry, which makes that the industry will try to secure its sourcing of sugar beets as much as possible to utilise their processing capacity in an optimal way. So EU production will only marginally adjust (-1\%).

Variants 6 to 8 provide the results of three maize yield shock simulations. The patterns are similar to those found for wheat. The reduced maize yield leads to a lower maize production in the concerned MS (Germany or Spain) and also to a lower EU production (the shares of Germany and Spain in EU-27 maize production are 6.5 and $7.9 \%$ respectively). The declines in maize production induce (limited) price increases. This is partly due to the fact that increases in maize production in other MSs reduce the 'scarcity', as well as due to an increase in the EU's maize imports, which also contributes to curbing the maize price increase as a result of the decline in EU maize production. 
Wageningen Economic Research P.O. Box 29703

2502 LS The Hague

The Netherlands

$\mathrm{T}+31(0) 703358330$

E communications.ssg@wur.nl

www.wur.eu/economic-research

Wageningen Economic Research REPORT

2021-150
The mission of Wageningen University \& Research is "To explore the potential of nature to improve the quality of life". Under the banner Wageningen University \& Research, Wageningen University and the specialised research institutes of the Wageningen Research Foundation have joined forces in contributing to finding solutions to important questions in the domain of healthy food and living environment. With its roughly 30 branches, $6,800$ employees ( $6,000 \mathrm{fte})$ and 12,900 students, Wageningen University \& Research is one of the leading organisations in its domain. The unique Wageningen approach lies in its integrated approach to issues and the collaboration between different disciplines. 



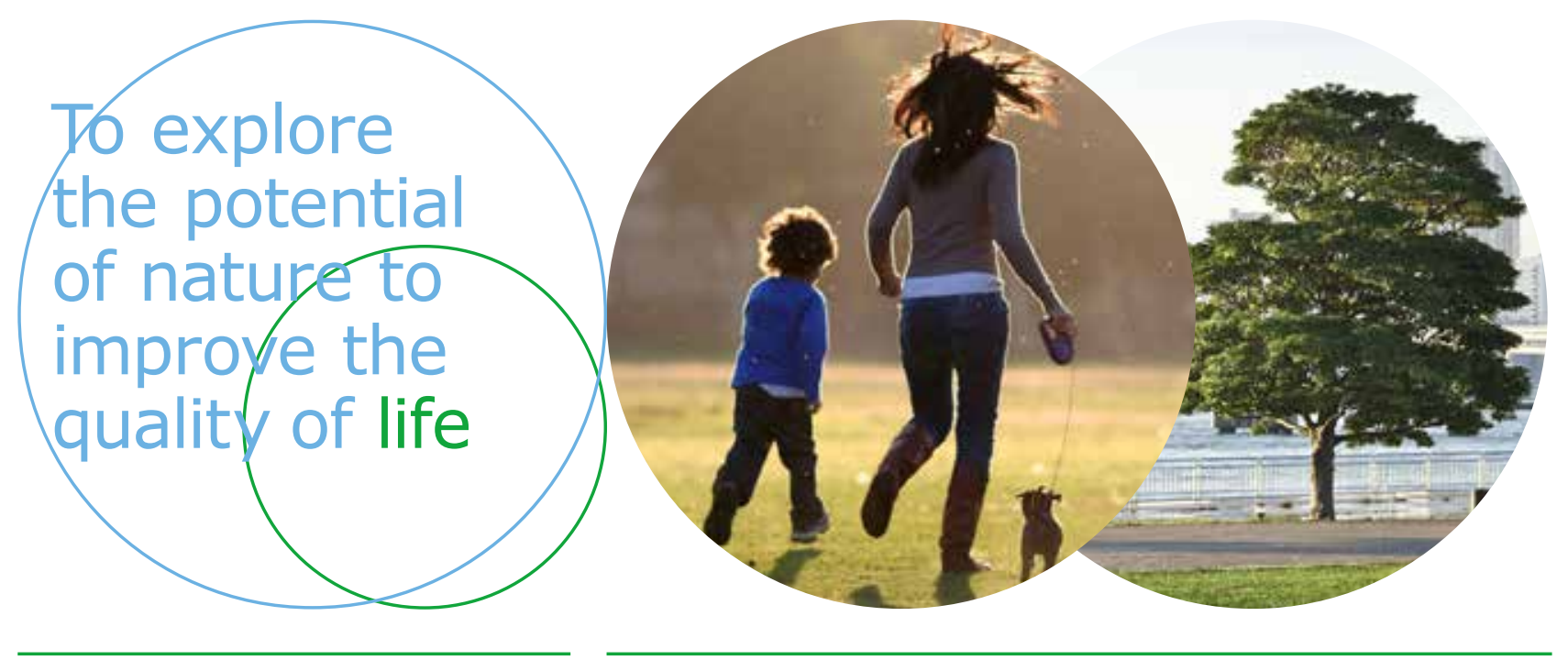

Wageningen Economic Research P.O. Box 29703

2502 LS Den Haag

The Netherlands

$\mathrm{T}+31(0) 703358330$

E communications.ssg@wur.nl

www.wur.eu/economic-research

Report 2021-150

ISBN 978-94-6447-041-3
The mission of Wageningen University \& Research is "To explore the potential of nature to improve the quality of life". Under the banner Wageningen University \& Research, Wageningen University and the specialised research institutes of the Wageningen Research Foundation have joined forces in contributing to finding solutions to important questions in the domain of healthy food and living environment. With its roughly 30 branches, 6,800 employees $(6,000 \mathrm{fte})$ and 12,900 students, Wageningen University \& Research is one of the leading organisations in its domain. The unique Wageningen approach lies in its integrated approach to issues and the collaboration between different disciplines. 